Keywords: Inner Canister, DOE 3013, Welding, Gas Tungsten Arc Welding, GTAW, Experimental

Retention: 25 yrs-10561

SRNL-STI-2012-00129

\title{
PDC IC Weld Failure Evaluation and Resolution
}

\author{
P. S. Korinko \\ S. R. Howard \\ D. N. Maxwell \\ J. B. Fiscus
}

March 29, 2012

\section{We Put Science To Work}


This Page Intentionally Left Blank 
SRNL-STI-2012-00129

\section{PDC IC Weld Failure Evaluation and Resolution}

Approvals:

Signature on File

P. S. Korinko, Author

Materials Compatibility and Welding Technology

Signature on File

S. R. Howard, Author

Materials Compatibility and Welding Technology

Signature on File

D. N. Maxwell, Author

Materials Compatibility and Welding Technology

Signature on File

J. B. Fiscus, Author

Research and Development Engineering

Signature on File

S. L. West, Technical Review

Weapons Technology

Signature on File

A. S. Busby, Project Lead

Research and Development Engineering

Signature on File

T. M. Adams, Manager

Materials Compatibility and Welding Technology

Signature on File

L. T. Reid, Manager

Mechanical Systems and Custom Equipment Development

Signature on File

4-16-2012

4-9-2012

$4-11-2012$

$4-11-2012$

$4-12-2012$

$4-12-2012$

$4-11-2012$

$4-12-2012$

$4-12-2012$

J. L. Varble, Design Authority

Pit Disassembly and Conversion Project 


\section{Table of Contents}

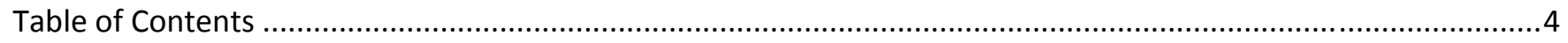

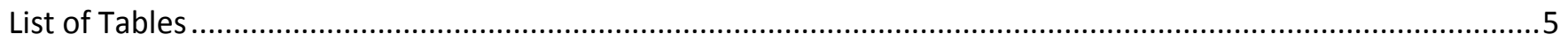

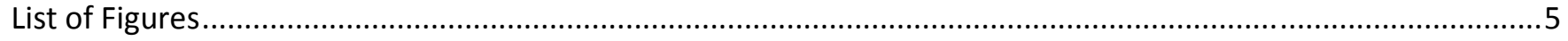

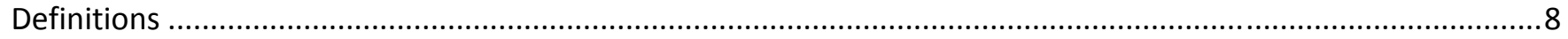

Summary

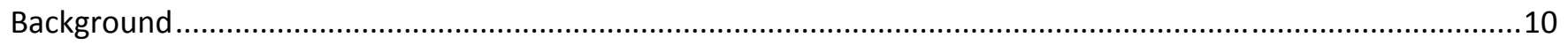

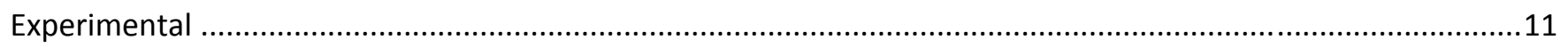

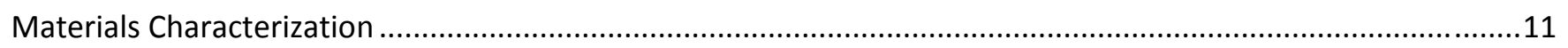

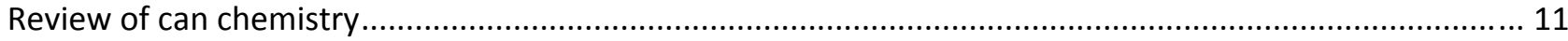

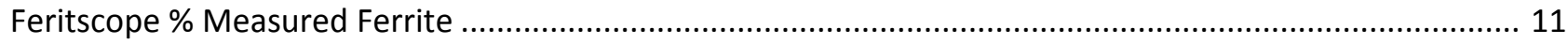

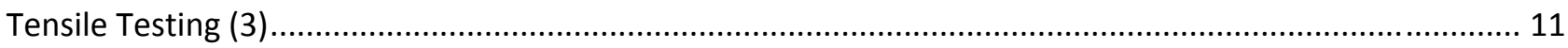

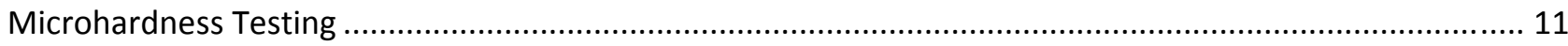

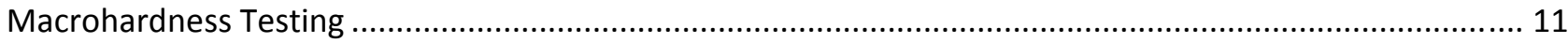

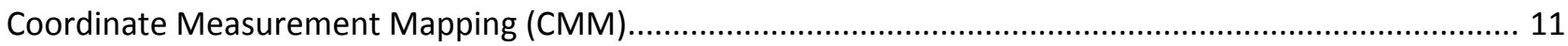

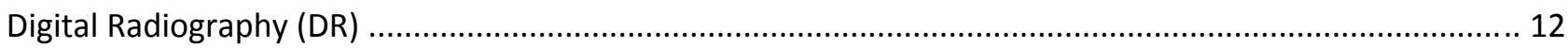

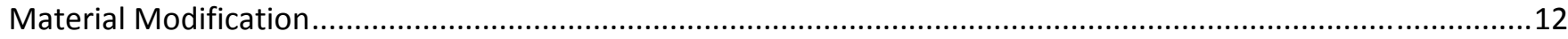

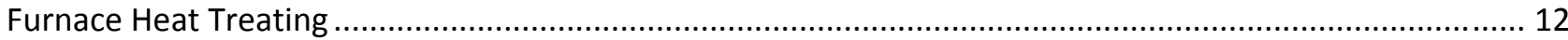

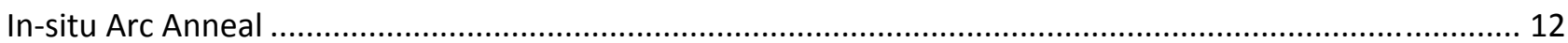

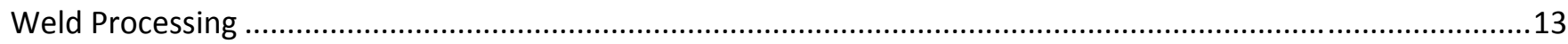

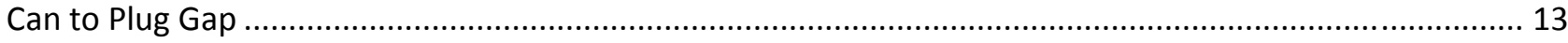

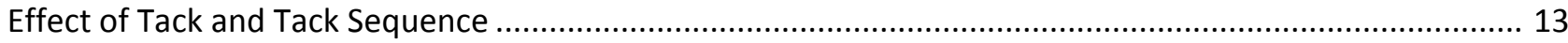

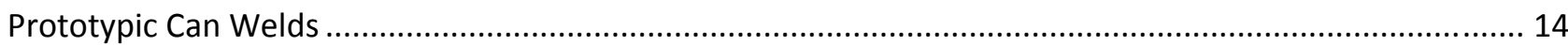

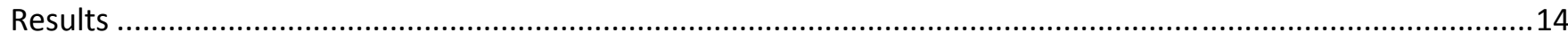

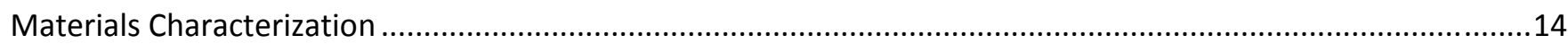

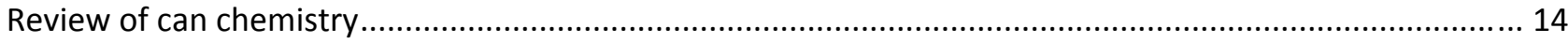

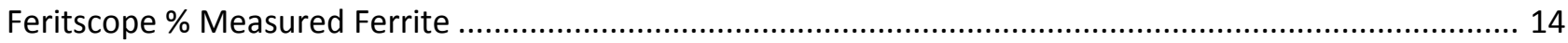

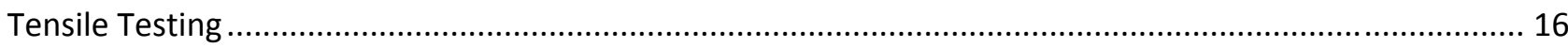

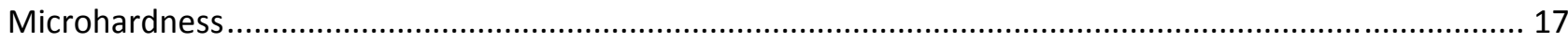

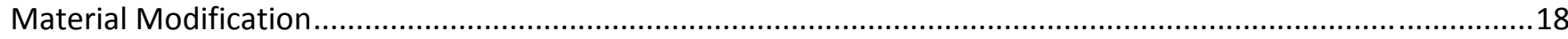

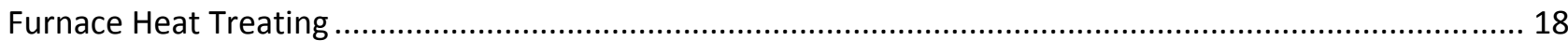




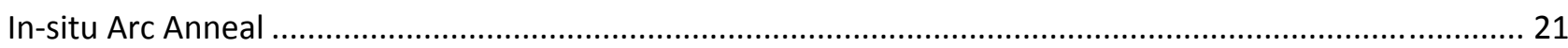

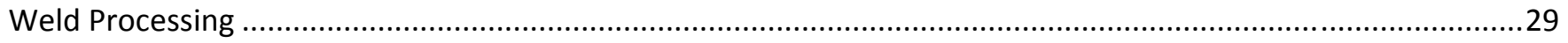

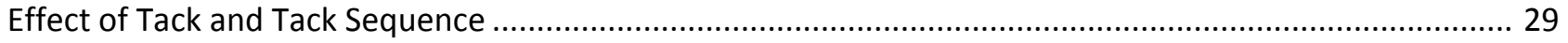

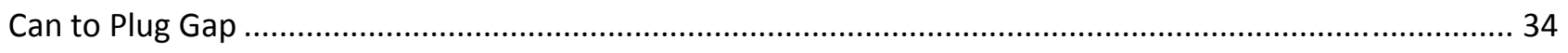

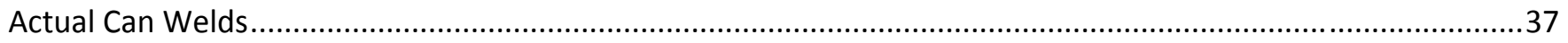

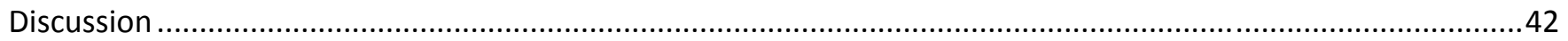

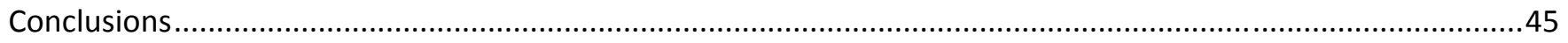

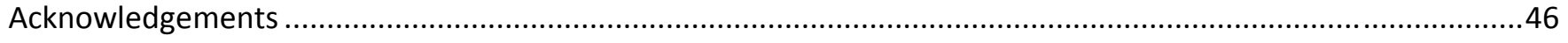

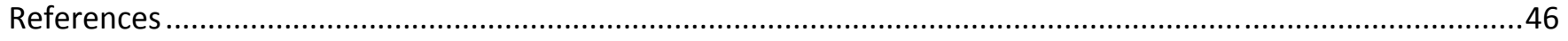

Appendix A. Weld Schedules for Standard Welds and 4, 5, and 6 Tack Welds ..............................................47

\section{List of Tables}

Table 1. CMTR data for the PDC, FBL, and HS cans and plugs used in production and for development work.... 15

Table 2. Measured \% Ferrite for PDC, HS, and FB-Line Cans................................................................ 16

Table 3. Individual mechanical property data for PDC, HS, and FBL cans................................................. 17

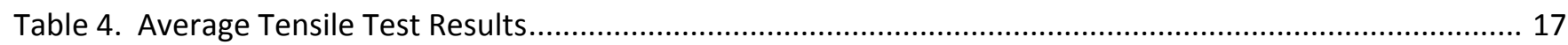

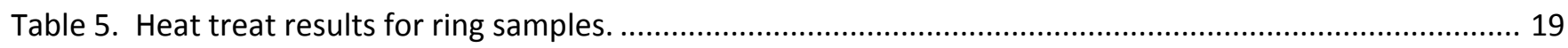

Table 6. Pre and Post Heat Treatment Dimensional Results................................................................. 19

Table 7. Displacement from Cutting and Hardness for Heat Treated Can Ring Samples................................. 20

Table 8. Standard deviations of characteristic attributes of the welds..................................................... 45

\section{List of Figures}

Figure 1. Weld failure on PDCF can. Arrow indicates lack of fusion defect. Note also undercut at weld toe. .... 10

Figure 2. General configuration of can, camera, thermocouples and welding torch on turntable for ISAA and gap

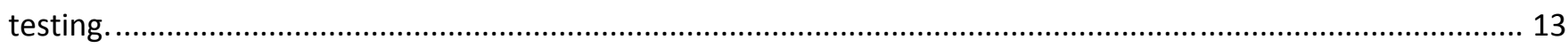

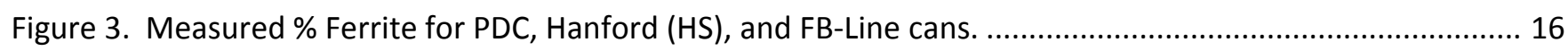

Figure 4. Microhardness profiles for PDC (009Q), HS (H6540), and FBL (3022) cans. ................................... 18

Figure 5. Photo and schematic of rings showing how distortion was measured......................................... 20

Figure 6. Graphical representation of hardness after heat treatment. Note that the hardness for $\mathrm{T}>800^{\circ} \mathrm{C}$ is estimated since HRC scale ends at 20. 
Figure 7. Scoping Study to Provide Initial Estimates for FZ and HAZ Width. 22

Figure 8. Photograph of ISAA01 showing thermocouple locations. 22

Figure 9. Temperature profile for ISAA01 showing $525^{\circ} \mathrm{C}$ at 0.203 inch from $\mathrm{FZ}$ centerline. 23

Figure 10. DR slices of ISAA01 at and near the location that can to plug bonding is suspected..... 23

Figure 11. DR images of the ISAA01 test showing possible fusion during arc anneal..... 24

Figure 12. Digital radiography for ISAA01 in the as annealed, as tack welded - three tacks and weld start for $15 / 16 "$, and fully welded conditions, the DR determined can to plug gap is indicated by the legend below the astack welded condition. The gaps are indicated in 0.001". 24

Figure 13. Thermal profile for ISAA02 showing $530^{\circ} \mathrm{C}$ was achieved between 0.15 and 0.2 inch..................... 25

Figure 14. DR of ISAA02 for arc anneal, six tack welds, and closure weld. ............................................... 26

Figure 15. Percent of DR data that has given gap width as a function of vertical position. ............................. 27

Figure 16. Percentage of weld that exhibits the DR measured gap.......................................................... 27

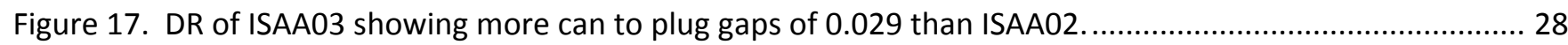

Figure 18. Fraction of the weld that exhibits the given can to plug gaps for ISAA and three conventionally welded cans. 28

Figure 19. Normalized vertical position of the weld ligaments showing the calculation values for weld figure of merit.

Figure 20. Digital radiographs of the tack welds showing traditional three tacks and extended weld start, four,

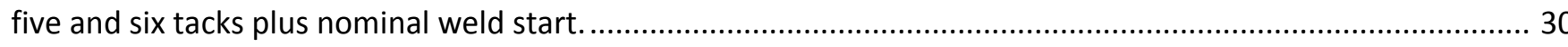

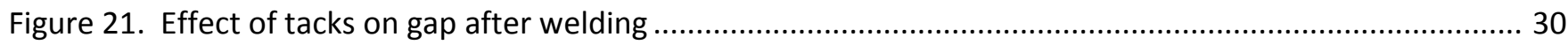

Figure 22. NDRDA of the tack weld showing that larger gaps are reduced with more tacks. .......................... 32

Figure 23. NDRDA of the welded samples after tacking and welding........................................................... 33

Figure 24. DR results in the as tack welded and as welded condition indicating the relative can to plug gap

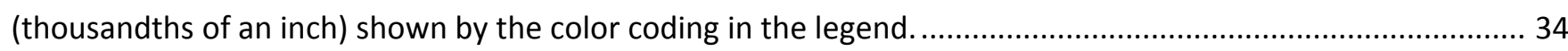

Figure 25. DR slices near lack of fusion defect for can PDCF014T.......................................................... 35

Figure 26. DR slices near lack of fusion defect for can PDCF014T............................................................. 35

Figure 27. DR slices near lack of fusion defect for can PDCF013T............................................................. 36

Figure 28. DR slices near lack of fusion defect for can PDCF013T............................................................ 36

Figure 29. DR of weld made with new clamp. Note weld toe instability arrow............................................ 37 
Figure 30. DR of traditional (PDCF-IC-006Q) and six tack weld (PDCF-IC-018Q) that failed 10-15 seconds into the weld. 37

Figure 31. DR results of PDCF-IC-025Q showing effect of mast movement during welding. 38

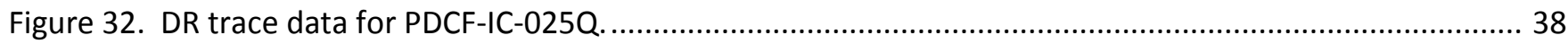

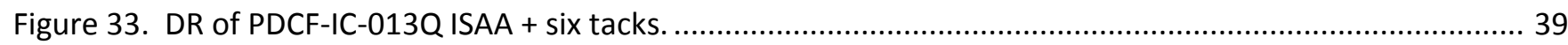

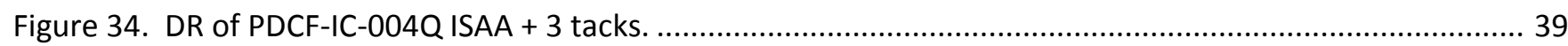

Figure 35. Gap analysis for PDCF-IC-013Q (6 tack welds) and PDCF-IC-004Q (3 tack welds) and the experimental welds (ISAAO\#) 40

Figure 36. Photograph of a can that has been pressure tapped prior to welding in the as welded and cut condition; note these photos are not of the same can. ICO25Q is depicted on the left (a) and ICO14Q on the right (b).

Figure 37. Pressure - time data for PDCF-IC-013Q (a) and 004Q (b)......

Figure 38. Pressure response from an OCW weld with a pressure tap. Notice the oscillations in pressure. These are consistent with the tack weld locations. 42

Figure 39. DR results for PDCF-IC-025Q that had a mast movement during welding shown at approximately $20^{\circ}$.

Figure 40. Weld attribute location for cans welded for PDC, FBL, and HS. .44 


\section{Definitions}

$\begin{array}{ll}\text { BTS } & \text { Bagless Transfer System } \\ \text { CMM } & \text { Coordinate Measurement Mapping } \\ \text { CMTR } & \text { Certified Materials Test Report } \\ \text { DR } & \text { Digital Radiography } \\ \text { FBL } & \text { Savannah River's FB-Line } \\ \text { FZ } & \text { Fusion Zone } \\ \text { HAZ } & \text { Heat Affected Zone } \\ \text { HS } & \text { Hanford Site } \\ \text { IC } & \text { Inner Can } \\ \text { ISAA } & \text { In-situ Arc Anneal } \\ \text { NDRDA } & \text { Numeric Digital Radiography Data Analysis } \\ \text { NIST } & \text { National Institute of Standards and Testing } \\ \text { PDC } & \text { Pit Disassembly and Conversion } \\ \text { PDCF } & \text { Pit Disassembly and Conversion Facility } \\ \text { PICN } & \text { Product Inner Canning }\end{array}$


SRNL-STI-2012-00129

\section{SRNL-STI-2012-00129}

\section{PDC IC Weld Failure Evaluation and Resolution}

\section{Summary}

During final preparations for start of the PDCF Inner Can (IC) qualification effort, welding was performed on an automated weld system known as the PICN. During the initial weld, using a pedigree canister and plug, a weld defect was observed. The defect resulted in a hole in the sidewall of the canister, and it was observed that the plug sidewall had not been consumed. This was a new type of failure not seen during development and production of legacy Bagless Transfer Cans (FB- Line / Hanford). Therefore, a team was assembled to determine the root cause and to determine if the process could be improved. After several brain storming sessions (MS\&T, R\&D Engineering, PDC Project), an evaluation matrix was established to direct this effort. The matrix identified numerous activities that could be taken and then prioritized those activities. This effort was limited by both time and resources (the number of canisters and plugs available for testing was limited).

A discovery process was initiated to evaluate the Vendor's IC fabrication process relative to legacy processes. There were no significant findings, however, some information regarding forging / anneal processes could not be obtained. Evaluations were conducted to compare mechanical properties of the PDC canisters relative to the legacy canisters. Some differences were identified, but mechanical properties were determined to be consistent with legacy materials.

A number of process changes were also evaluated. A heat treatment procedure was established that could reduce the magnetic characteristics to levels similar to the legacy materials. An in-situ arc annealing process was developed that resulted in improved weld characteristics for test articles. Also several tack welds configurations were addressed, it was found that increasing the number of tack welds (and changing the sequence) resulted in decreased can to plug gaps and a more stable weld for test articles. Incorporating all of the process improvements for the actual can welding process, however, did not result in an improved weld geometry. Several possibilities for the lack of positive response exist, some of which are that (1) an insufficient number of test articles were welded under prototypic conditions, (2) the process was not optimized so that significant improvements were observable over the "noise", and (3) the in-situ arc anneal closed the gap down too much so the can was unable to exhaust pressure ahead of the weld.

Several operational and mechanical improvements were identified. The weld clamps were changed to a design consistent with those used in the legacy operations. A helium puff operation was eliminated; it is believed that this operation was the cause of the original weld defect. Also, timing of plug mast movement was found to correspond with weld irregularities. The timing of the movement was changed to occur during weld head travel between tacks.

In the end a three sequential tack weld process followed by a pulse weld at the same current and travel speed as was used for the legacy processes was suggested for use during the IC qualification effort. Relative to legacy welds, the PDC IC weld demonstrates greater fluctuation in the region of the weld located between tack welds. 
However, canister weld response (canister to canister) is consistent and with the aid of the optical mapping system (for targeting the cut position) is considered adequate. DR measurements and METs show the PDC IC welds to have sufficient ligament length to ensure adequate canister pressure / impact capacity and to ensure adequate stub function.

The PDC welding process has not been optimized as a result of this effort. Differences remain between the legacy BTC welds and the PDC IC weld, but these differences are not sufficient to prevent resumption of the current PDC IC qualification effort. During the PDC IC qualification effort, a total of 17 cans will be welded and a variety of tests/inspections will be performed. The extensive data collected during that qualification effort should be of a sufficient population to determine if additional weld process optimization is necessary prior to production release.

\section{Background}

During final preparations for the PDC IC qualification effort, welding was being performed on the automated inner can welding system known as the PICN. During the first weld, a weld defect occurred, Figure 1 . The weld defect had a similar appearance to the BTC weld blow-out but was not initially characterized as such. Inspection of the weld defect also identified a lack of fusion between the canister sidewall and the plug sidewall. Also, BTC blowout failures typically result in the deposit of molten metal onto the tungsten weld tip, this condition did not exist for the PDC weld defect (1). ,

As a result of this "New" weld failure, a team was assembled to investigate the failure and to determine the root cause. After several brain storming sessions (MS\&T, R\&D Engineering, PDC Project), an evaluation matrix was established to direct this effort (2). The matrix identified numerous activities that could be taken and then prioritized those activities. Six activities were initially addressed. This effort was limited by both time and

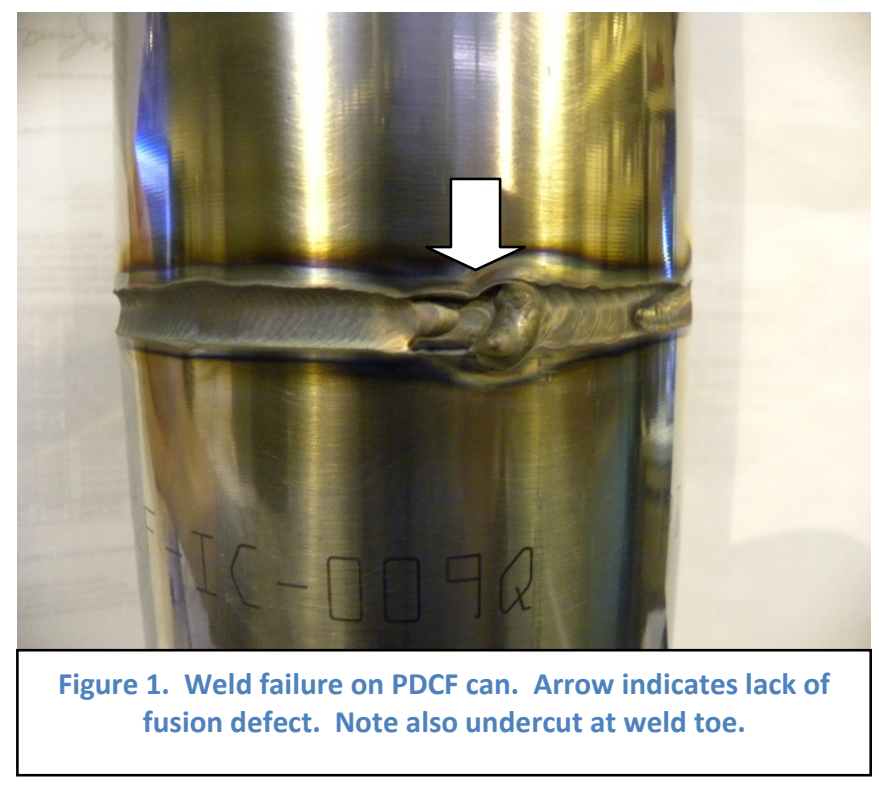
resources (the number of canisters and plugs available for testing was limited).

During the course of the investigation a number of tests were conducted to better characterize the can and lid material. Tests were also conducted to develop processes to modify the can properties and characterize the effects. Weld development tests were conducted to ascertain the effects of thermal processing on the weld characteristics, the maximum gap that could be successfully bridged, and the effect of the number of tacks on weld characteristics. As an outgrowth of these tests, a number of weld characterization tools were also developed. These will be described and reported in this document.

Also equipment and mechanical process changes were identified that deviated from the successful packaging systems that were used for both SRS (FB Line, FBL) and Hanford Site (HS). These equipment and mechanical process changes were found to have an effect on the weld characteristics. These effects will also be discussed. 


\section{Experimental}

\section{Materials Characterization}

\section{Review of can chemistry}

The certified materials test reports (CMTRs) for the PDC IC cans and plugs were compiled and compared to the historical data from FBL and HS.

\section{Feritscope \% Measured Ferrite}

A Fischer ferrite scope (Feritscope MP3) was used to determine the amount of magnetic material present in the PDC can and lid. This instrument works based on the magnetic permeability and is calibrated for \% ferrite in an austenite matrix, cold worked Type 304L stainless steel doesn't contain ferrite but strain induced martensite. There is a correlation between the martensite and ferrite \% in which 1.7 times the \% ferrite value indicates martensite \% (2). Numerous measurements were taken at various regions of interest on the can and plug and the average value was determined. The ferrite content of PDC, FBL and HS cans was measured and compared.

\section{Tensile Testing ( 3 )}

Flat tensile samples, $0.5^{\prime \prime}$ wide by $0.060^{\prime \prime}$ thick and a reduced section of 1.25 inch $\times 0.25$ inch, were received in Laboratory B061-773A of SRNL. The samples were tested on the Sintech Model 4507 Tensile Tester in Laboratory B061-773A according to ASTM E8-2009 (7). Loads were measured using a calibrated load cell traceable to National Institute of Standards and Technology (NIST). An extensometer with a one-inch gage length and travel of 0.5 inches was used for strain measurements during the test. The samples were pulled to failure using a crosshead speed of 0.05 inches per minute, except for sample 009Q-1 which was tested at 0.5 inches per minute. The tensile properties of PDC, FBL and HS cans were measured and compared.

\section{Microhardness Testing}

Samples were sectioned, mounted in epoxy, ground and polished per standard practices in preparation for microhardness testing. The testing was accomplished using a Buehler Micromet 5114 and a load of $50 \mathrm{gf}$ and a dwell time of 5 seconds were used. Hardness indentations were made at periodic locations across the can wall cross-section and the location / size of the indent was measured.

\section{Macrohardness Testing}

Samples were macrohardness tested using the Rockwell B and $Y$ scales. The ring samples $~ 1 " 11 / 2$ " wide were cut perpendicular to the canister axis. The rings were sectioned and the extent of axial twist and kerf separation due to stress relaxation was measured. A Wilson Rockwell hardness tester with H3ON and H30T scales was used, (applied to the OD and ID face of the rings). The data were then converted to HRC and HRB using available data tables (5).

\section{Coordinate Measurement Mapping (CMM)}

The outside diameters for several of the ring sections were measured by CMM to characterize the pre heat treatment $(\mathrm{HT})$ and post $\mathrm{HT}$ distortion. Six elevations were measured by CMM for each ring section outer diameter. The system measures the best circle fit and determines an outside diameter. Six diameters and the variance from those diameters are recorded. 


\section{Digital Radiography (DR)}

Digital radiography (DR) was used as an evaluation tool. The welded remnants or cans were inspected at $0.1^{\circ}$ increments in the weld region. The data were compiled into automated slices for review and comparison. In addition, the gap data were "colorized" to indicate the distance between the can and plug. The minimum resolvable distance is 1 pixel which is approximately $0.007 \mathrm{inch}$. The DR data was used to develop several quality metrics for the weld. One value was "Weld Merit" which is a measure of the nominal weld width using the average and two standard deviations while the second was a can to plug gap measure.

\section{Material Modification}

\section{Furnace Heat Treating}

Sample rings were cut from can IC009Q remnant. The rings were nominally 1 inch wide and a total of 9 samples were prepared. The rings were vacuum heat treated at a variety of temperatures. Prior to conducting any of the prescribed heat treatments, the furnace was vacuum baked at $1250^{\circ} \mathrm{C}$ for 2 hours. Samples were heat treated by evacuating the sample in the furnace to less than $10^{-5} \mathrm{Torr}$, heating to within $20^{\circ} \mathrm{C}$ of the target temperature at $20^{\circ} \mathrm{C} / \mathrm{min}$, reducing the rate to $3^{\circ} \mathrm{C} / \mathrm{min}$ to the target temperature, holding for 3 min and then furnace cooling, with an option for forced argon cooling below $250^{\circ} \mathrm{C}$.

Samples were characterized using the Fischer MP3 Feritscope, microhardness and hardness tests. These data were also used to determine the necessary thermal profile for the in-situ arc anneal (ISAA)

\section{In-situ Arc Anneal}

Scoping studies for the in-situ arc anneal concept were initially conducted using a 2.5" diameter austenitic stainless steel pipe, then a 4.6" diameter pipe and finally on 4.6" diameter T series test can remnant mockup assemblies. Vacuum furnace heat treating indicated that peak temperatures of $\sim 550{ }^{\circ} \mathrm{C}$ were needed to achieve a partial stress relief and to lower the measured \% ferrite values to levels consistent with values previously measured on FBL and HS inner cans. The test pieces were instrumented with 12 to 24 type $\mathrm{K}$, chromel-alumel, thermocouples to determine the width of the heat affected zone produced. An adjustable speed rotary fixture was used so that the can remnant could be purged with $\mathrm{He}$, held at the appropriate location for digital radiography (DR), and supported during testing. Thermocouples (TC) were spot welded to the can sidewall at locations that initially included the fusion zone (FZ) to a distance of about 0.35 inch from the FZ centerline. The TCs were placed both above and below the FZ centerline in a V-pattern. The actual location was measured using a microscope after the TCS were placed. The ISAA data were acquired digitally at 100 samples per second during the continuous arc travel rate of 1 revolution per minute (rpm) at 50 Amps non-pulsed arc current for the first mockup testing. Subsequent testing was completed at $50 \mathrm{Amps}$ and $1.25 \mathrm{rpm}$ and a second pass was also added. Final mockup testing was performed without TCs and without interruption between ISAA, tacking and welding.

The welding torch was mechanically fixtured for stability. Three cameras were used to monitor the thermal process. Auto darkening hood lenses set at the \#11 filter were used to protect the cameras that were positioned to monitor the leading and trailing edges of the weld pool. The inside of the can was monitored using a mirror tilted at the appropriate angle to see the thermally treated area; no lens filter was used for this view. ISAA was accomplished using a constant current of 50 amperes. The rotation speed and the number of revolutions were varied to achieve the desired final temperature. Two variations of the process were used, one in which the sample was ISAA, DR, tack welded, DR, final welded and DR and the other in which the sample was 
ISAA, tack welded, final welded and DR. An instrumented can and the general arrangement of cameras and the welding torch are shown in Figure 2.

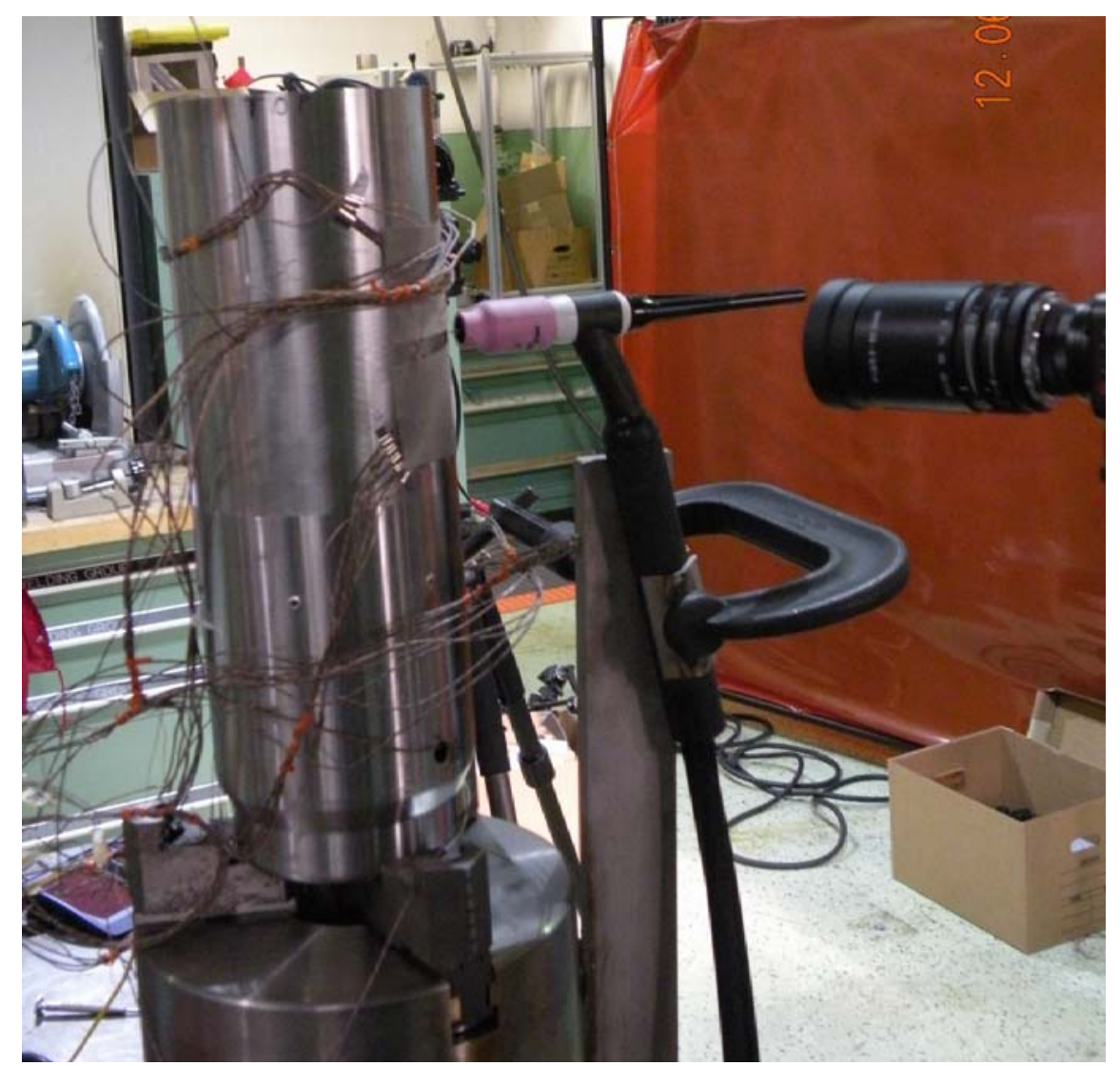

Figure 2. General configuration of can, camera, thermocouples and welding torch on turntable for ISAA and gap testing.

\section{Weld Processing}

\section{Can to Plug Gap}

An experiment was conducted to determine the size of the can to plug gap that could be successfully bridged during arc welding. The test was conducted by machining an undersized plug and inserting it into a T series (an early generation PDC can) remnant. The can to plug gap was set by fixing the plug to one side, the $0^{\circ}$ mark, so that it exhibited no gap and a shim that created a maximum gap of $\sim 0.056^{\prime \prime}$ at $180^{\circ}$. The assembly was tack welded into position and digitally radiographed. Two cans were assembled using this technique and a total of four welds were made. Each time the weld was initiated at the zero mark and progressed to can failure. A pulsed weld at $0.4 \mathrm{sec}$. at $145 \mathrm{~A}$ and $0.2 \mathrm{sec}$. at $65 \mathrm{~A}$ with continuous rotation at $0.4133 \mathrm{RPM}$ (to simulate stepped pulse welding at $.62 \mathrm{rpm}$ ) was used. The welds were videotaped and examined using DR to determine the can to plug gap that caused failure.

\section{Effect of Tack and Tack Sequence}

The effect of tack size and tack location/sequence was evaluated using the prototypic welder with can remnants and actual cans. The remnants were welded using 4, 5, and 6 tacks. The total length of tack weld was held roughly constant a $213 / 16\left(2.81^{\prime \prime}\right)$, the tack length used for the 3 tack baseline process (originally there were 3 tacks with a length of 15/16" each.). The arc was struck, a tack was made, the current was reduced to 15 
Amperes and the arc was sustained to the next location where the next tack was made, etc. until the requisite number of tacks in the desired sequence was completed. For the remnant and several actual can welds, the can was tack welded and DR measurements performed prior to final closure welding. Some of the cans were processed in a continuous manner (ISAA, tacking and closure welding were completed without interruption between these steps).

\section{Prototypic Can Welds}

Select PDC IC cans were welded using the automated weld system. All processes were conducted in a manner consistent with the automation and current operating procedures. The cans were evacuated and helium backfilled three times, the lid was inserted using the automated drive motor, the weld head was positioned automatically and the weld commenced.

\section{Results}

\section{Materials Characterization}

\section{Review of can chemistry}

Previous work for the bagless transfer cans identified that the chemistry of the plugs and cans is critical to achieving the desired weld geometry (6). It was determined that the chromium equivalent to nickel equivalent had to fall in a precise range and that the sulfur had to be fairly high. This combination of properties allows the weld geometry to be achieved without solidification cracking. The certified materials test reports (CMTR) for the PDC IC cans and plugs were compiled and compared to the historical data from FBL and HS and is presented in Table 1. The CMTRs all indicate that the materials are similar in composition and meet both the ASME code requirements in addition to meeting the tighter limits imposed by the procurement specifications.

\section{Feritscope \% Measured Ferrite}

The baseline \% measured ferrite, note that the flow formed cans contain the magnetic phase deformation induced martensite rather than ferrite, from the PDC, FBL and HS cans are shown in Figure 3 and Table 2. It is apparent from the data that the average values for the PDC cans are from a different population than either the FBL or HS cans. The measured \% ferrite content, typically $0.7-1.5 \%$, in the cup region is consistent for annealed 304L stainless. A more detailed discussion on the potential impacts of number on the mechanical and physical properties is presented in Ref. 1. 
Table 1. CMTR data for the PDC, FBL, and HS cans and plugs used in production and for development work.

\begin{tabular}{|c|c|c|c|c|c|c|c|}
\hline & PDC-Q1 & $\begin{array}{l}\text { PDC- } \\
\text { Q2 }\end{array}$ & PDC-T & BTS Qual & FBL & FBL & HS \\
\hline Product & $\begin{array}{l}24 \text { Cans } \\
30 \\
\text { Plugs }\end{array}$ & 6 cans & $\begin{array}{l}\text { Preliminary } \\
\text { Test Cans }\end{array}$ & Can(Job\#2440) & Job\#2507 & Job\#2559 & Can \\
\hline Heat No. & 5DR2 & 100345 & 045147 & $2559 \mathrm{H}$ & 8656422 & A19848 & 54033 \\
\hline $\mathrm{C}$ & 0.0168 & 0.021 & 0.015 & 0.017 & 0.016 & 0.024 & 0.023 \\
\hline $\mathrm{Mn}$ & 1.4445 & 1.6 & 1.9 & 1.73 & 1.75 & 1.82 & 1.73 \\
\hline $\mathrm{P}$ & 0.031 & 0.032 & 0.027 & 0.034 & 0.032 & 0.028 & 0.026 \\
\hline $\mathrm{S}$ & 0.025 & 0.025 & 0.024 & 0.026 & 0.022 & 0.017 & 0.024 \\
\hline $\mathrm{Si}$ & 0.259 & 0.426 & 0.51 & 0.6 & 0.61 & 0.72 & 0.52 \\
\hline $\mathrm{Cr}$ & 18.316 & 18.21 & 18.23 & 18.2 & 18.48 & 18.37 & 18.31 \\
\hline $\mathrm{Ni}$ & 8.6025 & 8.07 & 8.2 & 8.38 & 8.58 & 8.46 & 8.74 \\
\hline Mo & 0.409 & 0.37 & 0.33 & 0.43 & 0.45 & 0.38 & 0.45 \\
\hline $\mathrm{Nb}$ & 0.013 & 0.009 & 0.04 & & 0.005 & 0.05 & 0.05 \\
\hline $\mathrm{Al}$ & 0.003 & 0.005 & NR & & 0.005 & NR & NR \\
\hline $\mathrm{Cu}$ & 0.465 & 0.436 & 0.38 & 0.39 & 0.43 & 0.39 & 0.34 \\
\hline V & NR & 0.06 & NR & NR & NR & NR & NR \\
\hline $\mathrm{Ti}$ & 0.002 & 0.03 & NR & NR & 0.003 & NR & 0.005 \\
\hline $\mathrm{N}$ & 0.0765 & 0.091 & 0.08 & 0.089 & 0.0794 & 0.092 & 0.069 \\
\hline $\mathrm{Sn}$ & NR & 0.014 & NR & NR & NR & NR & NR \\
\hline Co & NR & 0.133 & 0.14 & NR & 0.1 & 0.12 & 0.125 \\
\hline B & NR & 0.004 & NR & NR & NR & NR & NR \\
\hline $\mathrm{Ta}$ & NR & NR & NR & NR & 0.01 & 0.005 & 0.005 \\
\hline Cr EQ S\&K & 18.73 & 18.59 & 18.59 & 18.63 & 18.93 & 18.79 & 18.80 \\
\hline Ni EQ S\&K & 10.84 & 10.73 & 10.42 & 10.85 & 10.84 & 11.24 & 11.01 \\
\hline $\mathrm{Cr} / \mathrm{Ni} \mathrm{EQ}$ & 1.73 & 1.73 & 1.78 & 1.72 & 1.75 & 1.67 & 1.71 \\
\hline Hard HVN & 170 & & 173 & 152 & & 156 & 183 \\
\hline .2 YS (ksi) & 44 & 39.6 & 41.3 & 39 & 42 & 36.8 & 46.7 \\
\hline UTS (ksi) & 87 & 88.6 & 86.8 & 84.2 & 83 & 84.5 & 87.4 \\
\hline$\% \mathrm{RA}$ & 67 & 76 & 78.1 & 74 & 76 & 74 & 76.9 \\
\hline \%Elong. & 50 & 57 & & 55 & 62 & 59.3 & 60 \\
\hline
\end{tabular}

The measured \% ferrite is related to the amount of cold work that is present in the alloy. These data suggest that the new cans may have more cold work than the legacy cans. Thus additional testing to determine the tensile and hardness was undertaken.

The impact of these different measured \% ferrite numbers may have on welding is unknown. Since the weld process has a significant electromagnetic component, the change in magnetic properties of the substrate may affect the arc characteristics although no testing was conducted to determine if there was any such influence. 


\section{Measured \% Ferrlte}

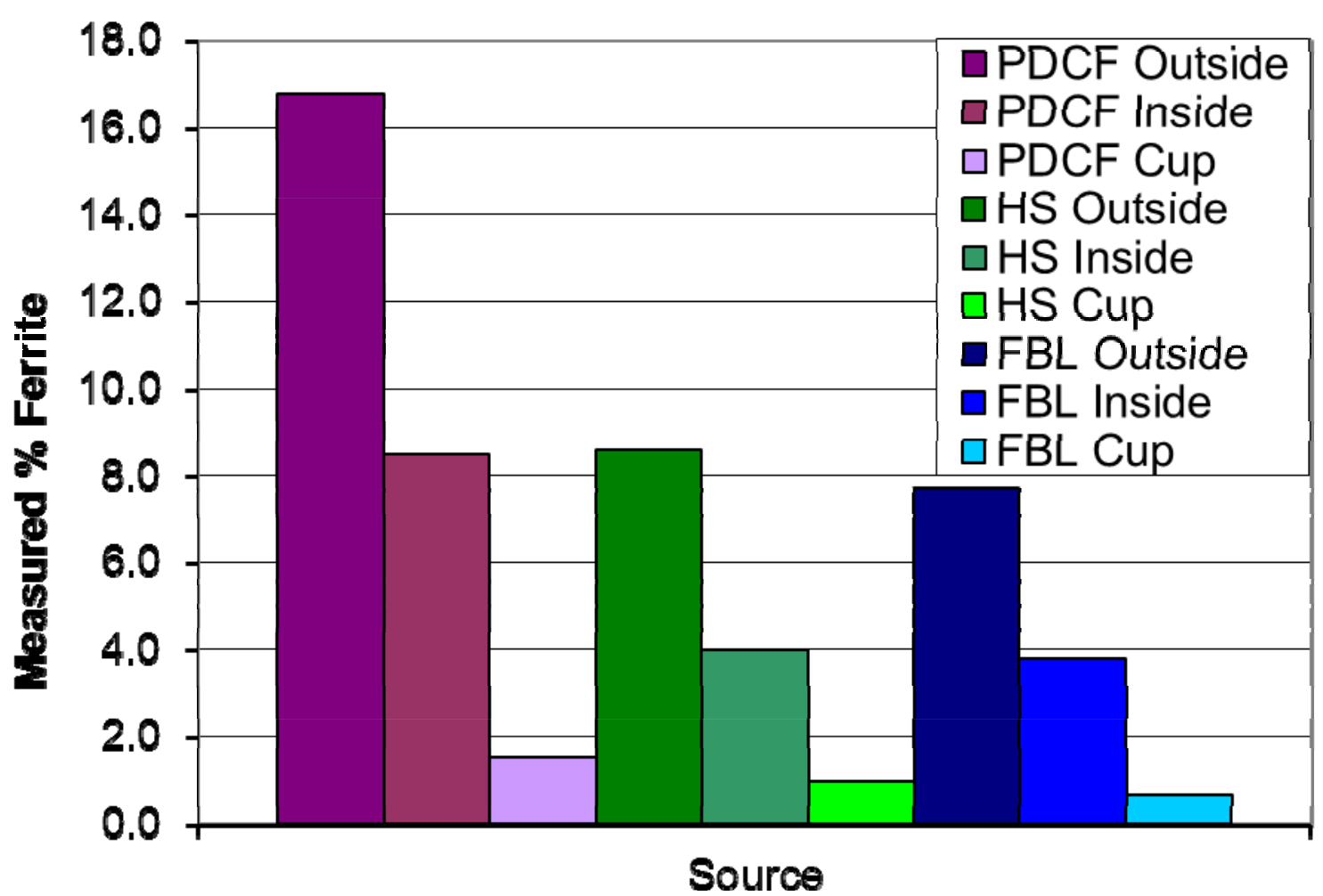

Figure 3. Measured \% Ferrite for PDC, Hanford (HS), and FB-Line cans.

Table 2. Measured \% Ferrite for PDC, HS, and FB-Line Cans.

\begin{tabular}{|l|l|l|}
\hline $\begin{array}{l}\text { Can ID and } \\
\text { Location }\end{array}$ & $\begin{array}{l}\text { Average \% } \\
\text { F }\end{array}$ & Std Dev \\
\hline PDCF Outside & 16.8 & 2.16 \\
\hline PDCF Inside & 8.5 & 1.74 \\
\hline PDCF Cup & 1.5 & 0.08 \\
\hline HS Outside & 8.6 & 0.58 \\
\hline HS Inside & 4.0 & 0.67 \\
\hline HS Cup & 1.0 & 0.42 \\
\hline FBL Outside & 7.7 & 2.33 \\
\hline FBL Inside & 3.8 & 1.47 \\
\hline FBL Cup & 0.7 & 0.20 \\
\hline
\end{tabular}

\section{Tensile Testing}

The individual mechanical properties of the PDC (009Q), HS (6540), and FBL (3022) cans are listed in Table 3 and the average data are listed in Table 4. These data identify no difference between the three materials, contrary to the results from the measured $\%$ ferrite testing. This lack of differentiation may be due to a surface effect that is not readily measured, slight differences in the amount of magnetic material, or exposure of the PDC cans to a magnetic field. A comparison to data from 2001 indicates that these values are 30 and 25 ksi lower for yield and tensile strength, respectively. In addition, the 2001 data exhibited only $4 \%$ strain to failure vs. $8.47 \%$ (8). The discrepancy between data may be due to differences in testing methodology and sample preparation. The 
reference data do not indicate strain rate / crosshead speed which can affect strength by about 5 ksi as well as elongation with faster rates generally resulting in higher strength and lower ductility measurements $(9,10)$. Sample size can also affect the measured properties.

Table 3. Individual mechanical property data for PDC, HS, and FBL cans.

\begin{tabular}{|l|l|l|l|l|l|l|l|l|}
\hline $\begin{array}{l}\text { Specimen } \\
\text { ID }\end{array}$ & $\begin{array}{l}\text { Thick } \\
\text { in }\end{array}$ & $\begin{array}{l}\text { Width } \\
\text { In }\end{array}$ & $\begin{array}{l}\text { Area } \\
\text { in }^{2}\end{array}$ & $\begin{array}{l}\text { Load At } \\
\text { Offset Yield } \\
\text { lbf }\end{array}$ & $\begin{array}{l}\text { Stress At } \\
\text { Offset Yield } \\
\text { Ksi }\end{array}$ & $\begin{array}{l}\text { Peak Load } \\
\text { Lbf }\end{array}$ & $\begin{array}{l}\text { Peak } \\
\text { Stress } \\
\text { ksi }\end{array}$ & $\begin{array}{l}\text { Strain } \\
\text { At } \\
\text { Break } \\
\%\end{array}$ \\
\hline 009 Q-1 & 0.0608 & 0.2512 & 0.0153 & 2550.694 & 167.007 & 2944.557 & 192.8 & $\mathbf{4 . 7 8 2}$ \\
\hline $009 Q-2$ & 0.0605 & 0.2473 & 0.0150 & 2364.884 & 158.063 & 2832.554 & 189.3 & 8.350 \\
\hline $009 Q-3$ & 0.0614 & 0.2490 & 0.0153 & 2431.660 & 159.050 & 2872.399 & 187.9 & 8.507 \\
\hline $009 Q-4$ & 0.0614 & 0.2510 & 0.0154 & 2506.004 & 162.607 & 2915.742 & 189.2 & $\mathbf{5 . 0 0 5}$ \\
\hline $6540-1$ & 0.0599 & 0.2472 & 0.0148 & 2182.455 & 147.390 & 2762.213 & 186.5 & 8.274 \\
\hline $6540-2$ & 0.0600 & 0.2525 & 0.0151 & 2493.024 & 164.556 & 2836.309 & 187.2 & 7.917 \\
\hline $6540-3$ & 0.0604 & 0.2457 & 0.0148 & 2482.676 & 167.293 & 2774.598 & 187.0 & $\mathbf{6 . 2 1 2}$ \\
\hline $6540-4$ & 0.0601 & 0.2457 & 0.0148 & 2301.150 & 155.835 & 2745.549 & 185.9 & 7.261 \\
\hline $3022-1$ & 0.0601 & 0.2445 & 0.0147 & 2417.516 & 164.519 & 2733.449 & 186.0 & 8.563 \\
\hline $3022-2$ & 0.0601 & 0.2475 & 0.0149 & 2407.734 & 161.867 & 2793.537 & 187.8 & 9.778 \\
\hline $3022-3$ & 0.0602 & 0.2516 & 0.0151 & 2414.206 & 159.399 & 2838.139 & 187.4 & $\mathbf{5 . 9 5 4}$ \\
\hline $3022-4$ & 0.0602 & 0.2505 & 0.0151 & 2481.712 & 164.568 & 2833.627 & 187.9 & 9.147 \\
\hline
\end{tabular}

Bold indicates failure outside of gauge section.

Table 4. Average Tensile Test Results

\begin{tabular}{|l|c|c|c|c|c|c|}
\hline Canister & \multicolumn{2}{|c|}{$\begin{array}{c}\text { Yield Strength } \\
(\mathrm{ksi})\end{array}$} & \multicolumn{2}{c|}{$\begin{array}{c}\text { Ultimate Strength } \\
(\mathrm{ksi})\end{array}$} & \multicolumn{2}{c|}{$\begin{array}{c}\text { Strain-to- Failure } \\
{ }^{*}(\%)\end{array}$} \\
\hline & Avg & StD & Avg & StD & Avg & StD \\
\hline $009 \mathrm{Q}$ & 161.7 & 4.1 & 189.8 & 2.1 & 8.43 & 0.11 \\
\hline 6540 & 158.8 & 9.0 & 186.7 & 0.6 & 7.82 & 0.51 \\
\hline 3022 & 162.6 & 2.5 & 187.3 & 0.9 & 9.16 & 0.61 \\
\hline Average & 160.5 & 5.6 & 187.5 & 1.9 & 8.47 & 0.76 \\
\hline
\end{tabular}

${ }^{*}$ Average strain values do not include data from samples that failed outside the gauge section.

\section{Microhardness}

Microhardness measurements were used to characterize the profile of the PDC cans and to compare them to the FBL and HS cans. The microhardness profiles for the three cans at three locations each are shown in Figure 4. These data show that there is a hardness gradient from the inside to the outside of the can, consistent with the measured \% ferrite values that show a lower value on the inside of the can compared to the outside for all three can vintages, however, unlike the $\%$ ferrite measurements there is not a significant difference in the measured microhardness values for the PDC canisters relative to the legacy canisters. Two of the three measurements for the PDC can are slightly higher than that those observed for both the FBL and HS cans, but there is a significant amount of overlap in the data so these are inconclusive with respect to property differences. Reference 8 indicates a hardness of 44-45 HRC, or similar to that measured in this study. 


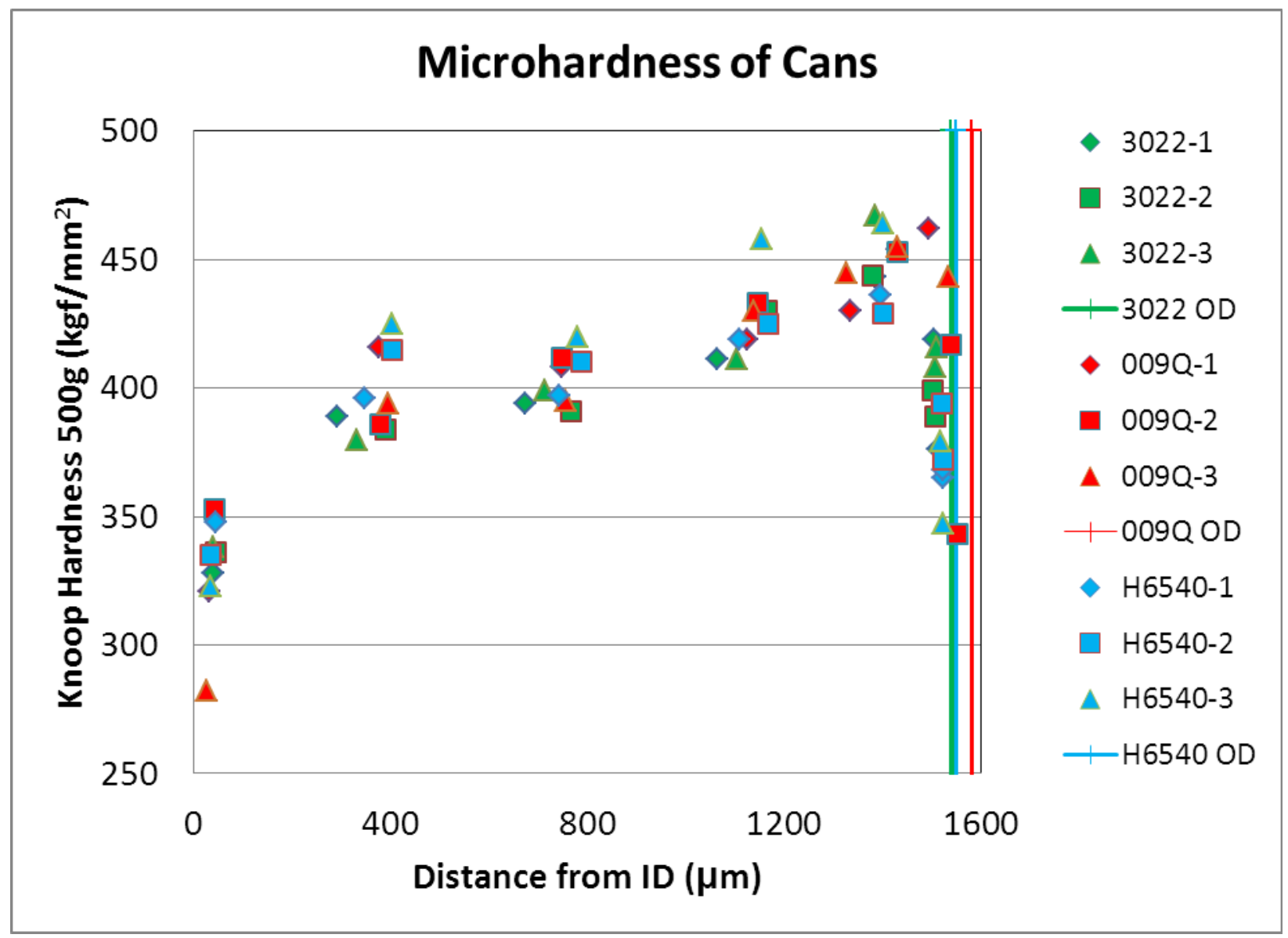

Figure 4. Microhardness profiles for PDC (009Q), HS (H6540), and FBL (3022) cans.

\section{Material Modification}

\section{Furnace Heat Treating}

Hardness testing, measured \% ferrite, and dimensional measurements (CMM) were used to examine the efficacy of heat treatment to develop comparable measured \% ferrite values for the PDC cans vs. the FBL or HS cans. In addition, $\mathrm{CMM}$ was used to determine if the heat treatment caused excessive movement during stress relaxation. Heat treatments were conducted using the profile indicated previously at target temperatures from 500 to $1100^{\circ} \mathrm{C}$. The measured $\%$ ferrite results for the outside of the ring are shown in Table 5 . These data indicate that there is no change at $500^{\circ} \mathrm{C}$ and that recovery (11) of the material likely starts at $525^{\circ} \mathrm{C}$. The temperature at which recovery is initiated depends on the time at temperature as well as the amount of cold work. A rule of thumb is that recovery can occur at temperatures as low as $0.4 \mathrm{~T}_{\mathrm{m} \text { (ABS) }}$ or $376^{\circ} \mathrm{C}$ for a typical melting point of $1350^{\circ} \mathrm{C}$. The nominal measured $\%$ ferrite values for the $\mathrm{FBL}$ and $\mathrm{HS}$ cans was about 8 consequently, the ISAA targeted a value of $550^{\circ} \mathrm{C}$ at a distance 0.3 inch from the edge of the fusion zone (FZ). These results show that it is possible to reduce the measured \% ferrite values to those consistent with FBL and HS cans. 
Table 5. Heat treat results for ring samples.

\begin{tabular}{|l|c|c|c|}
\hline \% ferrite, using Application \#1 & Outside & AVG & StD \\
\hline All 9 rings Avg, before HT & All 9 & 13.1 & 0.68 \\
\hline at 500 hold 3 min & R2 & 13.3 & 0.46 \\
\hline at $525^{\circ} \mathrm{C}$ hold 3 min & R9 & 10.6 & 0.52 \\
\hline at $550^{\circ} \mathrm{C}$ hold 3 min & R8 & 7.9 & 0.17 \\
\hline at $575^{\circ} \mathrm{C}$ hold 3 min & R7 & 5.8 & 0.23 \\
\hline at $600^{\circ} \mathrm{C}$ hold 3 min & R6 & 5.1 & 0.07 \\
\hline at $630^{\circ} \mathrm{C}$ max $\left.3.6 \mathrm{~min}>600\right)$ & R1 & 4.8 & 0.15 \\
\hline at $700^{\circ} \mathrm{C}$ hold 3 min & R3 & 1.2 & 0.10 \\
\hline at $900^{\circ} \mathrm{C}$ hold 3 min -null rdg & R5 & N/A & N/A \\
\hline at $1100^{\circ} \mathrm{C}$ hold 3 min, -null rdg & R4 & N/A & N/A \\
\hline
\end{tabular}

The heat treated rings were subsequently dimensionally inspected to determine how much they may have moved during the sub critical anneal. The CMM data were used to calculate the nominal can diameter and the deviations from the nominal diameter were also determined. The data for heat treated rings are listed in Table 6. These data show that some can movement occurs during all the annealing tests. The nominal diameter is $4.540+/-0.005$ inches with an intentional tri-lobe effect for improved gas movement. This tri-lobe attribute may increase the variance somewhat but it should be fairly consistent. With the heat treatment at temperatures above $630^{\circ} \mathrm{C}$ there is an increase in the variance by nearly three times with it going from an average of 18 to an average of 47 . The amount of variance that the can experiences for heat treatment between 500 and $600^{\circ} \mathrm{C}$ is less than 0.020 inch. It is expected that this amount can be accommodated in the insitu arc anneal but would be unacceptable for the finished can. It may be possible to accommodate this much movement if the can were annealed in process (prior to final machining) rather than at the end of fabrication. The heat treatments were very useful in defining target temperatures for the ISAA tests.

Table 6. Pre and Post Heat Treatment Dimensional Results.

\begin{tabular}{|c|c|c|c|c|}
\hline $\begin{array}{l}\text { Diameter Measurements, @ } 6 \\
\text { Elevations by CMM, Design is } \\
4.540+/-0.005 "\end{array}$ & $\begin{array}{l}\text { Before HT Avg. } \\
\text { Diam }\end{array}$ & $\begin{array}{l}\text { Before HT Diam } \\
\text { Variance }\end{array}$ & $\begin{array}{l}\text { After HT } \\
\text { Avg. Diam }\end{array}$ & $\begin{array}{l}\text { After HT Diam } \\
\text { Variance }\end{array}$ \\
\hline R2 / HT @ 500 ${ }^{\circ} \mathrm{C}$ hold $3 \mathrm{~min}$ & $\mathrm{~N} / \mathrm{A}$ & $\mathrm{N} / \mathrm{A}$ & 4.540 & 0.013 \\
\hline R9 / HT @ 525ㄷ hold 3 min & 4.539 & 0.018 & 4.539 & 0.017 \\
\hline R8 / HT @ 550 hold 3 min & 4.539 & 0.014 & 4.539 & 0.004 \\
\hline R7 / HT @ 575 hold 3 min & 4.538 & 0.014 & 4.538 & 0.010 \\
\hline R6 / HT @ 600 ${ }^{\circ} \mathrm{C}$ hold 3 min & 4.538 & 0.025 & 4.538 & 0.014 \\
\hline $\begin{array}{l}\mathrm{R} 1 / \mathrm{HT} @ 630^{\circ} \mathrm{C} \max \\
\left(3.6 \min >600^{\circ} \mathrm{C}\right)\end{array}$ & $\mathrm{N} / \mathrm{A}$ & $\mathrm{N} / \mathrm{A}$ & 4.537 & 0.022 \\
\hline R3 / HT @ 700 C hold 3 min & $\mathrm{N} / \mathrm{A}$ & $\mathrm{N} / \mathrm{A}$ & 4.536 & 0.065 \\
\hline R5 / HT @ 900C hold 3 min & $\mathrm{N} / \mathrm{A}$ & $\mathrm{N} / \mathrm{A}$ & 4.536 & 0.047 \\
\hline R4 / HT @ $1100^{\circ} \mathrm{C}$ hold 3 min & $\mathrm{N} / \mathrm{A}$ & $\mathrm{N} / \mathrm{A}$ & 4.536 & 0.032 \\
\hline
\end{tabular}


As further verification of the amount of residual stress that was removed or reduced by heat treatment, the cans were measured after cutting in preparation for the hardness testing. The level of spring-back for twist and opening are listed in Table 7, with the orientation shown in Figure 5. These data clearly show that there is a large amount of residual stress that caused the ring samples to twist and open up when cut in the as received can and that these stresses are reduced as the heat treatment temperature is increased.

Table 7. Displacement from Cutting and Hardness for Heat Treated Can Ring Samples.

\begin{tabular}{|c|c|c|c|c|}
\hline ID / Condition & $\begin{array}{c}\text { Circ. } \\
\text { Sep.(in) }\end{array}$ & $\begin{array}{c}\text { Axial } \\
\text { Twist } \\
\text { (in) }\end{array}$ & $\begin{array}{l}\text { Hardness } \\
\text { Inside }\end{array}$ & $\begin{array}{c}\text { Hardness } \\
\text { Outside }\end{array}$ \\
\hline R2 / HT @ 500 hold 3 min & 0.818 & 0.892 & $46.6 \mathrm{HRC}$ & 49.7 HRC \\
\hline R9 / HT @ 525ㄷ hold 3 min & 0.425 & 0.756 & $49.0 \mathrm{HRC}$ & $45.9 \mathrm{HRC}$ \\
\hline R8 / HT @ 550 hold 3 min & 0.322 & 0.517 & 46.0 HRC & 48.4 HRC \\
\hline R7 / HT @ 575 hold 3 min & 0.208 & 0.431 & $45.3 \mathrm{HRC}$ & $48.2 \mathrm{HRC}$ \\
\hline R6 / HT @ 600 ${ }^{\circ} \mathrm{C}$ hold 3 min & 0.156 & 0.308 & 47.3 HRC & 44.8 HRC \\
\hline $\begin{array}{l}\mathrm{R} 1 / \mathrm{HT} @ 630^{\circ} \mathrm{C} \max \\
\left(3.6 \mathrm{~min}>600^{\circ} \mathrm{C}\right)\end{array}$ & 0.230 & 0.283 & 45.4 HRC & 46.6 HRC \\
\hline R3 / HT @ 700 ${ }^{\circ} \mathrm{C}$ hold 3 min & 0.413 & 0.062 & $39.7 \mathrm{HRC}$ & $38.1 \mathrm{HRC}$ \\
\hline R5 / HT @ 900 hold 3 min & 0.101 & 0.010 & 78.97 HRB & $73.5 \mathrm{HRB}$ \\
\hline R4 / HT @ 1100C hold 3 min & 0.300 & 0.100 & $62.1 \mathrm{HRB}$ & $45.9 \mathrm{HRB}$ \\
\hline
\end{tabular}

Circ Sep. is the amount of opening of the cylinder that occurred after cutting; it includes the gap due to the saw kerf. The axial twist is the distance about the measurement surface that the piece was displaced. All hardness data were converted from H3ON and H3OT, HRC and HRB, respectively. No macrohardenss scale exists that can be used on thin samples over this entire range of hardness; estimates were made so that the data could be plotted on a single scale, but HRC values less than 20 are estimates.
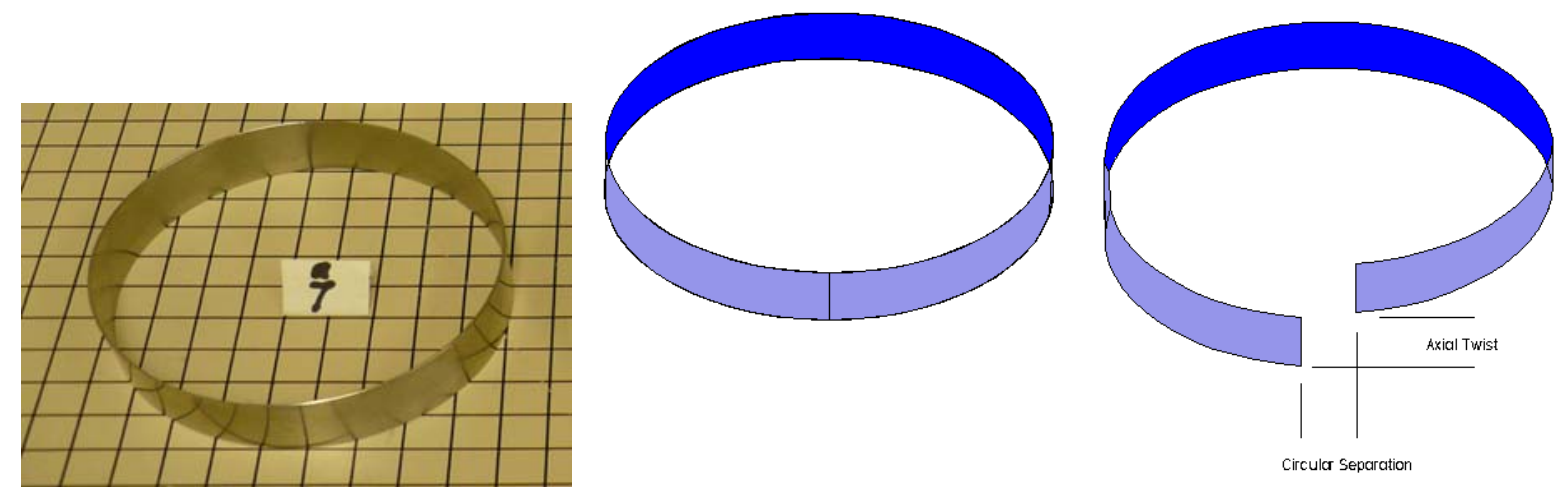

Figure 5. Photo and schematic of rings showing how distortion was measured.

The hardness was also determined for the heat treated rings. These values are listed in Table 7 also. The thermal treatments were very effective at reducing the hardness at temperatures in excess of $630^{\circ} \mathrm{C}$. This temperature is generally consistent with the rule of thumb that recrystallization occurs at temperatures in excess of $0.5 \mathrm{~T}_{\mathrm{m}(\mathrm{ABS})}$ or about $540^{\circ} \mathrm{C}$. (11). It must be noted that the recrystallization temperature is dependent on time at temperature as well as the temperature itself, thus an $\sim 100^{\circ} \mathrm{C}$ difference between the rule of thumb and test temperature is reasonable for a three minute cycle. 


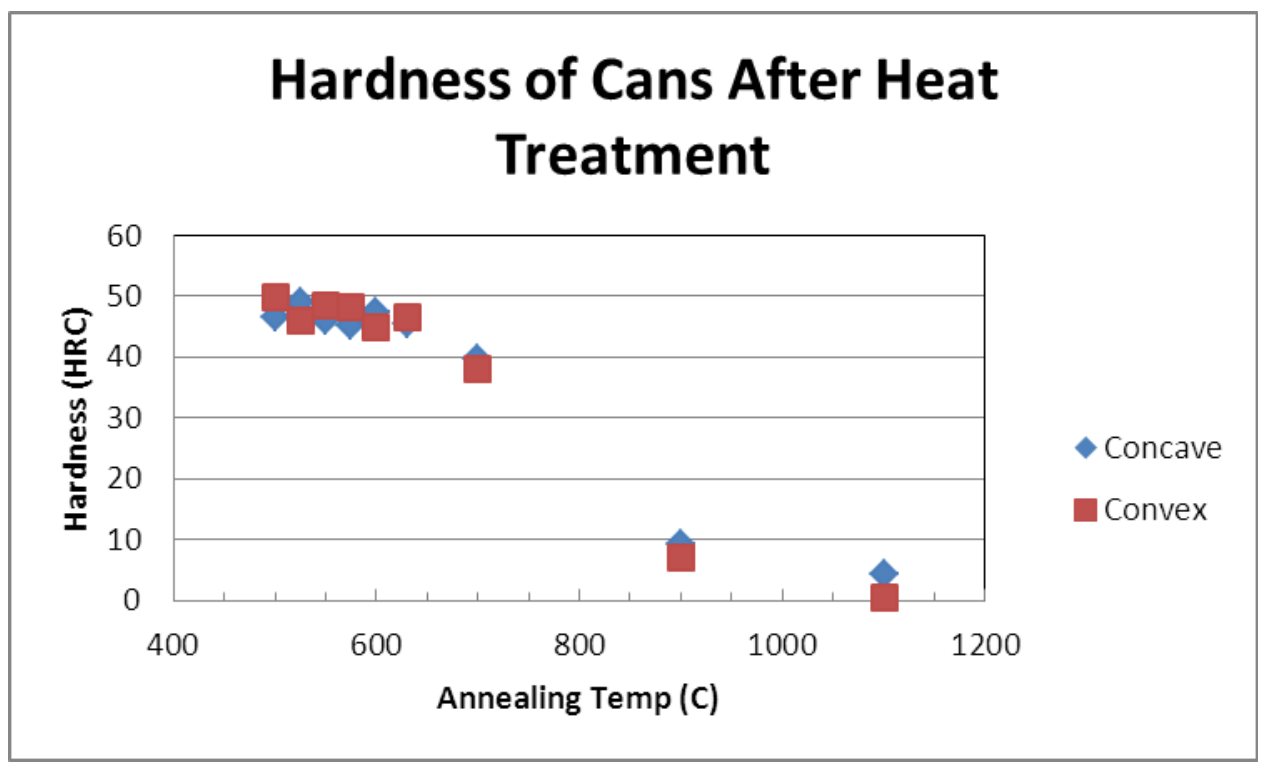

Figure 6. Graphical representation of hardness after heat treatment. Note that the hardness for T $>800^{\circ} \mathrm{C}$ is estimated since $\mathrm{HRC}$ scale ends at 20.

\section{In-situ Arc Anneal}

Several scoping studies were conducted on the ISAA to determine the nominal current, rotational speed, and thermally affected zone. Initially 2.5" OD S/S test pipe sections were used to estimate the appropriate heating conditions. ISAA evaluations were started by using targeted currents of $50 \mathrm{~A}, 75 \mathrm{~A}$, and $100 \mathrm{~A}$ continuous travel at $\sim 0.6 \mathrm{rpm}$, no pulse. Two travel speeds were used $\sim 7$ and 14 inches per min. These tests were used to locate the edge of the fusion zone (FZ) and heat affected zone (HAZ) based on the surface discoloration. The results of the scoping tests are shown in Figure 7.

From these scoping tests it was determined to place thermocouples at the centerline of the FZ and outboard as indicated by the inset sketch. The actual thermocouple placement for the first ISAA test is shown in Figure 8. The dimensions from the first thermocouple in the plane of the weld and the distance from the centerline were measured and used to ascertain the location at which the temperature exceeded $550^{\circ} \mathrm{C}$, the temperature at which a reduction of the measured \% ferrite dropped to eight. The graphical temperature output from the first test is shown in Figure 9, several data points had to be eliminated from the data set since the electromagnetic interference of the arc caused inordinate levels of noise in the data. These data indicate that the target temperature is achieved for the thermocouple positioned at 0.20 inch from the FZ centerline which provides a target zone of 0.4 inch. 


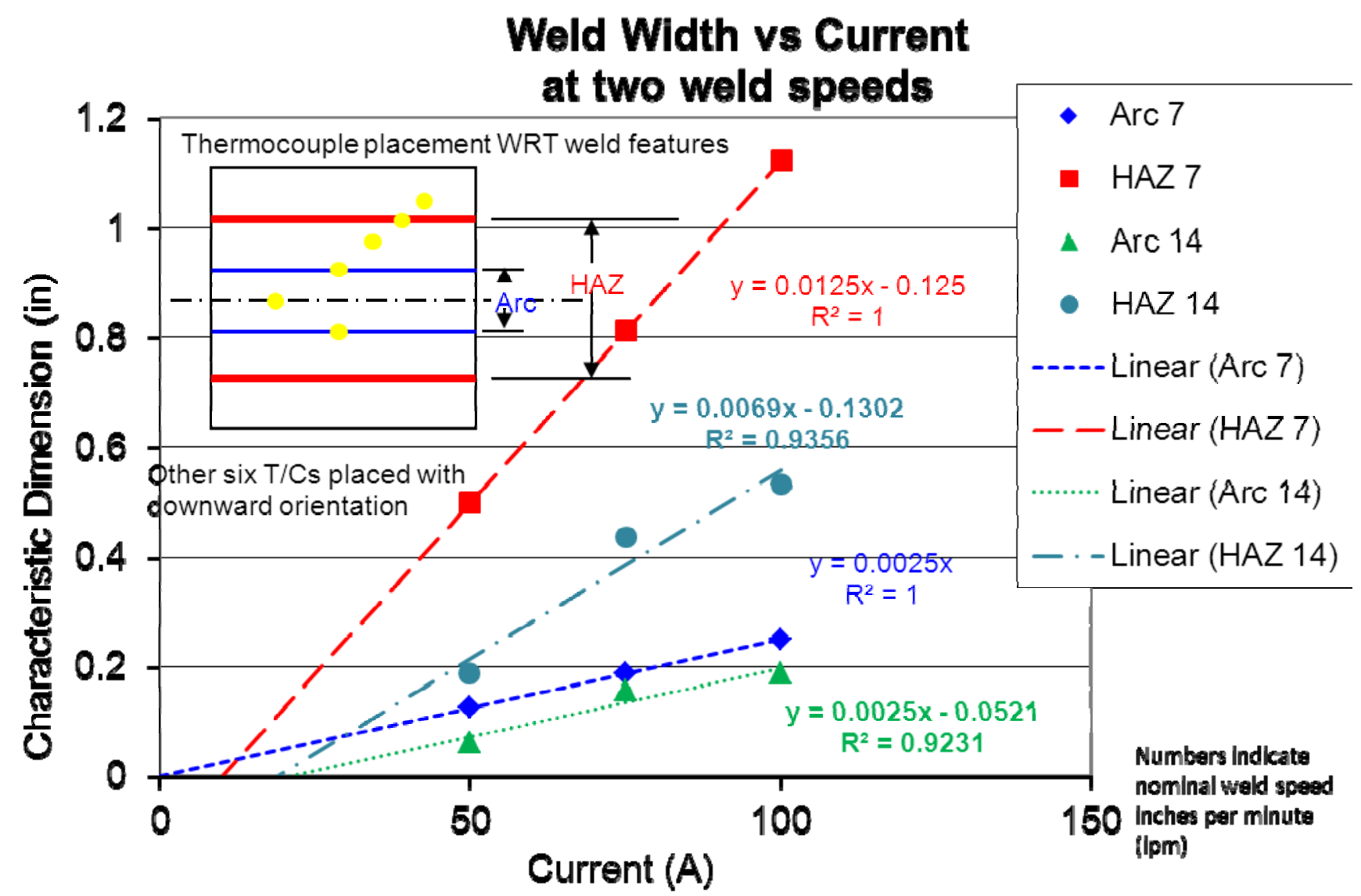

Figure 7. Scoping Study to Provide Initial Estimates for FZ and HAZ Width.

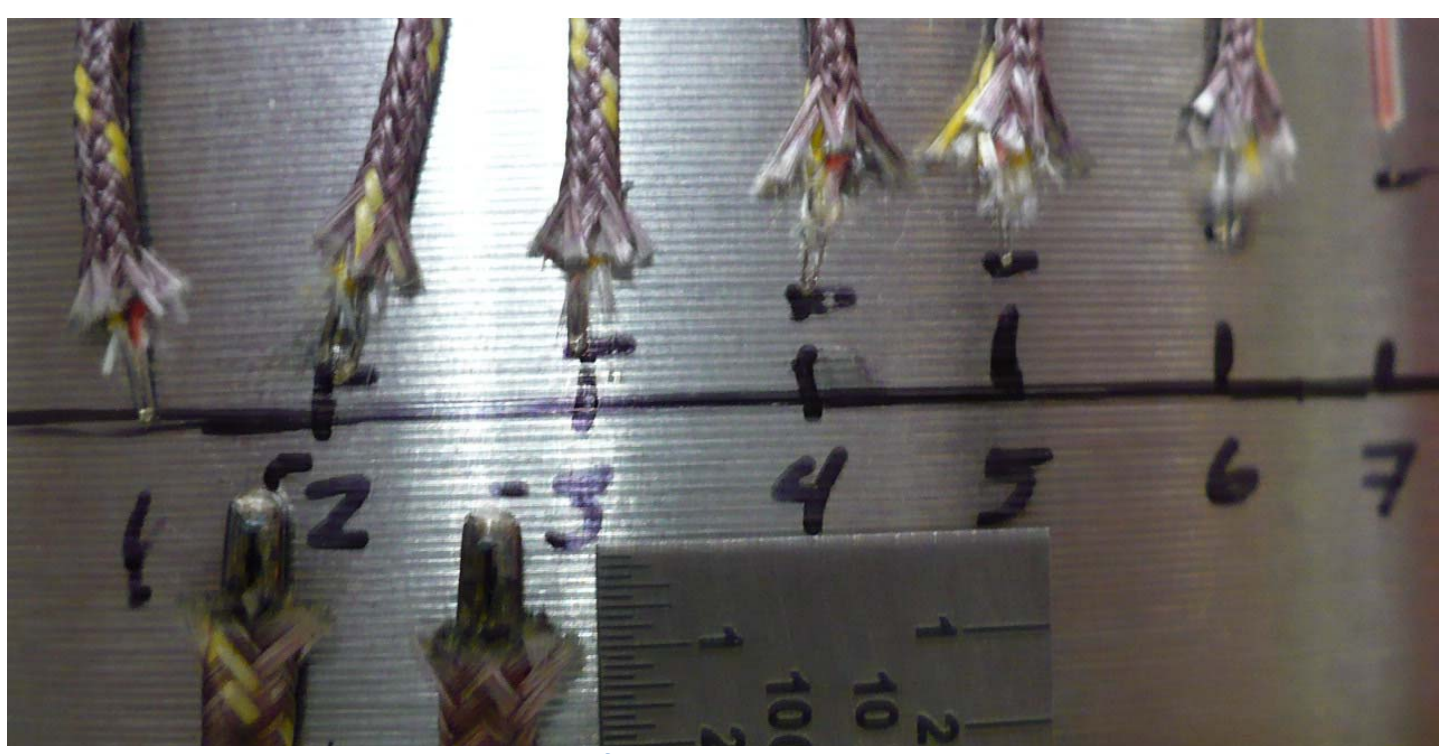

Figure 8. Photograph of ISAA01 showing thermocouple locations. 


\section{ISAA01}

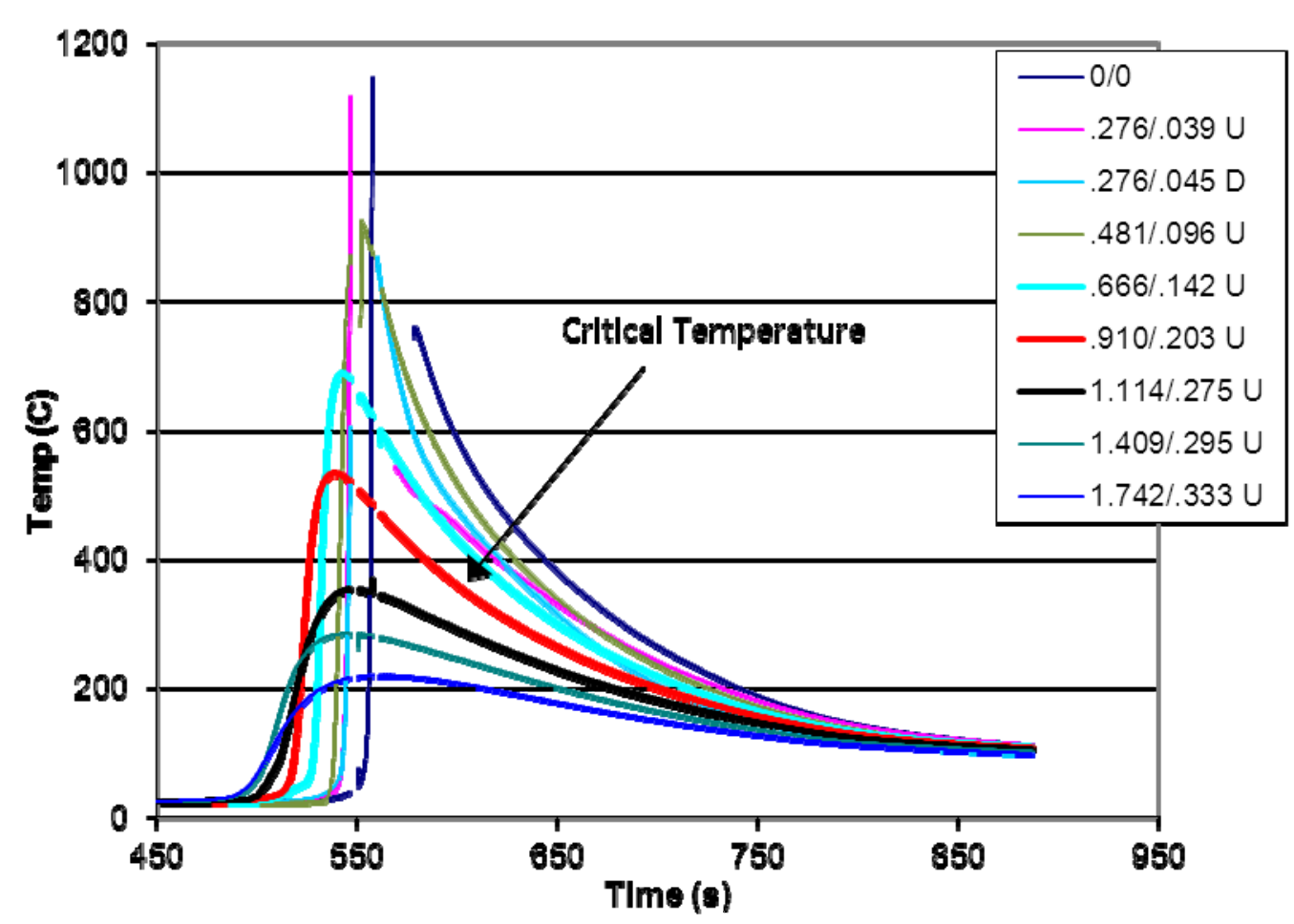

Figure 9. Temperature profile for ISAA01 showing $525^{\circ} \mathrm{C}$ at 0.203 inch from FZ centerline.

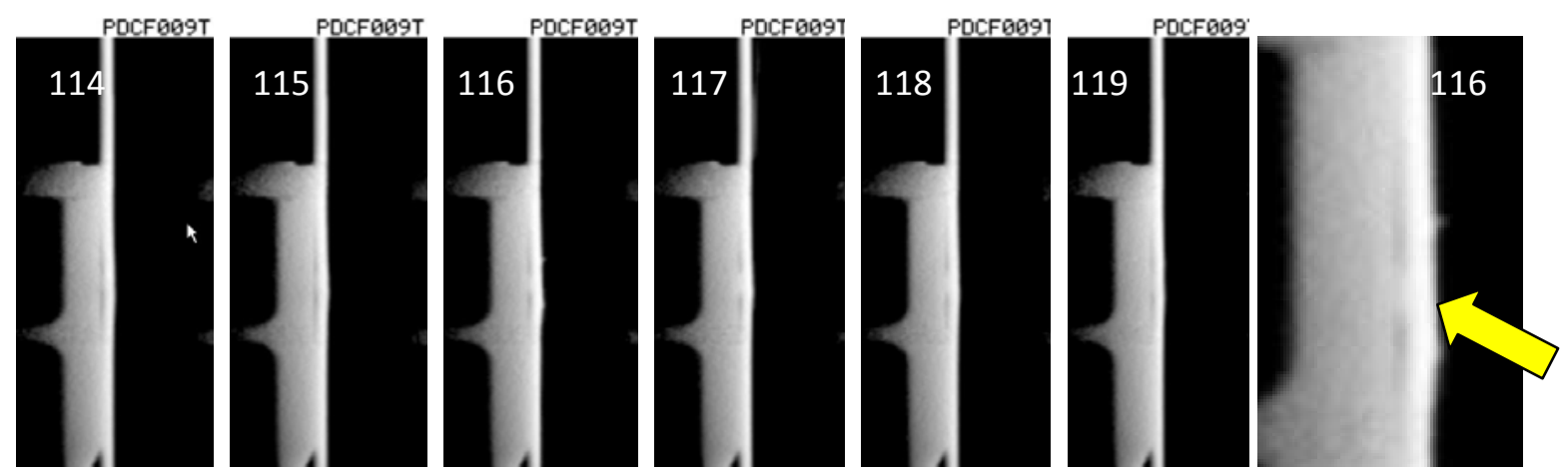

Figure 10. DR slices of ISAA01 at and near the location that can to plug bonding is suspected.

Digital radiography was used to examine the condition in the as-heat treated, tacked, and welded conditions. These three conditions were merged into one DR animation of the weld images. Review of the DR animation indicated that a minor amount of melting may have occurred over a small segment of the arc anneal, Figure 10. DR images from the animation were captured and are presented in Figure 11. The images are numbered as slices which are $1^{\circ}$ apart. In slices 116,117 , and 118 it appears that a small amount of can to plug fusion may have occurred, as further shown in the magnified shot of slice 116 in Figure 10. Also of note is the slight increase of can to plug gap that occurs around the tacks. This result is expected and occurs to varying degree with and without the ISAA and is based on the fit up of the can to the plug, the size of the tack, tack sequence, the residual stresses in the can, etc. The overall weld DR images are shown in Figure 12. These data indicate 
that there may be a small amount of separation between the can and plug during the ISAA at rotational positions of 100,190 and $300^{\circ}$; this small amount of separation is visible in the $\mathrm{x}$-ray slices in and around these locations. As indicated by the DR for the ISAA and tack welded condition, there is some localized change in the can to plug gap such that it increases around the tacks and is shown to be as high as 0.022 inch for T3.
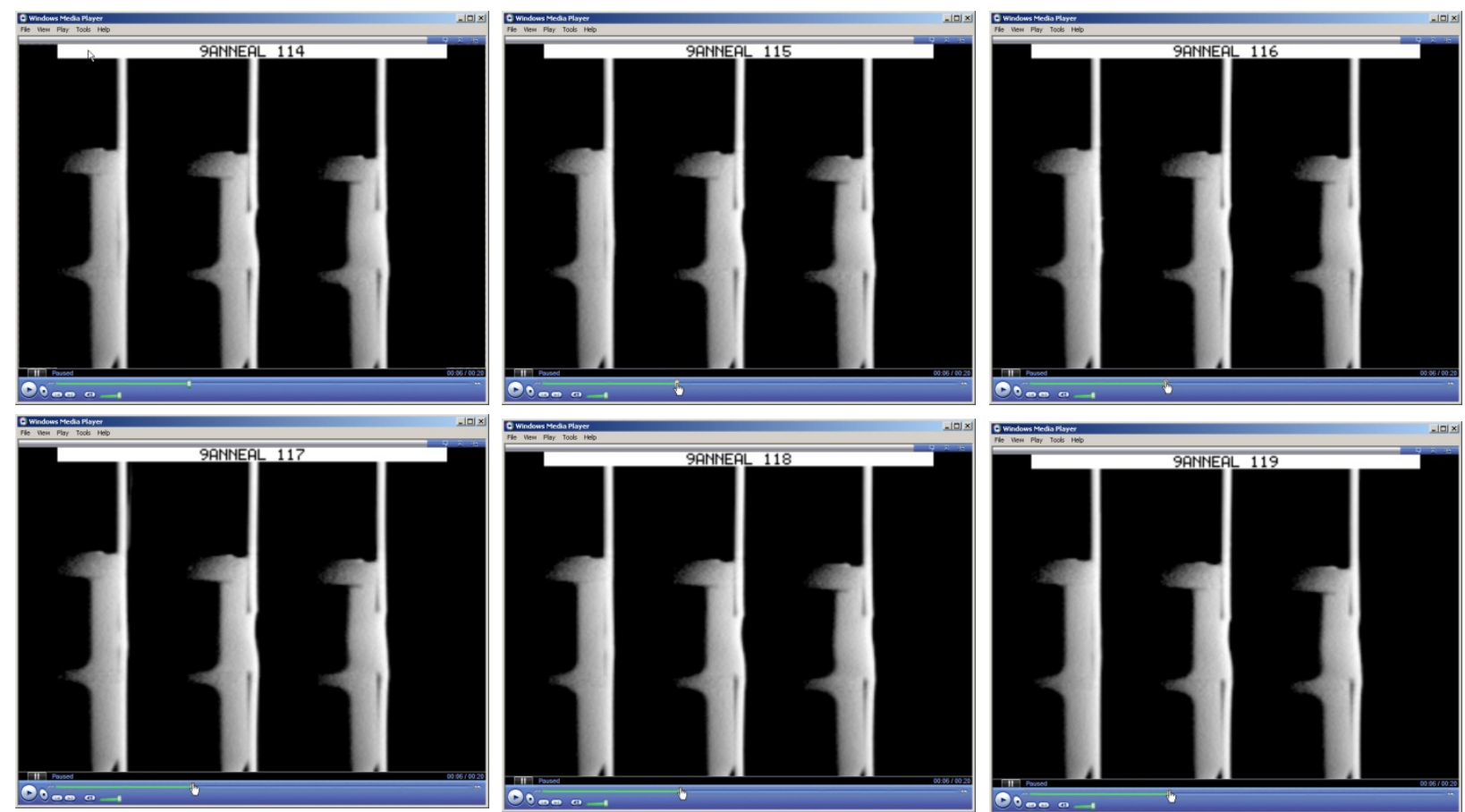

Figure 11. DR images of the ISAA01 test showing possible fusion during arc anneal

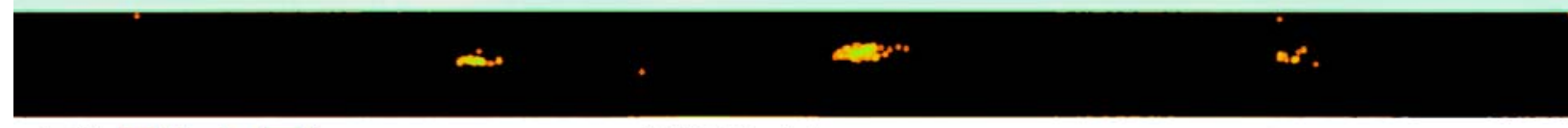

$\square 0 \square 1 \square \square 2$

Stretched color scale

PDC;009T:Annealed

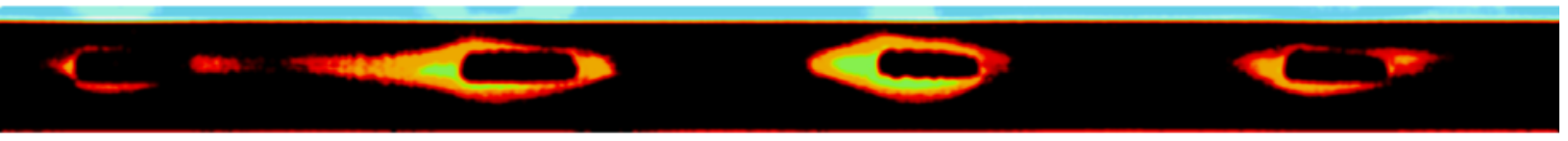

$\square 0 \square 7 \square 15 \square 22 \square 29$

PDC;009T;Tacked

T3

T2

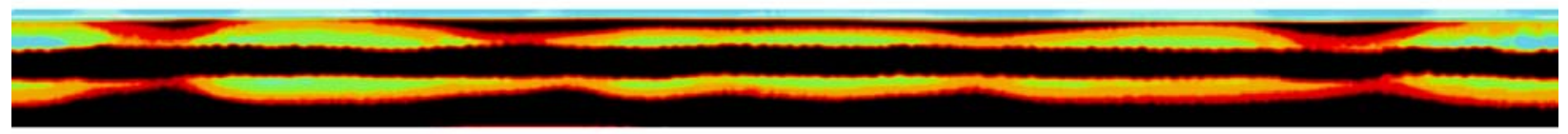

PDC:009T;Welded

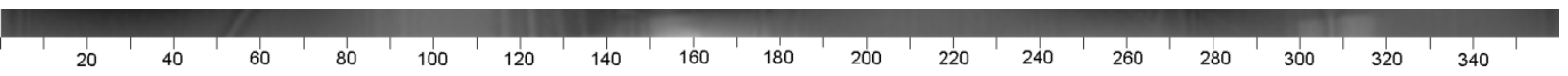

Figure 12. Digital radiography for ISAA01 in the as annealed, as tack welded - three tacks and weld start for 15/16", and fully welded conditions, the DR determined can to plug gap is indicated by the legend below the as-tack welded condition. The gaps are indicated in 0.001". 
The presence of localized apparent fusion (Figure 10 -- 116-118 ) between the can and plug during the arc anneal indicated that the conditions used may have been a little hotter than desired. The concern about premature fusion of the can to plug is that if it is extensive, then it could reduce the number and size of the gas paths for venting and promote the propensity for weld blow-outs. It was considered desirable to increase the width of the heat treated zone to approximately 0.5 inches which would require additional heat. To achieve both a reduction in the instantaneous heat that promotes fusion, and an increase in the residual heat that promotes annealing, it was decided that the rotational speed should be increased from 1 RPM to 1.25 RPM and the duration should be increased from 1 revolution to 2 revolutions. A second can remnant was instrumented and a similar test was conducted using 1.25 RPM, continuous 50 Amperes current, and 2 revolutions. Several changes were made to the instrumentation as well, the thermocouples were positioned outside of the FZ since the temperature of the FZ was not critical, due to the loss of data as the arc passed by the thermocouples, stainless steel screening was attached to the can over the thermocouples to act as an electromagnetic shield.

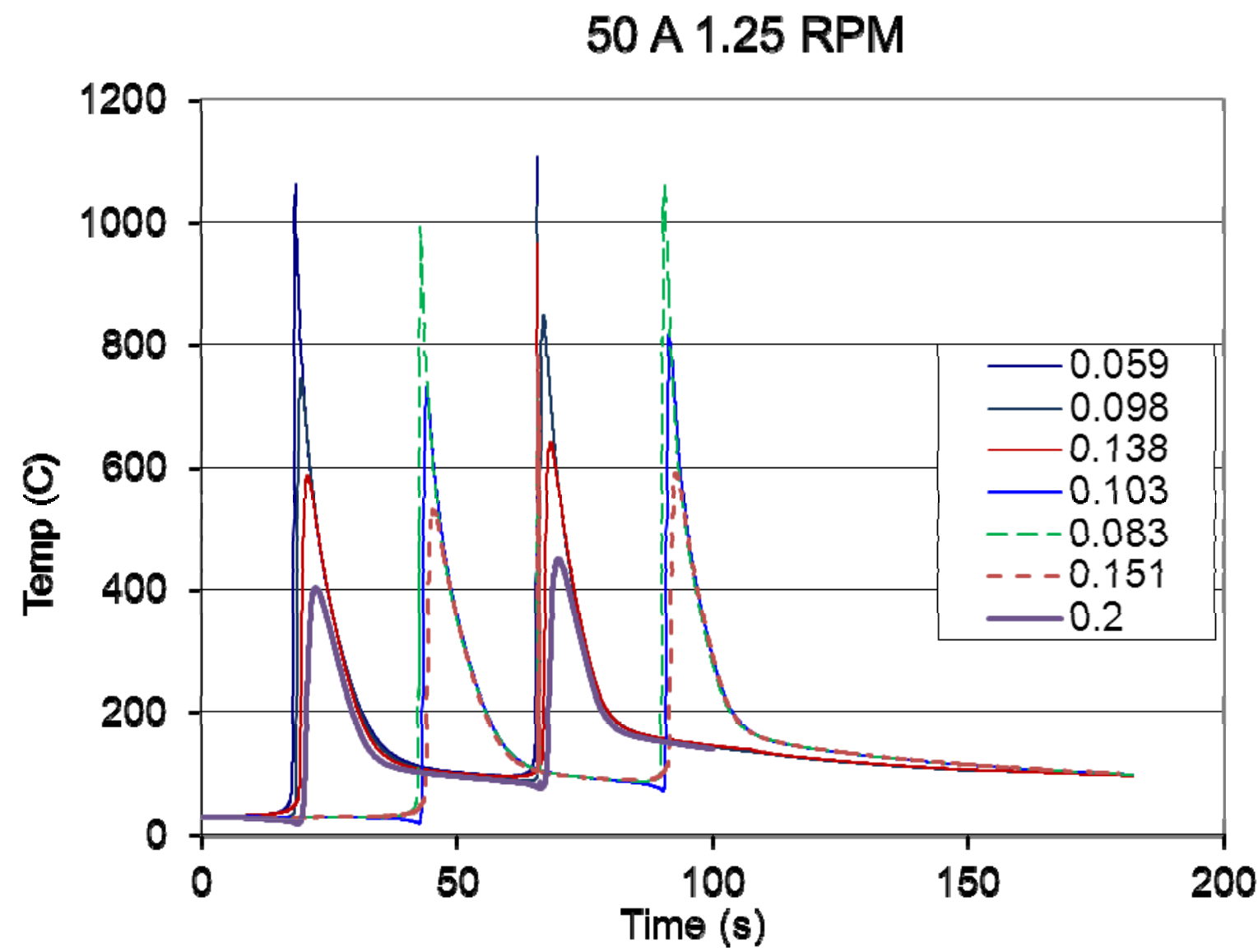

Figure 13. Thermal profile for ISAA02 showing $530^{\circ} \mathrm{C}$ was achieved between 0.15 and 0.2 inch.

The thermal profile for two revolutions at 1.25 RPM is shown in Figure 13. These data indicate that the target temperature was achieved for material that is between 0.15 and 0.20 inches from the FZ centerline. This value is a little lower than what was observed for the 1 RPM single revolution. The peak temperatures were slightly higher for the second pass, but the overall heat input process did not achieve the desired goals, with the exception that no fusion between the can and plug was observed. This can remnant was welded using a six tacking sequence, to be described later, that had demonstrated improvement in reducing can to plug gaps. The 
DR images are shown in Figure 14. These images show that there is less lifting in the arc annealed condition, and that six tack weld sequence has a smaller can to plug gap than the three tack sequence that was used for ISAA01. Only a small area around the fifth tack from the left shows any indication of 0.022 inch gap. Also of note is that there are virtually no areas that exhibit can to plug gaps of 0.029 inches. These qualitative results indicated that there may be a way to use DR to determine quantitatively if improvements were made for the can to plug gap.

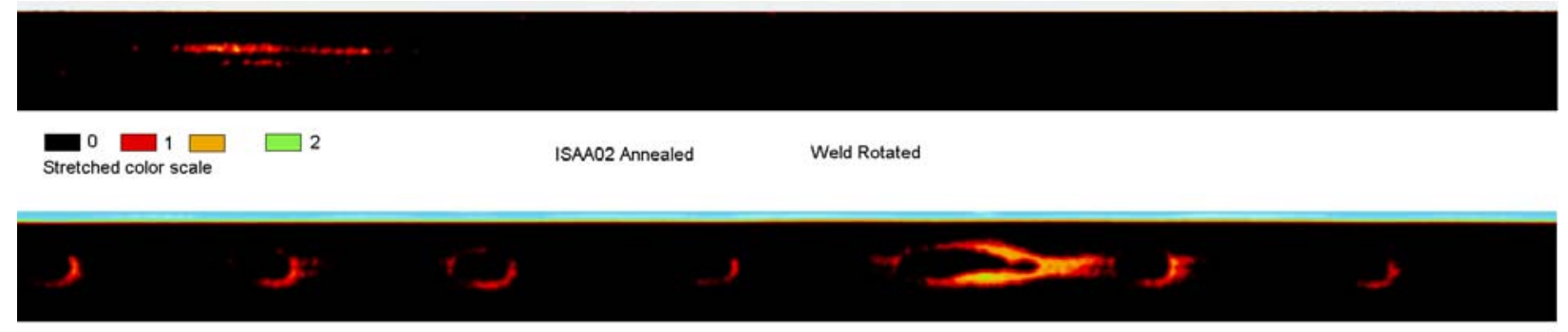

$\square 0 \square 7 \square 15 \square 22 \square 29$

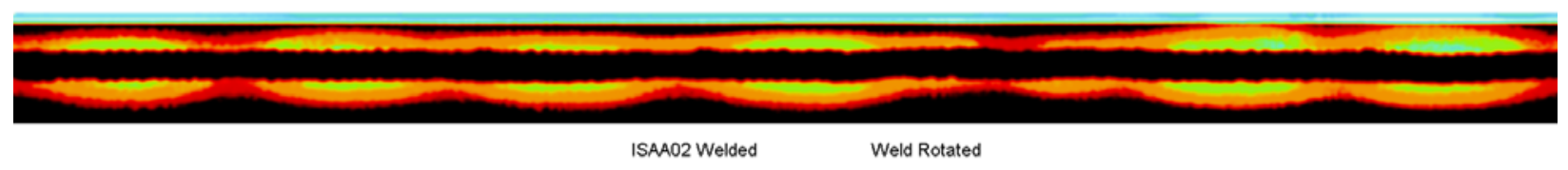

Figure 14. DR of ISAA02 for arc anneal, six tack welds, and closure weld.

The DR data were interrogated using a simple spreadsheet that determined the number of pixels illuminated during radiography; this value is a physical limit of 0.007 inch. The technique was called Numeric Digital Radiography Data Analysis (NDRDA) The number of slices in the vertical plane from top to bottom that had integer values of 1-5 were summed, these data can be plotted to show the can to plug gap as a function of position above (< 95) and below ( $>\sim 130$ ) the weld, as indicated in Figure 15 for ISAA01. This data shows the predominance of large gaps, 0.022 inch and greater, occurs adjacent to the weld bead. It also indicates that a sizable fraction of the gap is equal to or less than $0.015 \mathrm{inch}$. The data can be further analyzed by determining the percentage of the weld that has each can to plug gap. These data are considerably more useful since they could be possibly used as weld failure predictors.

These data were further manipulated and the fractional quantity of gap distance was determined and is plotted in Figure 16. These analyses are useful for determining the effect of process changes on the resultant can to plug gap. The results for ISAA01 indicate about $17 \%$ of the weld exhibits a can to plug gap of 0.022 or more. Can to gap testing, conducted coincidentally but discussed subsequently, demonstrated that gaps in excess of 0.029 are more prone to lack of fusion defects compared to lesser gaps. 


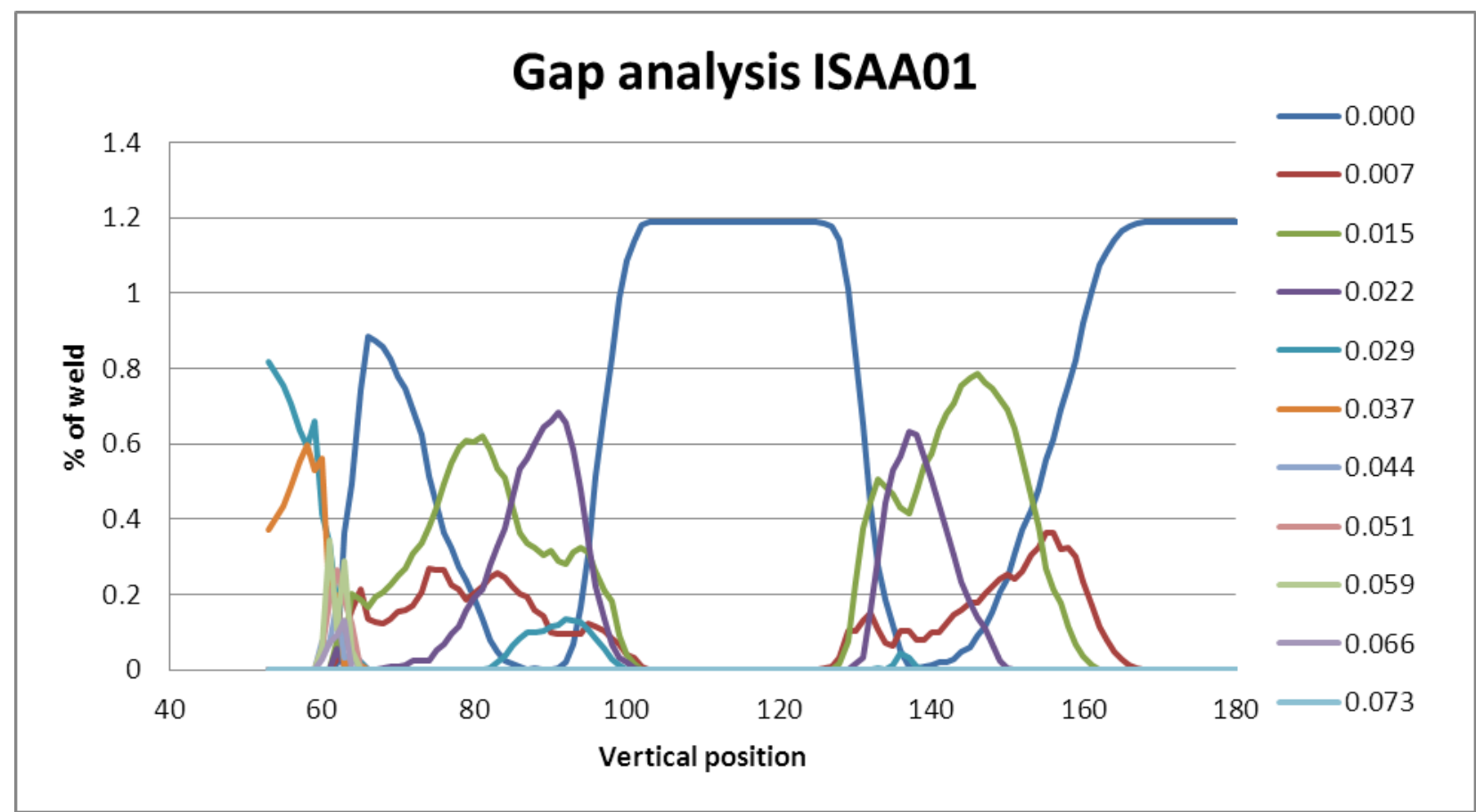

Figure 15. Percentage of DR data that exhibits the stated gap as a function of vertical position.

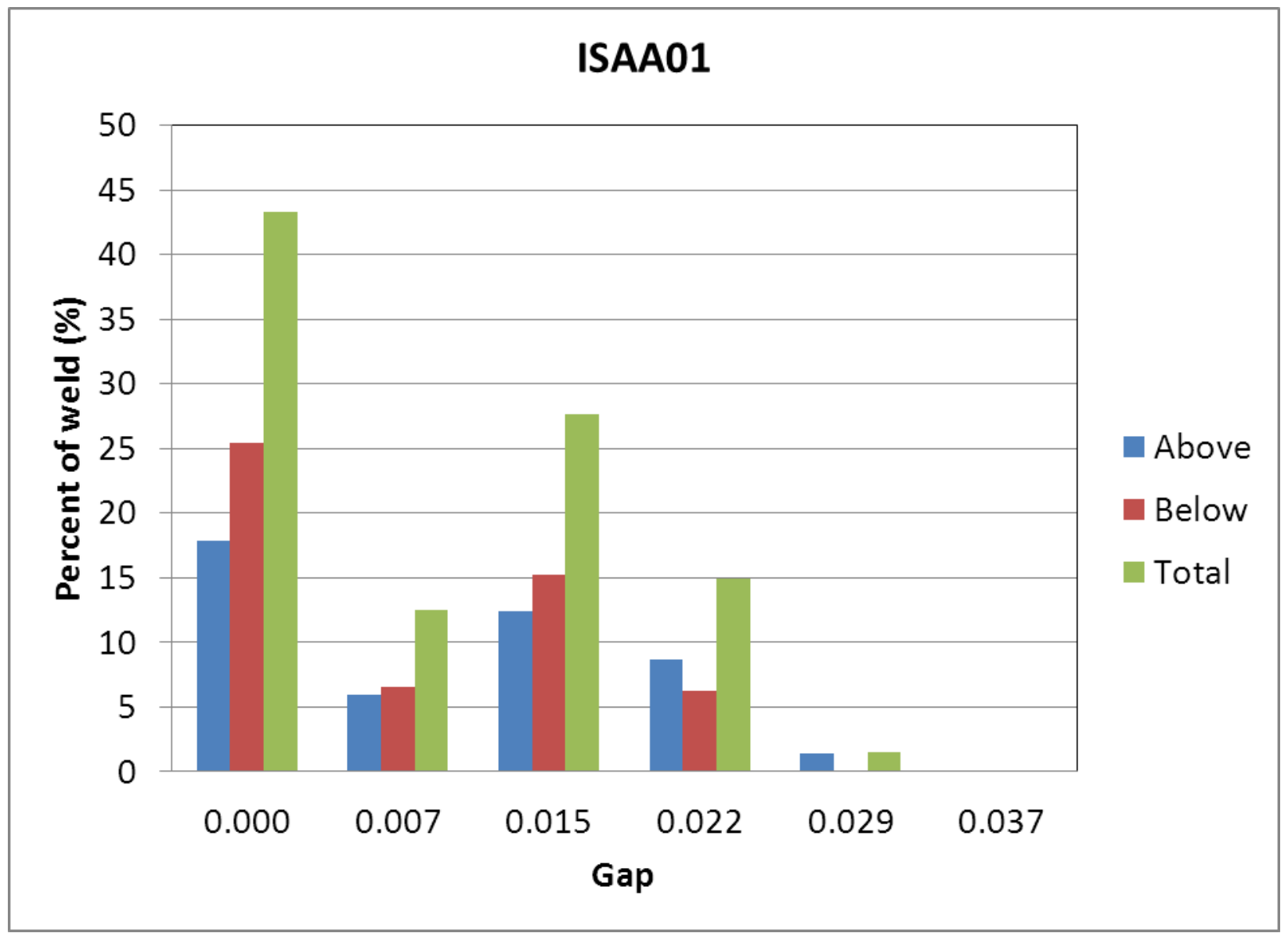

Figure 16. Percent of weld region that exhibits the DR measured gap. 
Based on the improvements in weld characteristics, can to plug gap, and weld dimension consistency a third ISAA can was welded. Since this can was fully processed in the prototype weld system, the can was not instrumented. In addition it was processed in a continuous manner so DR occurred after complete processing. The DR of the weld is shown in Figure 17. This weld exhibits slightly more gap that is 0.022 inch than ISAA02, the weld after which it was modeled. All of the ISAA test welds reduced the amount of can to plug gap that is 0.022 and greater compared to the traditional three tack weld without the ISAA, as shown in Figure 18.

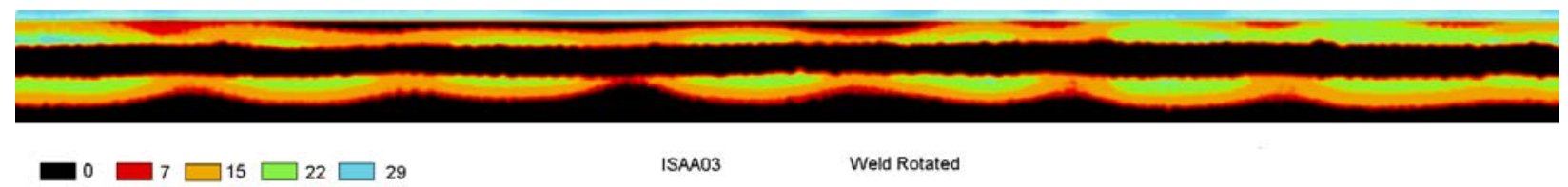

Figure 17. DR of ISAA03 showing more can to plug gaps of 0.029 than ISAA02.

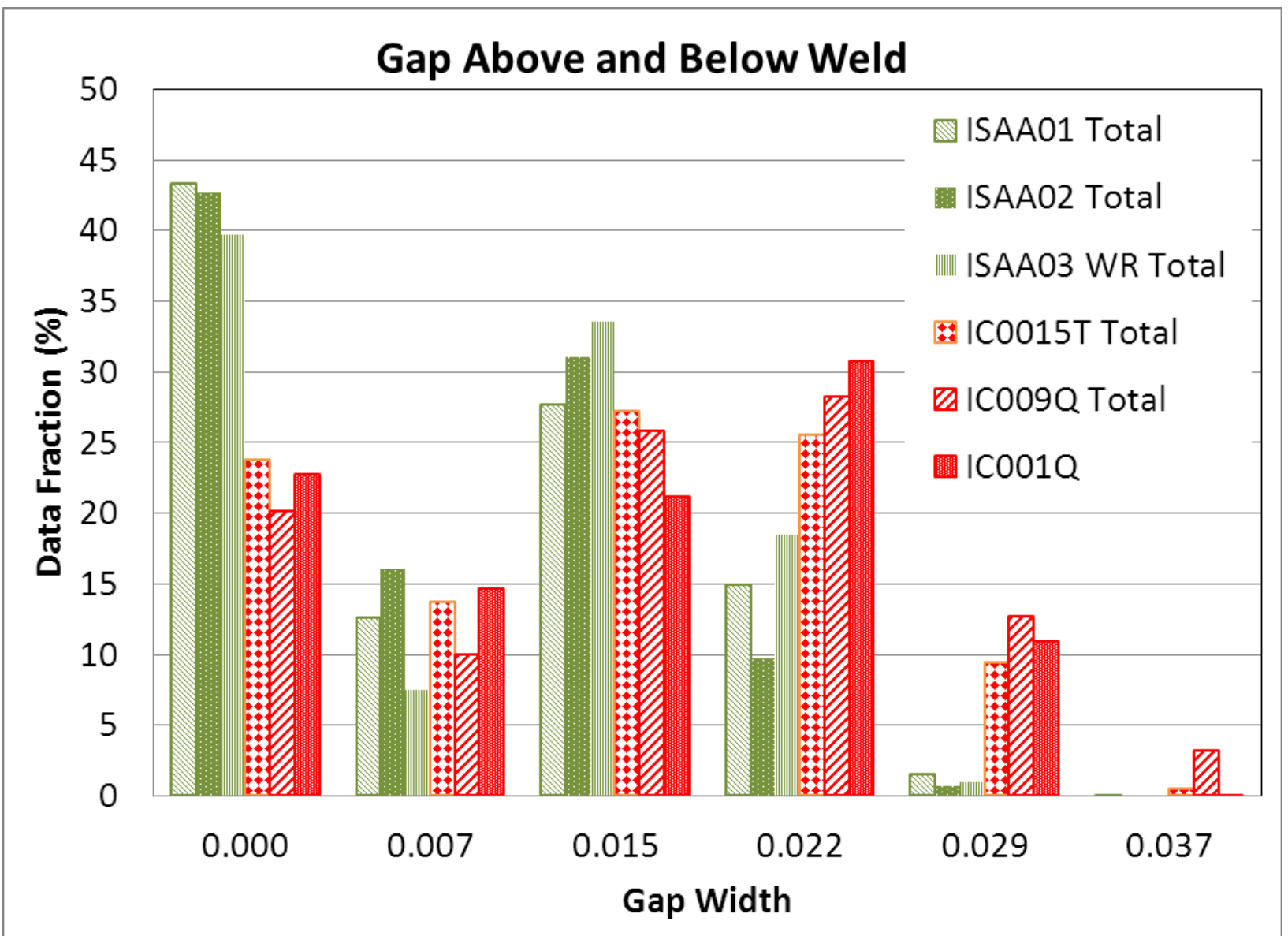

Figure 18. Fraction of the weld that exhibits the given can to plug gaps for ISAA and three conventionally welded cans.

The welds on the can remnants provided encouraging results and indicated that the can to plug gaps could be reduced in the post welded condition to be largely less than 0.029 and the total amount of the weld with gaps of 0.022 and larger were less than $20 \%$. On the other hand, the traditional process of three tacks and weld on actual cans have total gaps greater than 0.022 inches of $35 \%$ and higher. This result suggests that the likelihood of lack of fusion defects due to excessive can to plug gap should be lower for ISAA than for the traditional process. 
DR was also used to determine the length of the weld ligament that was obtained. A figure of merit term was derived that considered the average top and bottom weld position and the standard deviation along those positions. Thus a value of weld merit is:

$$
\begin{gathered}
W M=\left(U_{1}-L_{1}\right) * 100 \\
U_{1}=U_{a v e}-2 * U_{S D} \\
L_{I}=L_{a v e}-2 * L_{S D}
\end{gathered}
$$

$\mathrm{U}_{\mathrm{AVE}}$ is the average position of the upper edge of the ligament as determined by $D R, \mathrm{U}_{S D}$ is the standard deviation of the upper position of the weld, and the $L_{A V E}$ and $L_{S D}$ are the same values for the lower position of the weld ligament, as shown in Figure 19. The weld figure of merit was used to compare weld quality in subsequent tests.

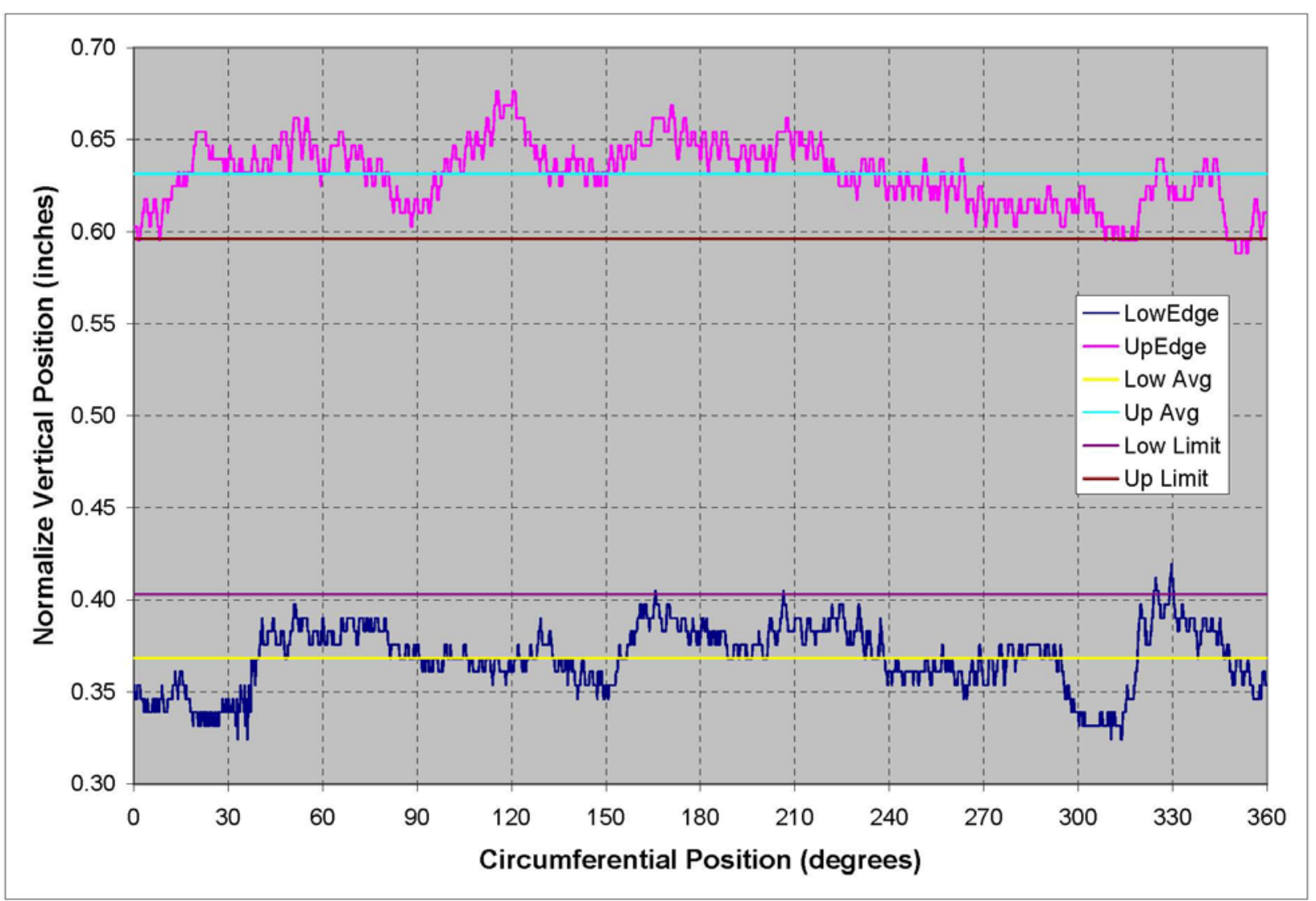

Figure 19. Normalized vertical position of the weld ligaments showing the calculation values for weld figure of merit.

\section{Weld Processing}

\section{Effect of Tack and Tack Sequence}

The number and sequence of tack welding the plug to the can wall was varied from the traditional three sequential tacks of 15/16" length to four, five, or six tacks in a "cross-tightening" sequence with the same total tack length of 45/16". The welds were evaluated using visual and DR inspection. The DR data were further interrogated using the NDRDA and weld merit described above. 
Three tacks are 15/16" long (9 sec) with tack(T) welds T1 at $0^{\circ}, \mathrm{T} 2$ at $90^{\circ}, \mathrm{T} 3$ at $180^{\circ}$, and Weld Start (WS) at $270^{\circ}$. The four tacks were applied using the following sequence: $0.70^{\prime \prime}$ long $(6.75 \mathrm{sec})$ with T1 at $0^{\circ}, \mathrm{T} 2$ at $216^{\circ}$, $\mathrm{T} 3$ at $72^{\circ}, \mathrm{T} 4$ at $288^{\circ}, \mathrm{WS}$ at $144^{\circ}$. The five tack sequence used 9/16" $(5.4 \mathrm{sec})$ long tack welds with T1 at $0^{\circ}, \mathrm{T} 2$ at $180^{\circ}, \mathrm{T} 3$ at $300^{\circ}, \mathrm{T} 4$ at $120^{\circ}, \mathrm{T} 5$ at $240^{\circ}, \mathrm{WS}$ at $60^{\circ}$. The six tack sequence had $0.468^{\prime \prime}(4.5 \mathrm{sec})$ tack welds with T1 at $0^{\circ}, \mathrm{T} 2$ at $154^{\circ}, \mathrm{T} 3$ at $309^{\circ}, \mathrm{T} 4$ at $103^{\circ}, \mathrm{T} 5$ at $257^{\circ}, \mathrm{T} 6$ at $51.4^{\circ}, \mathrm{WS}$ at $205.7^{\circ}$. The weld schedules are presented in Appendix A

The as tacked digital radiographic results are shown in Figure 20. It is apparent from these data that size of the gap varies with the number of tacks. The traditional three tack exhibits more large gaps than the other tack sequences. These visual data were subsequently examined using the NDRDA tool. This quantitative examination of the data shows that the number of larger gaps is lower for more tack welds, and conversely the number of smaller gaps is larger for the samples with more tacks.

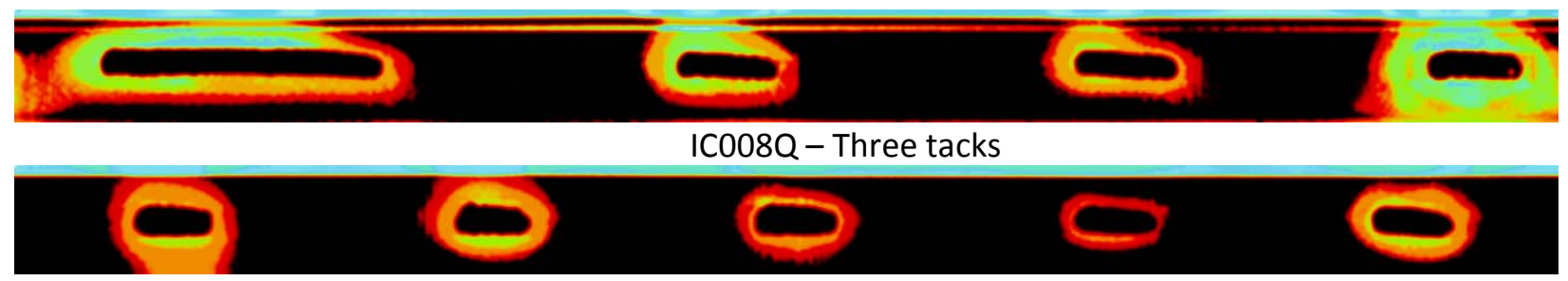

Four tacks

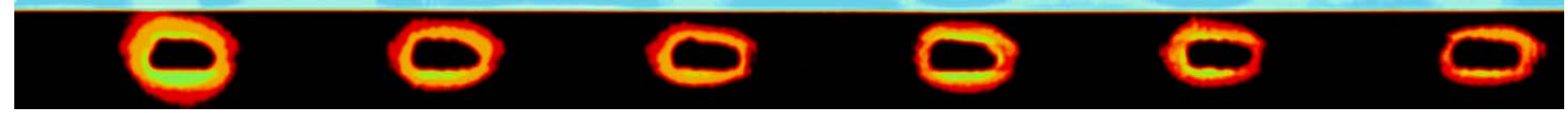

Five tacks

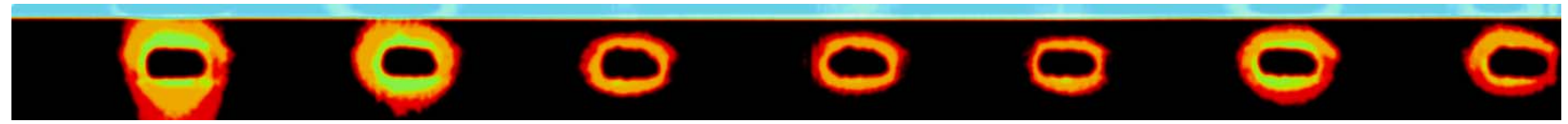

Six tacks

Figure 20. Digital radiographs of the tack welds showing traditional three tacks and extended weld start, four, five and six tacks plus nominal weld start.

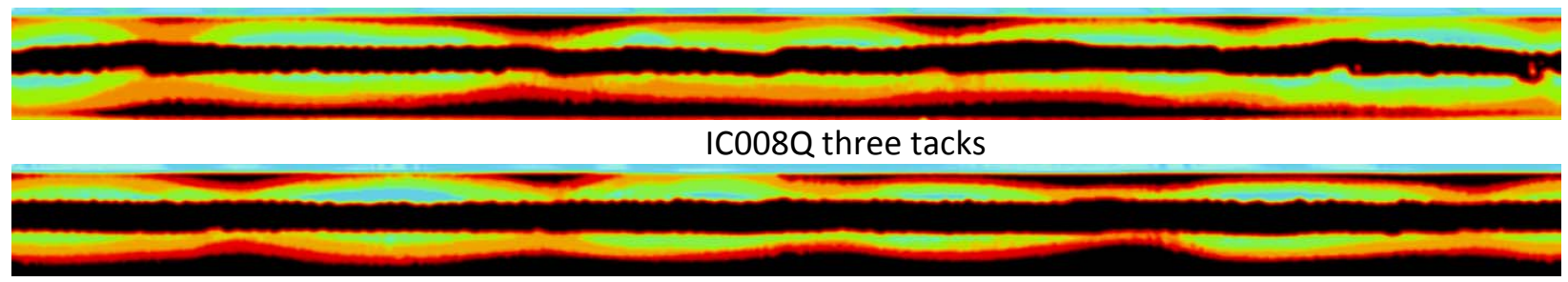

Four tacks

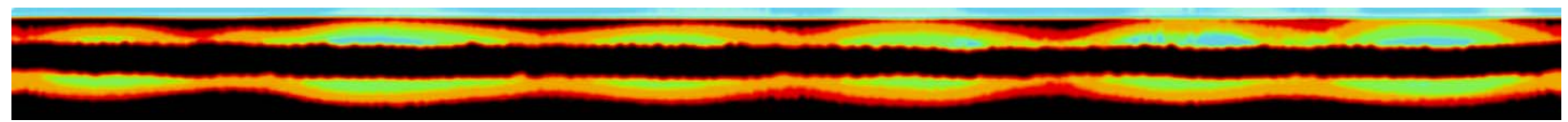

Five tacks

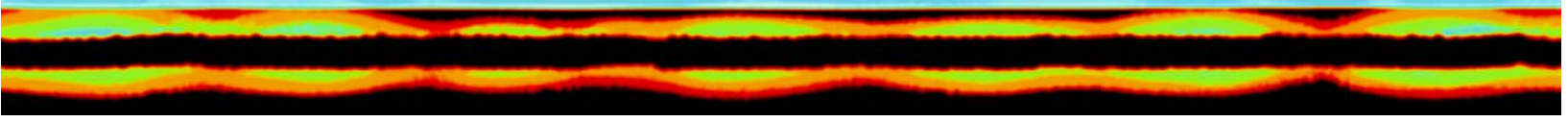

Six tacks

Figure 21. Effect of tacks on gap after welding 
The samples were welded and analyzed using these same evaluation techniques. The weld DR images are shown in Figure 21. Qualitatively it appears that more tack welds reduce the observed gap. It is suspected that the smaller the gap, the less likely that lack of fusion defects will occur. The NDRDA tool was also used to evaluate the welded sample data. These data are shown in Figure 22 and Figure 23.

The data indicate that the gap, and consequently the expectation of lack of fusion defects should be reduced for more tack welds. Due to these results, testing using actual cans, rather than mock-up PDC can remnants and plugs was initiated. 

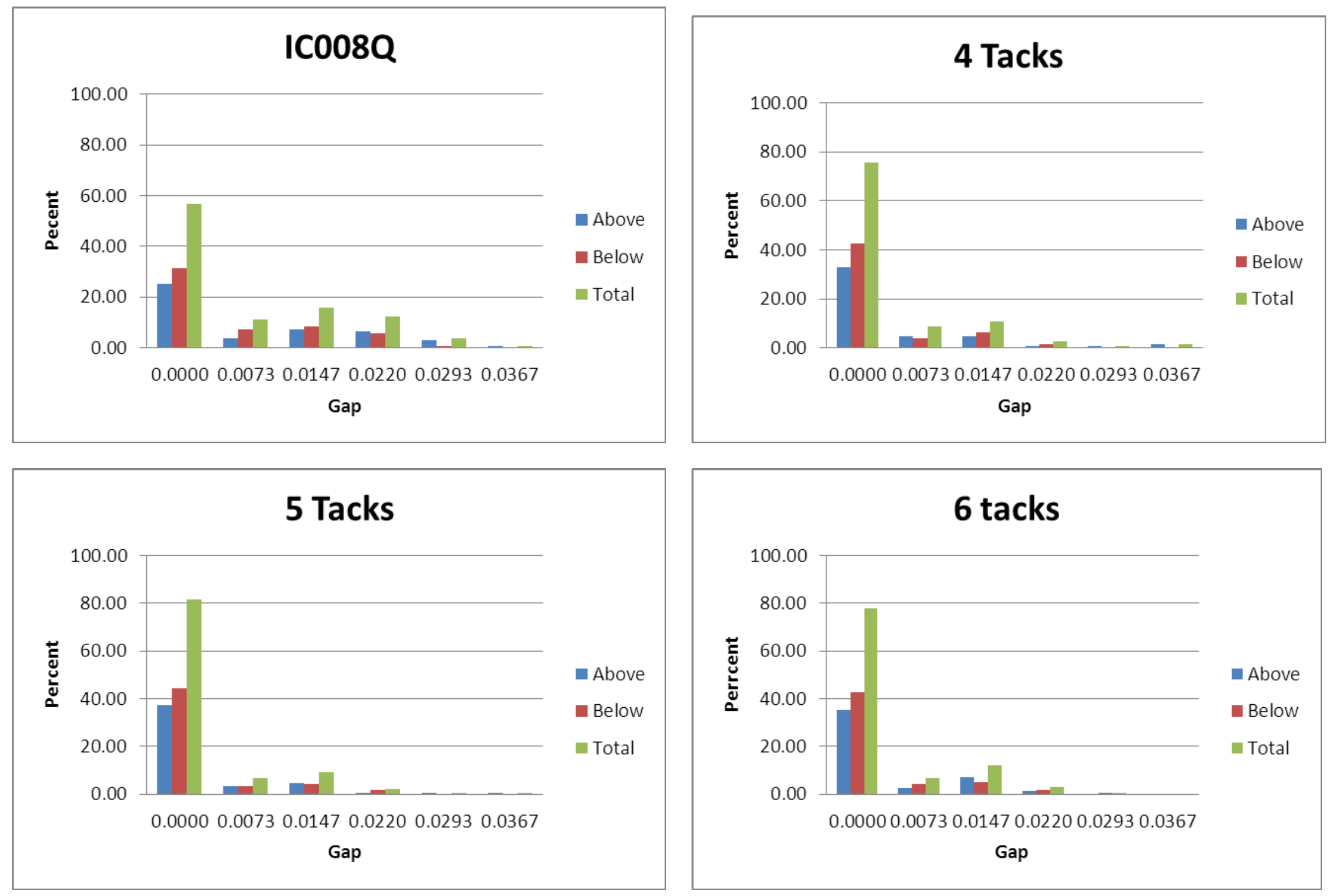

Figure 22. NDRDA of the tack weld showing that larger gaps are reduced with more tacks. 

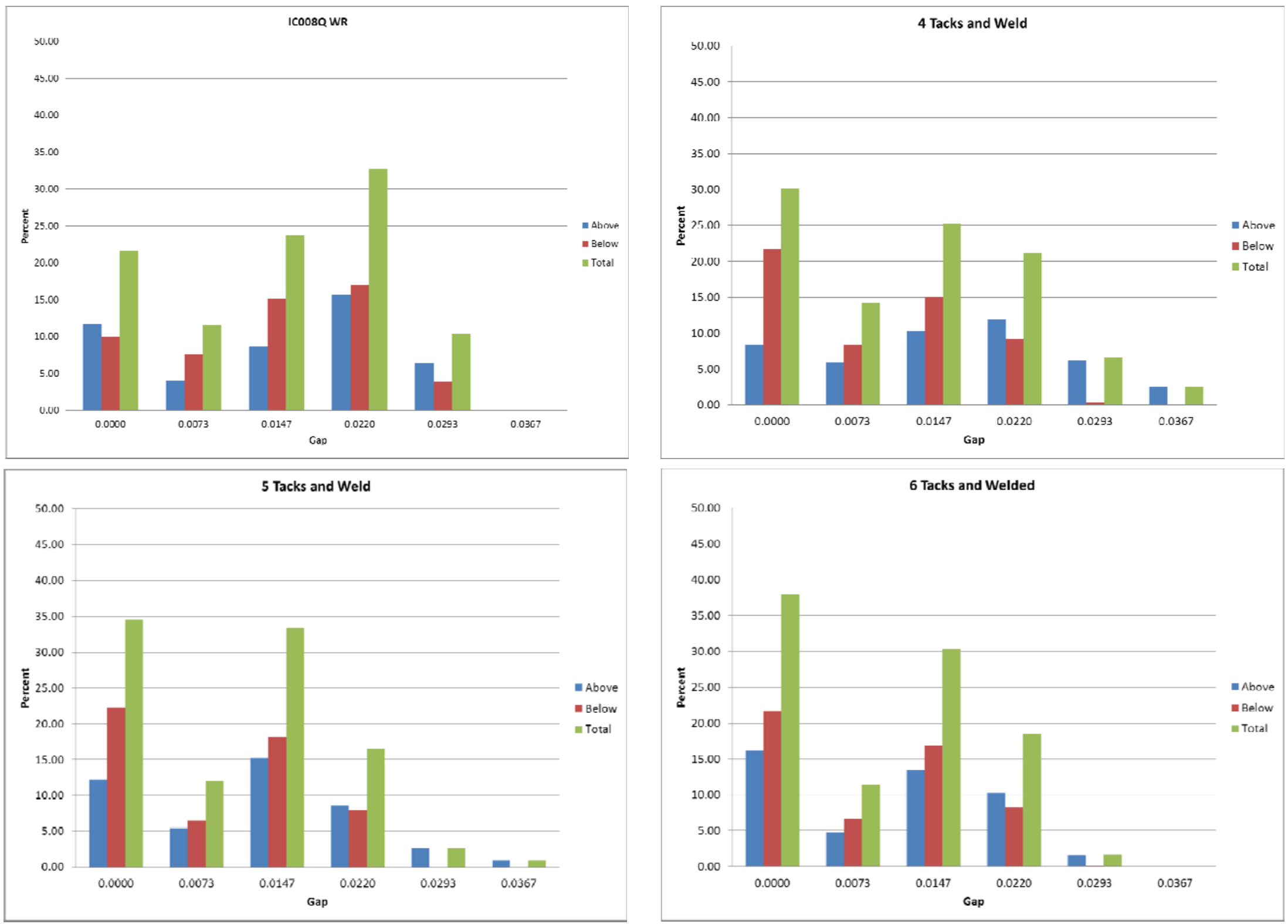

Figure 23. NDRDA of the welded samples after tacking and welding. 


\section{Can to Plug Gap}

The results of the DR gap measurement are shown in Figure 24. The measurements are discrete with the increments indicated in the legend. For the welds shown on the right side of the image, the lack of fusion defect occurred at about 14 to 22 mils while the weld defect occurred at approximately 29 mils for the 014T can and 37 mils for the 013T can. These variations may be attributable to changes in the actual can to plug gap that occurred during welding of the first side. It is interesting to note that the post weld gap above and below the intact weld bead increases with increasing initial gap distance. It is also notable that the gap at the lack of fusion defect appears to increase to 44 mils. This width of gap may not represent the in-process gap since there is some mechanical stress applied by the weld on the side that is first welded in addition to possibly some relaxation when the lack of fusion defect occurs.

The weld was characterized using DR and the individual slices of the weld immediately before the lack of fusion defects occurred are shown in Figure 25, Figure 26, Figure 27, and Figure 28. One can see that the upper weld metal starts to thin and eventually pulls away and results in a lack of fusion defect. The weld then begins to slump. This weld failure evolution occurred for all four weld trials.
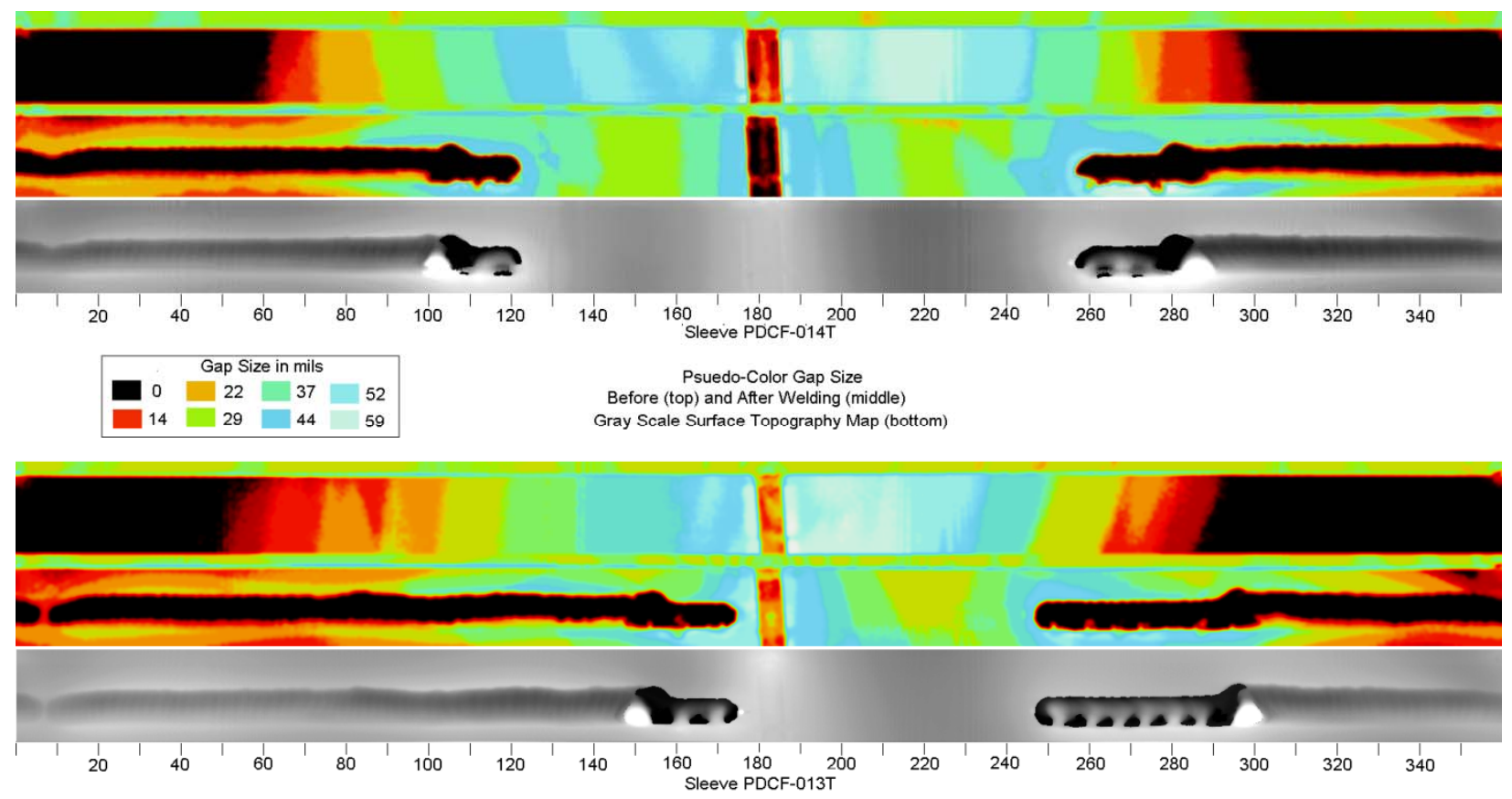

Figure 24. DR results in the as tack welded and as welded condition indicating the relative can to plug gap (thousandths of an inch) shown by the color coding in the legend. 


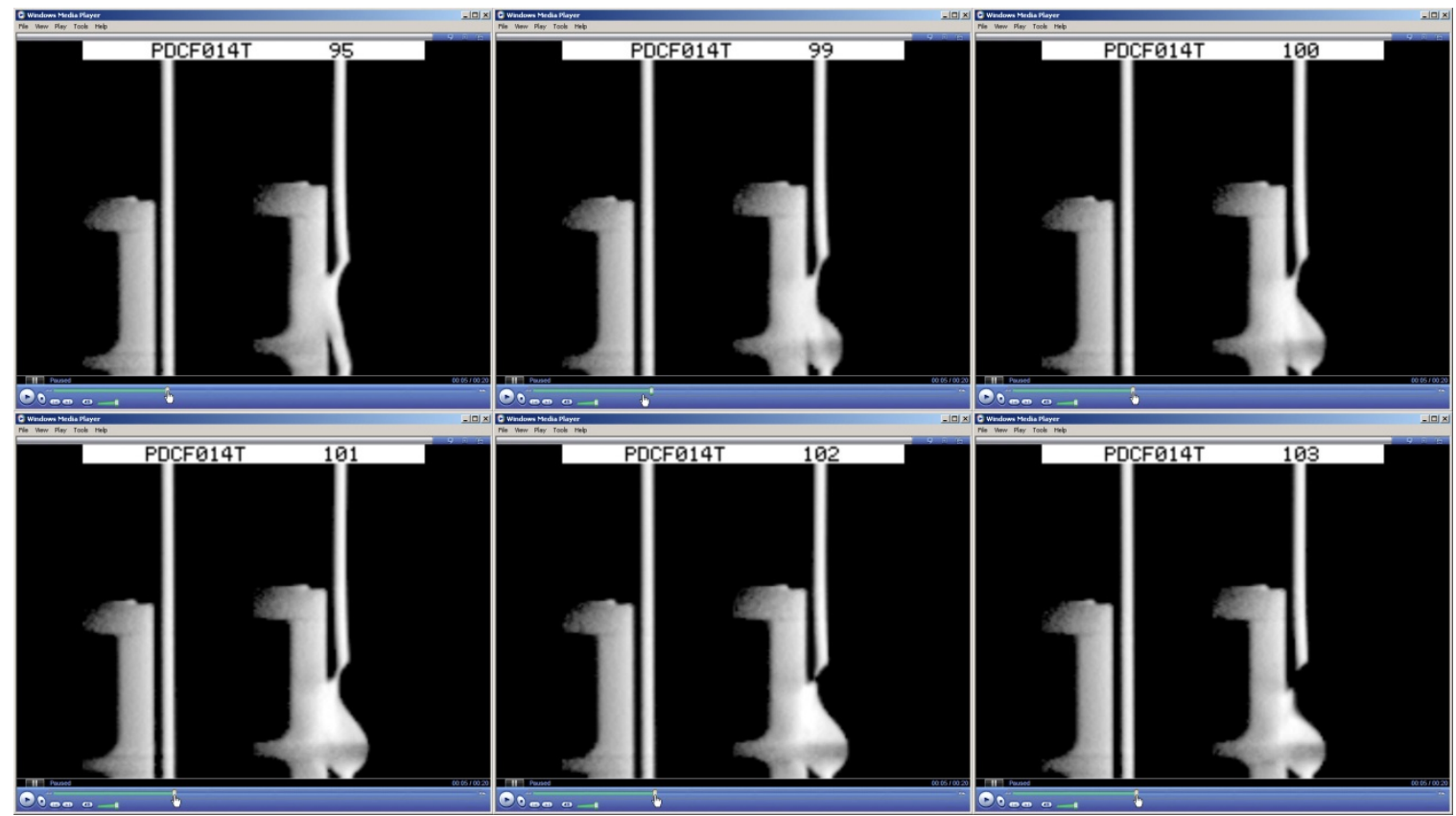

Figure 25. DR slices near lack of fusion defect for can PDCF014T.
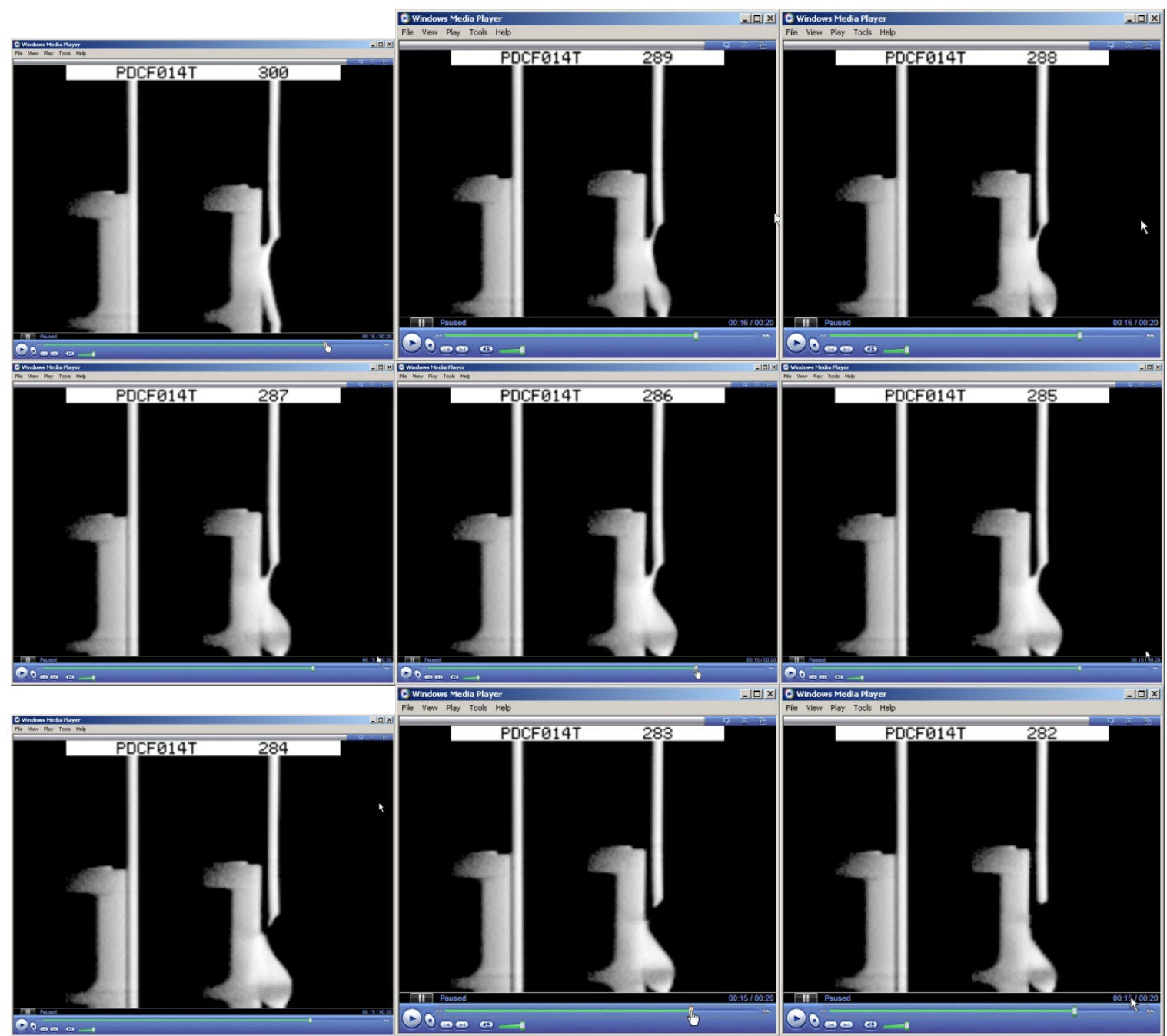

Figure 26. DR slices near lack of fusion defect for can PDCF014T. 

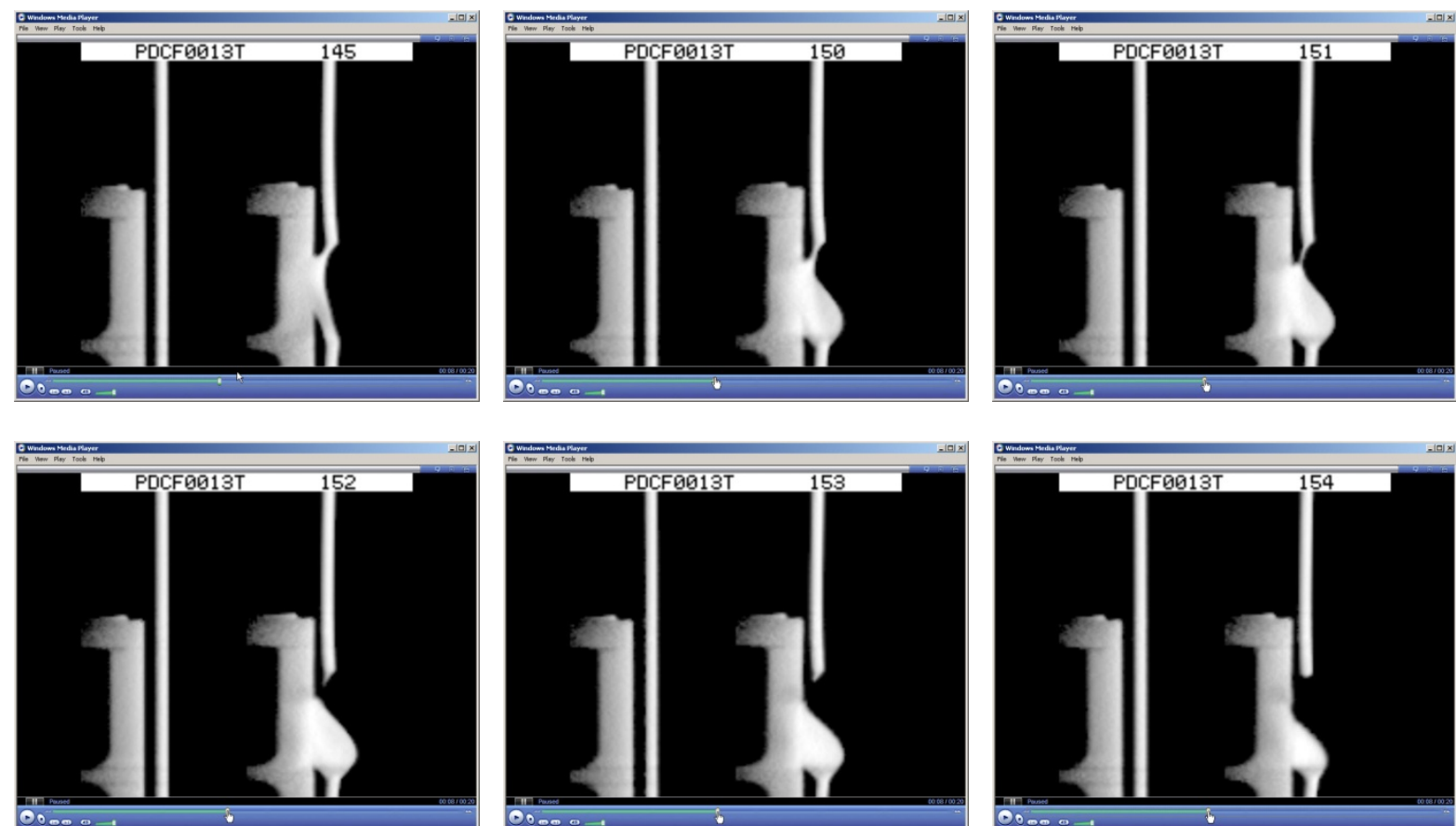

Figure 27. DR slices near lack of fusion defect for can PDCF013T.
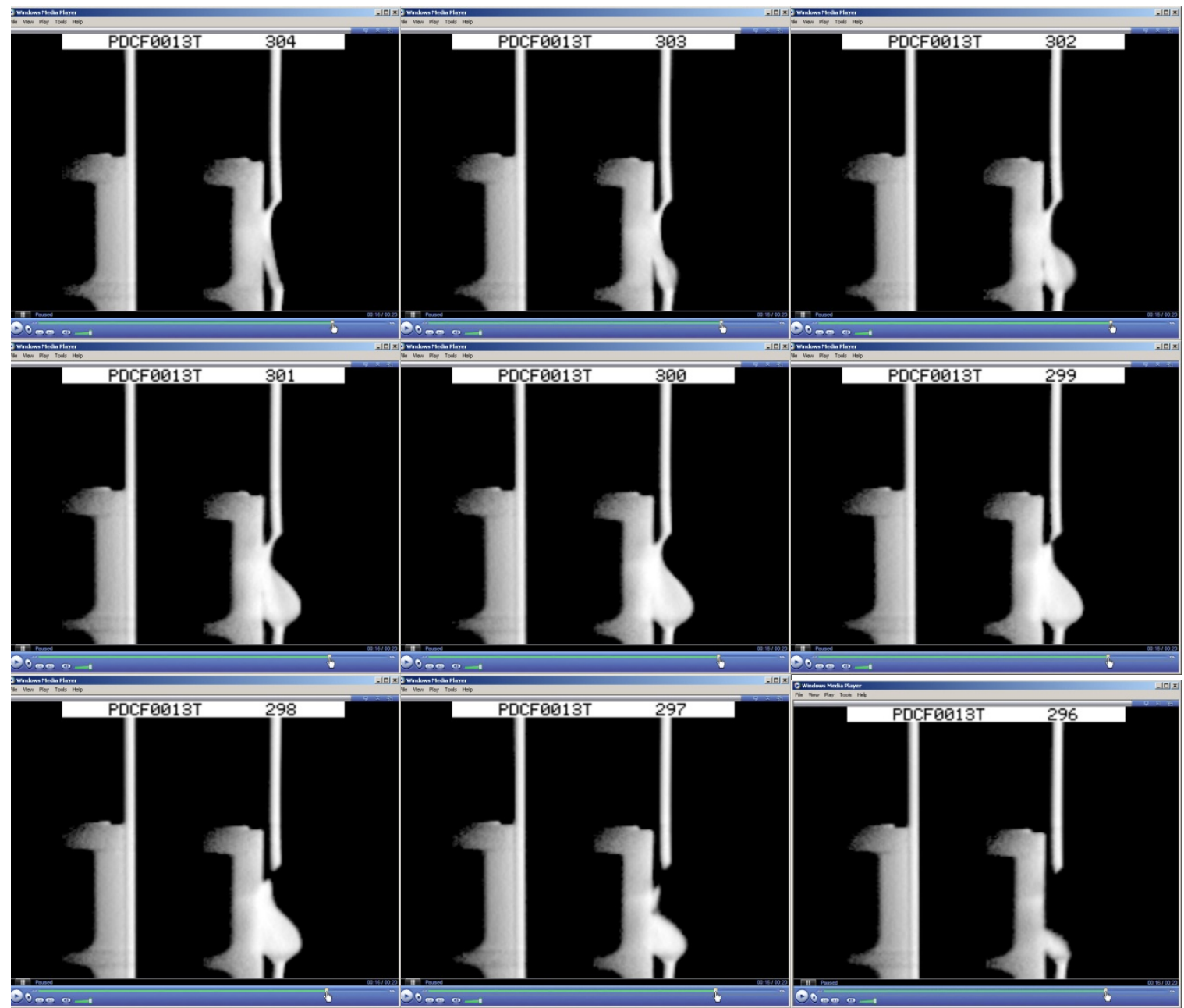

Figure 28. DR slices near lack of fusion defect for can PDCF013T. 


\section{Actual Can Welds}

As part of the trouble shooting of the process, it was ascertained that the weld head used a different clamping mechanism. The new clamp promoted an ovalizing of the can. It was suspected that this change may have increased the local can to plug gap and promoted lack of fusion defects. Consequently, a replacement clamp was ordered that increased the number of contact points to make it more like the ones used for FBL and Hanford. The initial weld(PDCF-IC-001Q) made using the new clamp and the traditional three tacks and weld was successful, but it exhibited a weld instability after about 10-15 seconds into the weld. The DR for this weld is shown in Figure 29. The next two welds experienced failures, one weld (PDCF-IC-006Q) was a traditional three tack weld and one weld (PDCF-IC-018Q) was a six tack weld. Both of these welds experienced the lack of fusion failures at about the same time/location, i.e., 10-15 seconds into the weld and are visible at approximately $150^{\circ}$ in the radiograph of PDCF-IC-006Q and at $220^{\circ}$ in the radiograph of PDCF-IC-018Q, Figure 30.

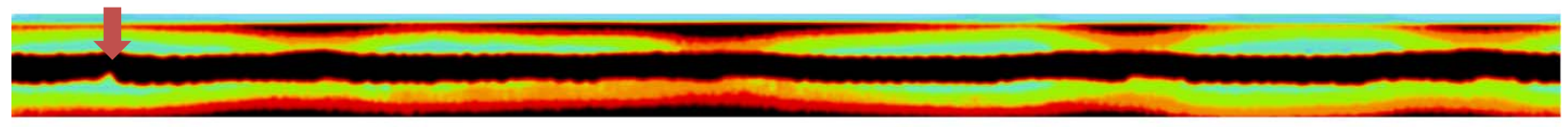

$\square 0 \square 7 \square 15 \square 22 \square 29$

PDC-IC-001Q

Figure 29. DR of weld made with new clamp. Note weld toe instability arrow.

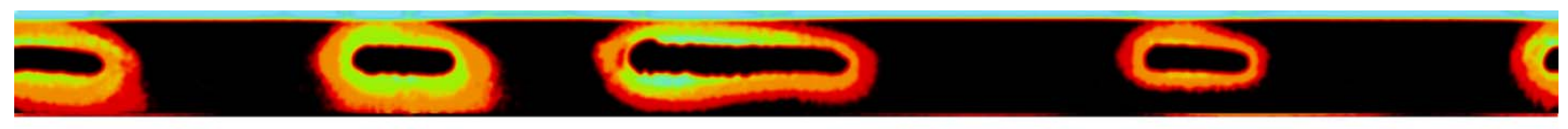

$\square 0 \square 7 \square 15 \square 22 \square 29$

PDCF-IC-006Q
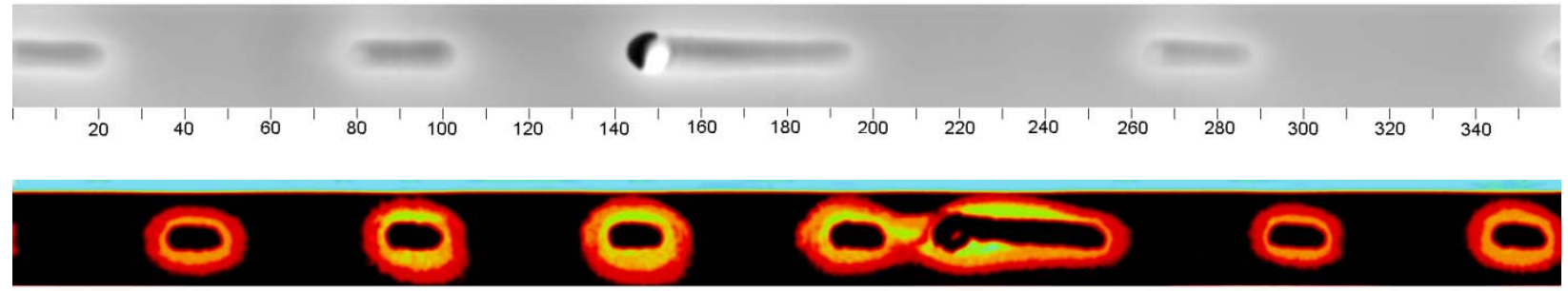

$\square 0 \square 7 \square 15 \square 22 \square 29$

PDCF-IC-0018Q

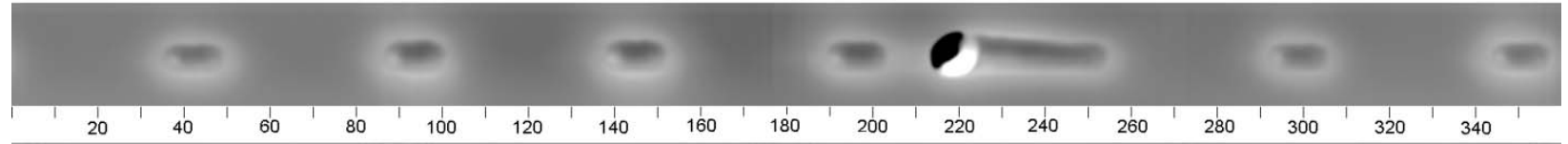

Figure 30. DR of traditional (PDCF-IC-006Q) and six tack weld (PDCF-IC-018Q) that failed 10-15 seconds into the weld.

This persistent weld defect was analyzed and was determined to be caused by two separate steps that were initiated for the automated welding. These included a helium gas release--"puff"-- that was used to ensure that the suction cup was released from the plug and a coincident raising of the mast that is used to seat the plug. Upon further investigation it was discovered that the "puff" was being maintained by the controller system for an extended period of time ( $\sim 13$ seconds), a momentary puff was used during earlier machine development. This extended discharge time resulted in the bell jar being pressurized slightly but sufficiently to blow out the weld puddle. The "puff" was therefore eliminated, the suction cup is now simply vented prior to being decoupled from the plug. The timing of the mast movement was changed so that it would not occur during welding (tacks or continuous main weld), rather the movement is completed during the low current arc drag between the tack and weld start. 
The effect of just the mast movement during welding can be seen in the DR results from can PDC-IC-025Q in Figure 31. The weld exhibits some variation in the lower edge of the weld in addition to a significant offset in the weld plane that is observed at about $20^{\circ}$. There is also a fair amount of can to plug gap that is over 0.029 inch. Examination of this weld led to the knowledge that the mast movement during the weld resulted in a weld disturbance and consequently led to the change in weld process alluded to above.

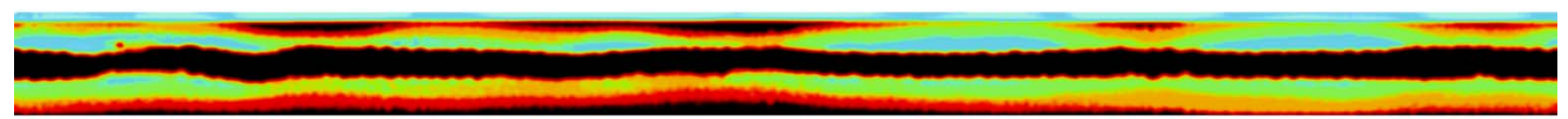

$\square 0 \square 7 \square 15 \square 22 \square 29$

PDC-IC-025Q

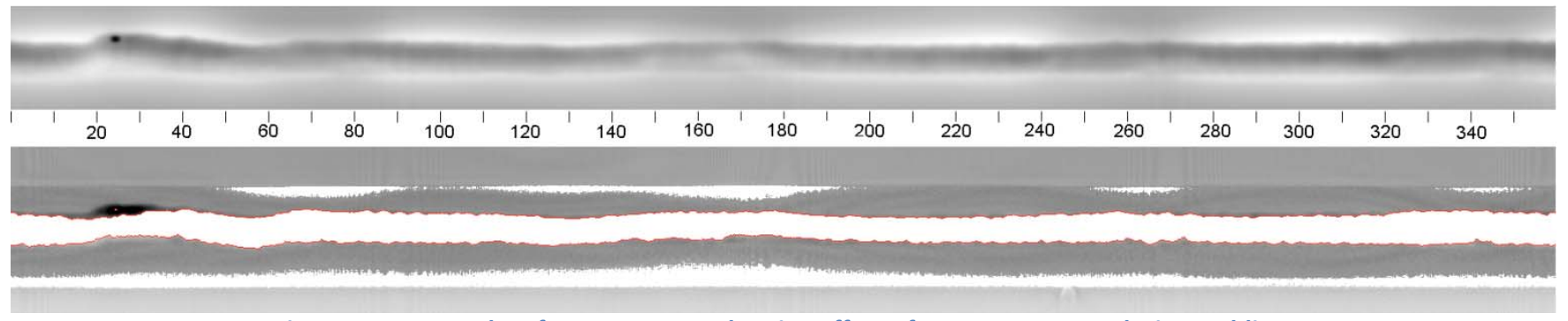

Figure 31. DR results of PDCF-IC-025Q showing effect of mast movement during welding.

The surface and ligament traces from the DR data are shown in Figure 32. These data provide an indication of the upper, lower, and nadir of the weld on the surface and also indicate the location of the upper and lower weld ligament. Notice the relative roughness of the weld surface and ligament. In addition, note that there is a potentially thinnest ligament $\left(\mathrm{WR}_{\mathrm{u}(\min )}-\mathrm{WR}_{\mathrm{I}(\max )}\right)$ of about $0.126 \mathrm{inch}$. This weld ligament will be cut and must result in weld length of at least 0.045 inch on the can and a hermetic seal on the remnant.

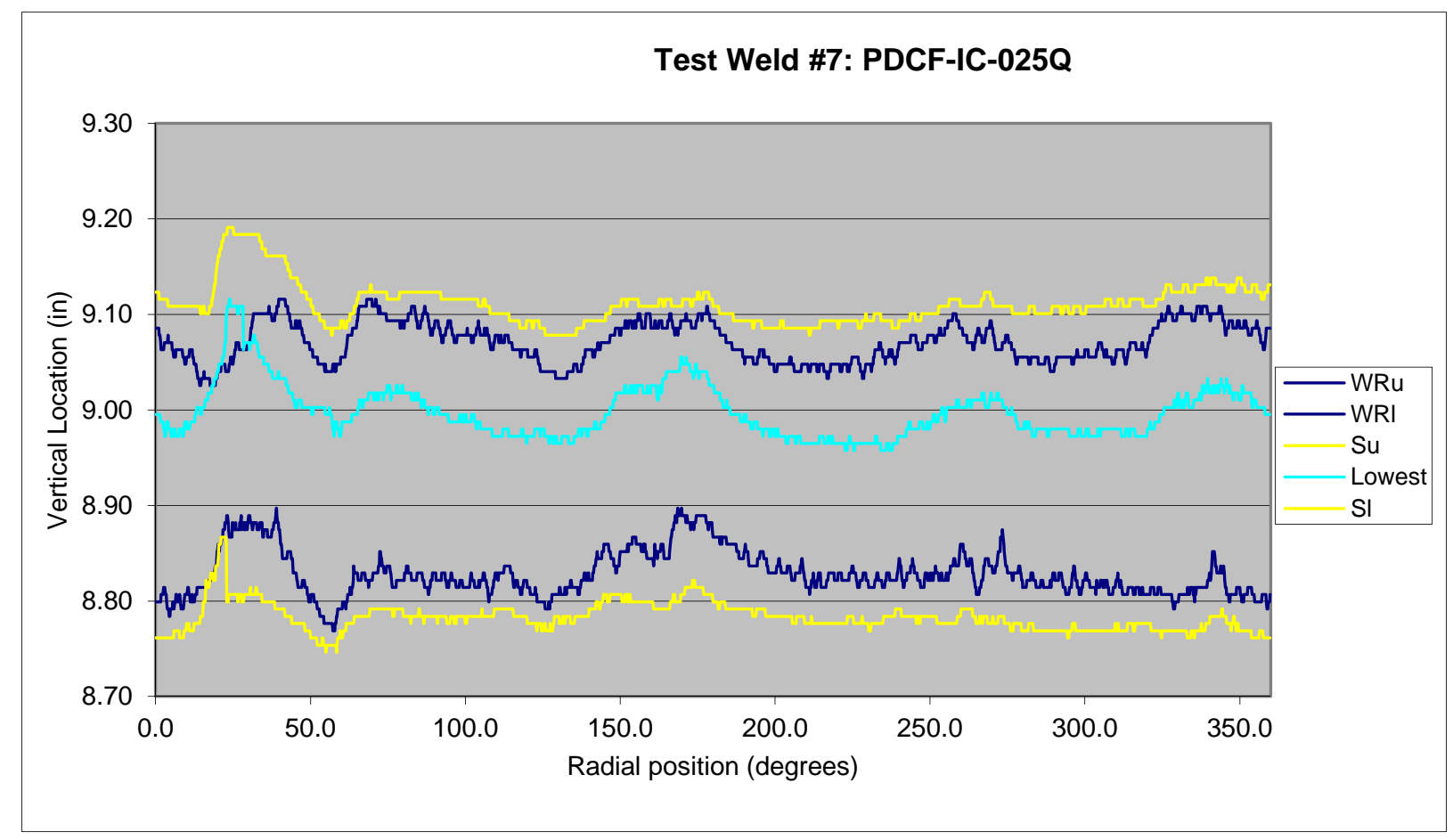

Figure 32. DR trace data for PDCF-IC-025Q. 
The relative jaggedness of the weld on PDC-IC- $025 Q$ and the encouraging results from the seemingly prototypic ISAA welds indicated that incorporation of an ISAA into the weld process would be beneficial. Several welds were made using the two pass arc anneal and three or six tacks. The goal behind the ISAA was to reduce the surface weld (toe) to weld ligament gap, i.e., to make the weld have more of a " $U$ " cross sectional shape rather than a "V" cross sectional shape.

Two cans were successfully welded using the double pass $50 \mathrm{~A}, 1.25 \mathrm{RPM}$, thermal cycle that was used for the ISAA03 and either six or three tacks, PDCF-IC-013Q and PDCF-IC-004Q, respectively. These welds exhibit more variability and a shorter ligament than ISAA02. The DR results for PDCF-IC-013Q that was welded with the ISAA followed by six tacks are shown in Figure 33. The weld appears to wander along the lower edge while the upper edge of the weld and ligament is more consistent. This weld exhibits a weld merit value of 11.8; recall that the weld merit is a measurement of the average weld width, so a high standard deviation will result in a lower weld merit.

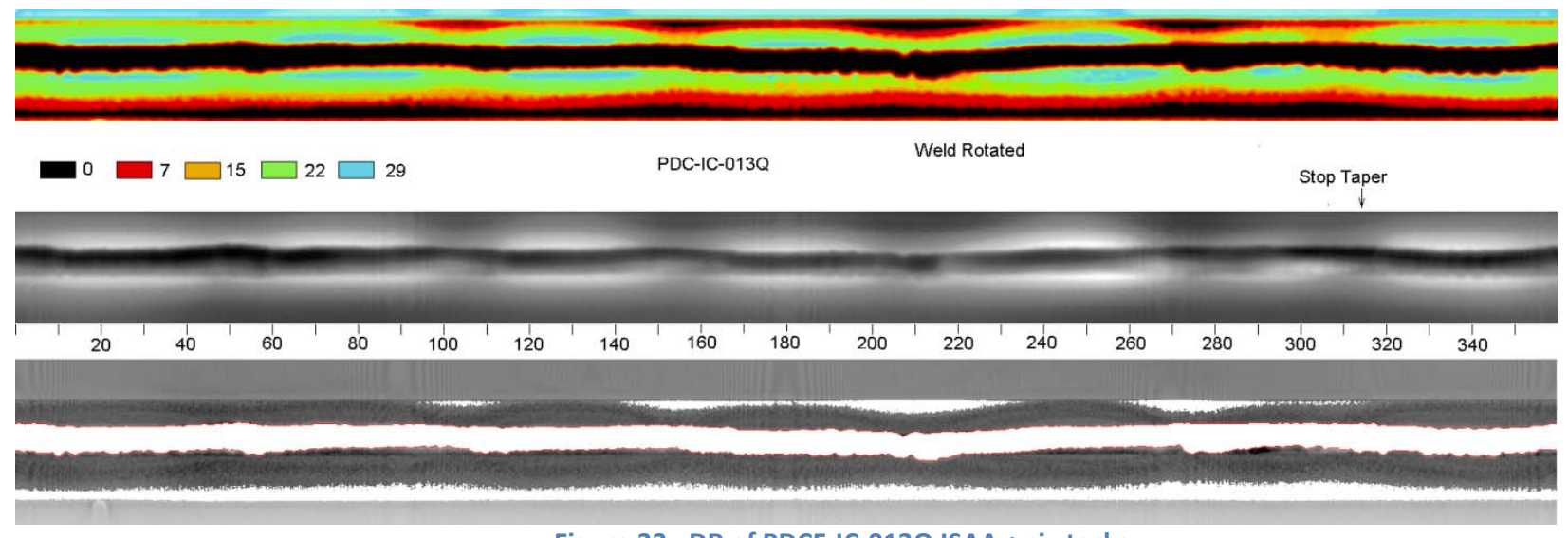

Figure 33. DR of PDCF-IC-013Q ISAA + six tacks.

A second can was welded with the ISAA as was used on PDCF-IC-004Q except only three tacks were used, similar to ISAA01. The DR for this can is shown in Figure 34. This weld is also rough along the lower edge but exhibits a slightly improved weld merit of 16.3. The gaps were analyzed for both of these welds and the results are compared to the two prototypic welds in Figure 35. This graph shows that the number of areas that exhibit gaps larger than 0.022 for the actual cans is greater than what was observed for the developmental welds, i.e., the ISAA series.

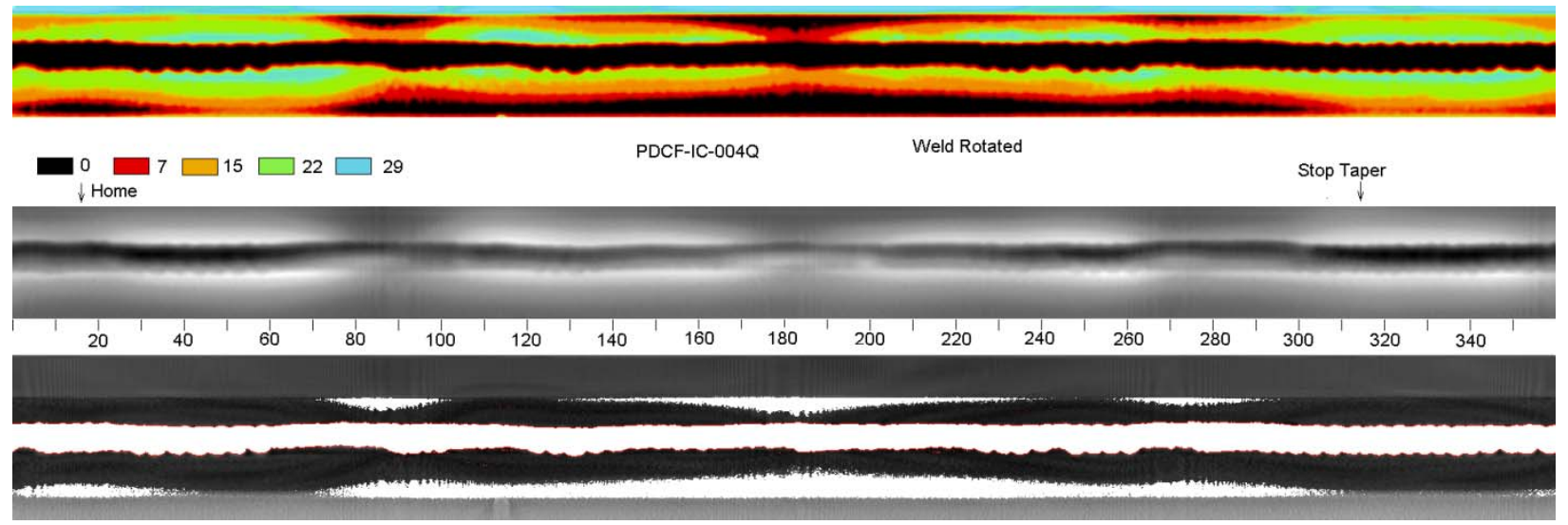

Figure 34. DR of PDCF-IC-004Q ISAA + 3 tacks. 
As the weld development on cans proceeded, a question regarding potential pressure increase was investigated. To address this question, several cans were prepared with a pressure tap that was located away from the weld head in the lower portion of the can. The placement of the tap relative to the weld is shown in Figure 36 . It is apparent that the weld and plug are away from the pressure measurement zone. The pressure data shows a consistent increase in pressure followed by a spike, drop, and subsequent increase, Figure 37 . This result suggests that the pressure measurement methodology is adequate for gross pressure rise. In the second can, the pressure was fairly constant until weld closure had occurred. The pressure - time data for two of the cans are shown in Figure 37. Unlike the outer can weld system that exhibited increases in pressure and sudden releases Figure 38when tack welds were crossed, the PDC-IC exhibits very little pressure response during the weld until the can is nearly closed and then there is a slight increase in pressure after the weld closure is made; the pressure continues to rise for a short period of time after the weld is complete. Note that the entire pressure scale is only 0.4 psi.

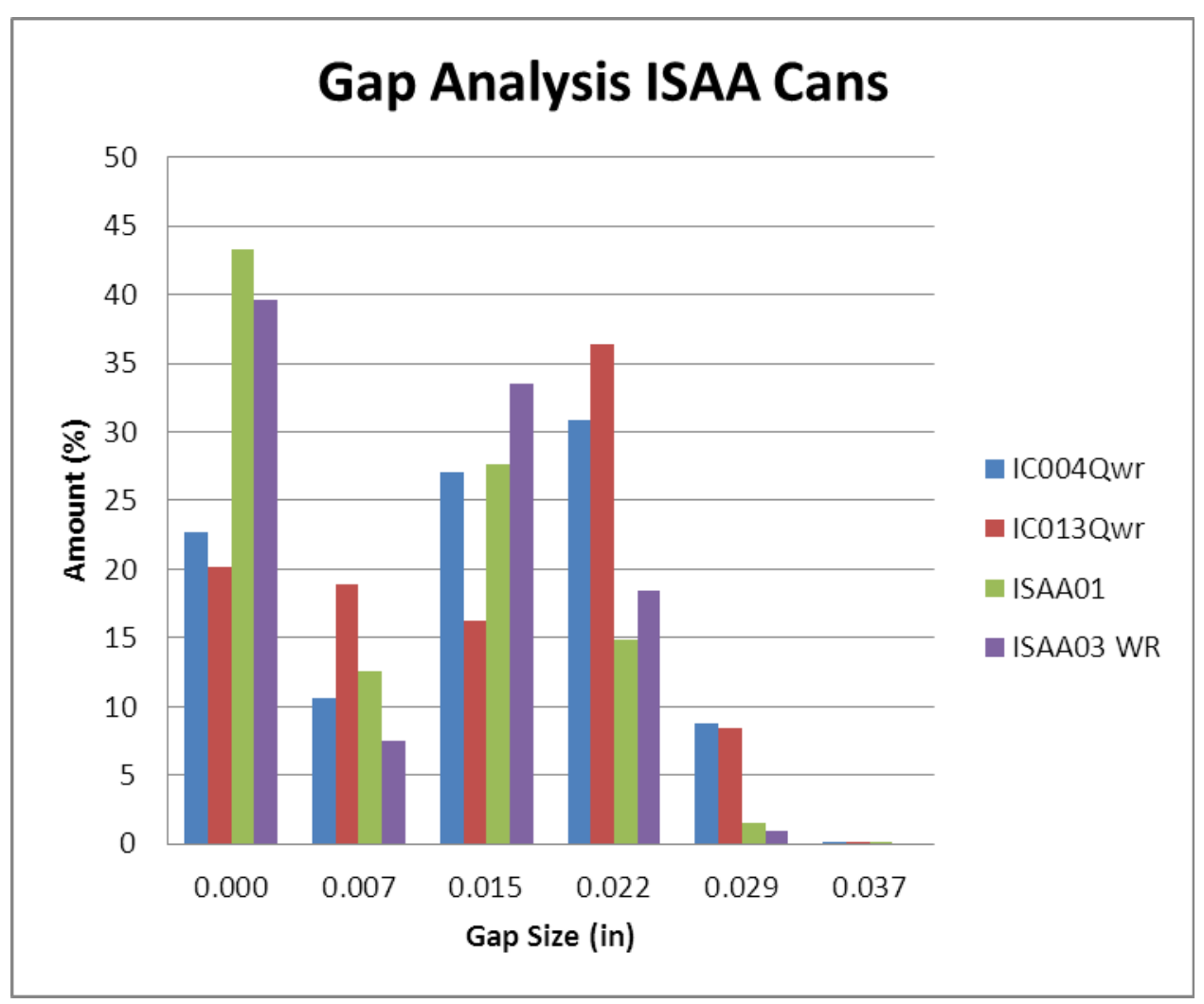

Figure 35. Gap analysis for PDCF-IC-013Q (6 tack welds) and PDCF-IC-004Q (3 tack welds) and the experimental welds (ISAA0\#). 

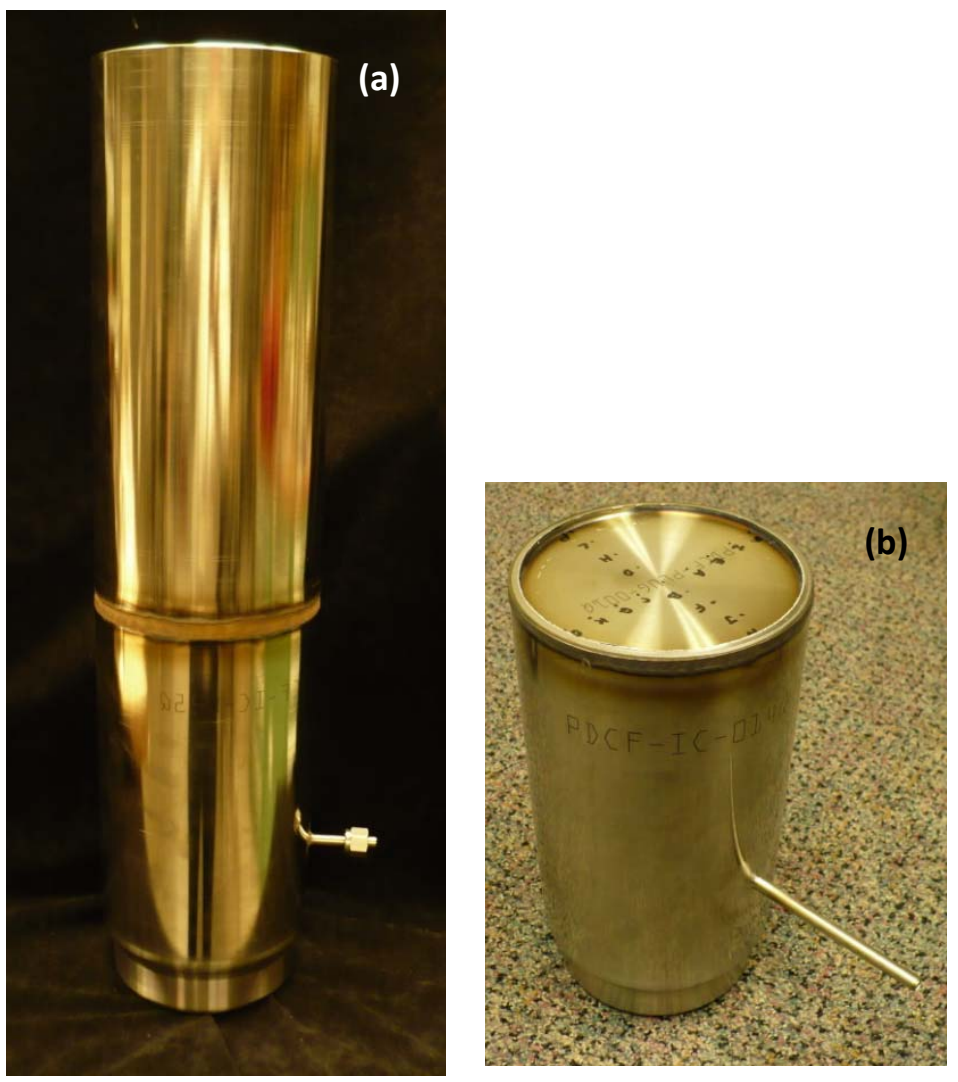

Figure 36. Photograph of a can that has been pressure tapped prior to welding in the as welded and cut condition; note these photos are not of the same can. ICO25Q is depicted on the left (a) and ICO14Q on the right (b).
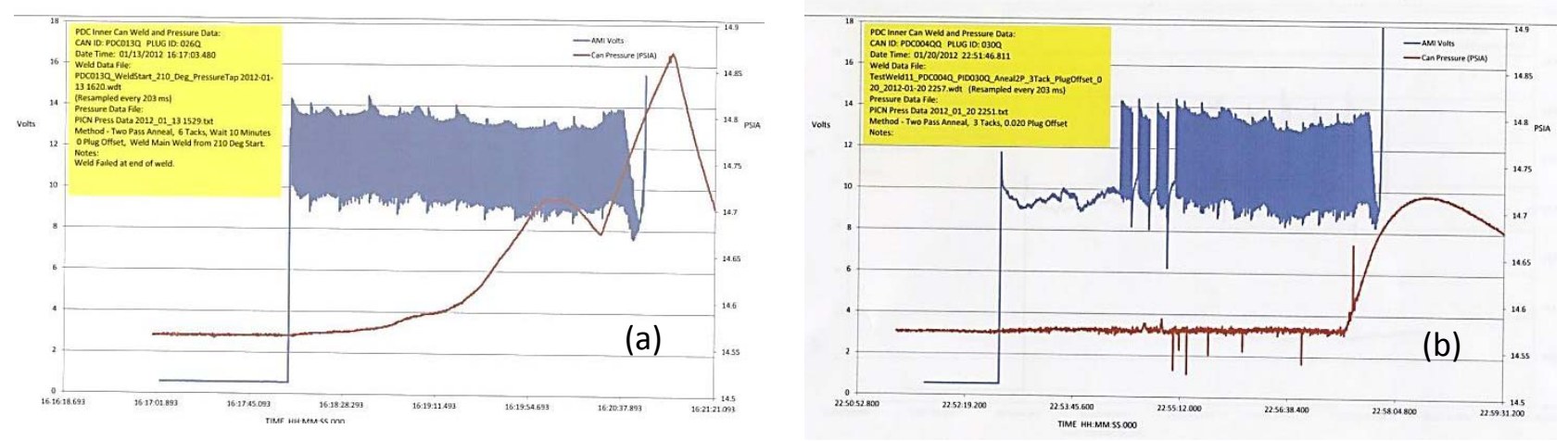

Figure 37. Pressure - time data for PDCF-IC-013Q (a) and 004Q (b). 


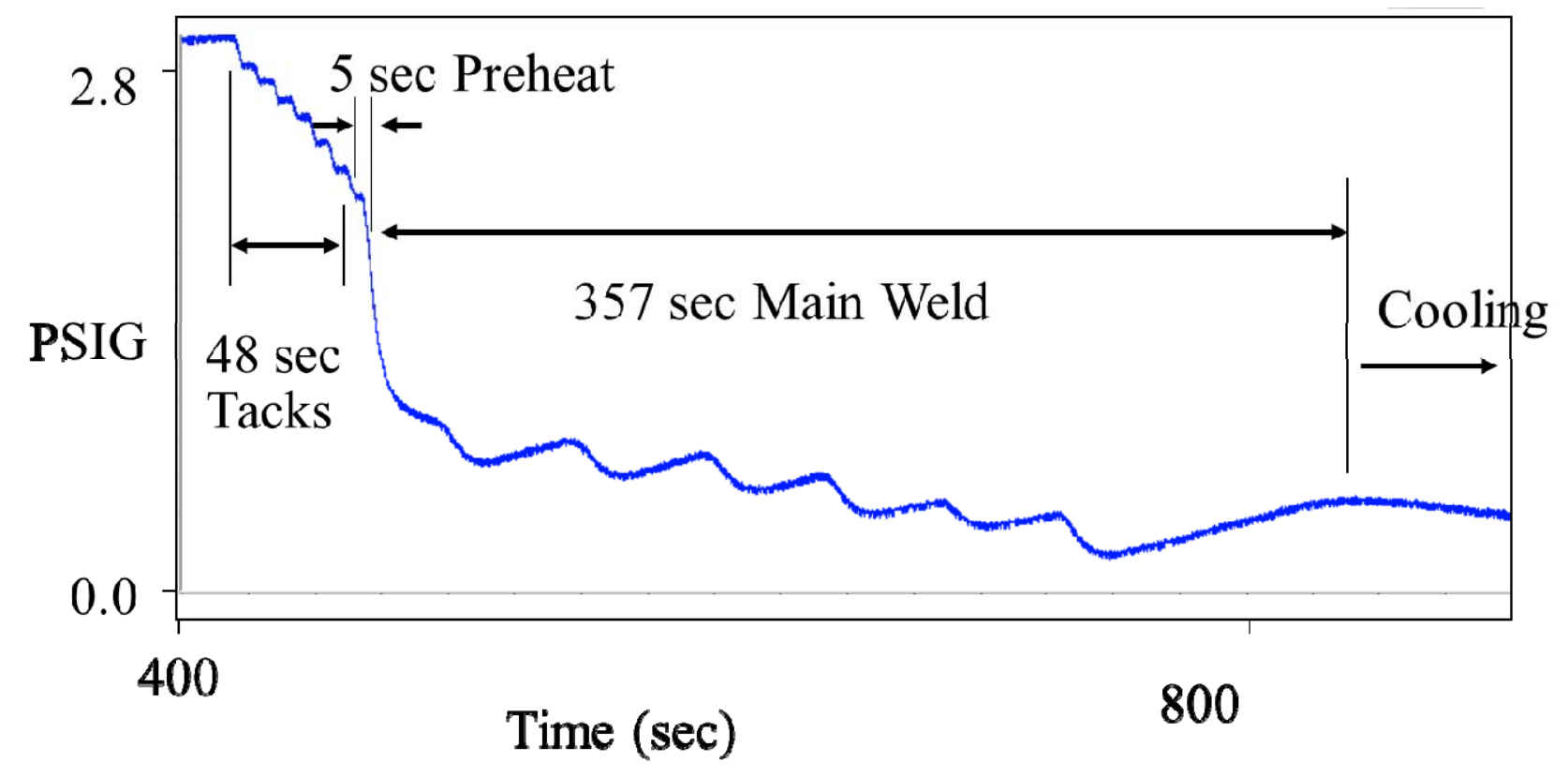

Figure 38. Pressure response from an OCW weld with a pressure tap. Notice the oscillations in pressure. These are consistent with the tack weld locations.

In going from PDCF-IC-013Q to PDCF-IC-010Q, a change was made to the plug placement to attempt to increase the gas path communication between the plug and the lower part of the can. It was theorized that the new plug design, which has an extended skirt below the lid (the lid that remains with the IC after the cut) was deflecting radially (as a result of stresses associated with the welding process) and sealing against the chamfered plug seat in the IC. To reduce this tendency to seal, the plug was raised up off of the plug seat, thereby providing additional radial clearance. Several tests were performed, first at $0.010^{\prime \prime}$ off of the plug seat and then at $0.020^{\prime \prime}$ off of the plug seat. At $0.020^{\prime \prime}$ up from the plug seat, the edge on the plug (that comes in contact with the plug seat in the canister) has been raised above the plug seat in the canister (maximum available gap has been attained). During the weld for can PDCF-IC- 013Q there was a gradual pressure increase starting almost immediately after the start of the continuous weld, see the graph on the left of Figure 37 . The pressure continued to increase as the weld progressed and at weld closure reach a peak value ( 14.7 psia), this response would be expected if the volume of gas below the plug had been trapped (not able to vent by the plug). It was observed that the pressure then went down and then rebounded to a maximum value > 14.85 psia; no obvious explanation was apparent for this behavior. During the welding of PDCF-IC-004Q and 025Q, there was essentially no pressure buildup during the weld prior to can closure. Also, the pressure measured after weld closure was reduced, see the graph on the right of Figure 37.

\section{Discussion}

A significant attempt has been made to characterize the flow formed cans that are being used for the PDC IC. A simple test of the magnetic properties indicated that there may be as much as twice as much magnetic phase, i.e., deformation induced martensite (DIM), present near the surface of the PDC IC compared to either the FBL or HS inner canisters. In addition, the PDC IC cans exhibited several differences in weldability. The weld 
ligaments were measured and found to be shorter. A number of cans experienced lack of fusion defects during the weld but these failures are contributed to automation processes. Welding engineers and equipment engineers teamed together to develop a plan to solve the issue. As part of the effort the weld head and process were examined. During this evaluation, it was determined that the weld head manufacturer, Arc Machines Incorporated, had made changes to the clamp / insert design. The FBL and HS inner canister welders had inserts that provided a uniform circumferential clamping force while the new PDC insert provided only eight points of contact and tended to ovalize the can; this ovalization resulted in locally can to plug gaps that may have contributed to weld failures. The new PDC insert, although at the bottom end of its working range, also imparted a larger clamping force to the canister, this too could have resulted in larger canister deflections in the region of the weld. As a result of this finding a new insert was procured that was similar to the FBL and HS insert.

In addition, the automation and associated weld sequence were evaluated. It was during this evaluation when it was determined that there was a helium gas release "puff" and concurrent mast movement. The effect of the puff on the weld reliability was tested. It was found that the puff of helium during the weld was sufficient to produce local pressure above the plug to cause the weld to blow out since the liquid metal can only withstand a pressure differential of 0.25-0.3 psi. This puff was the likely cause of the lack of fusion defects.
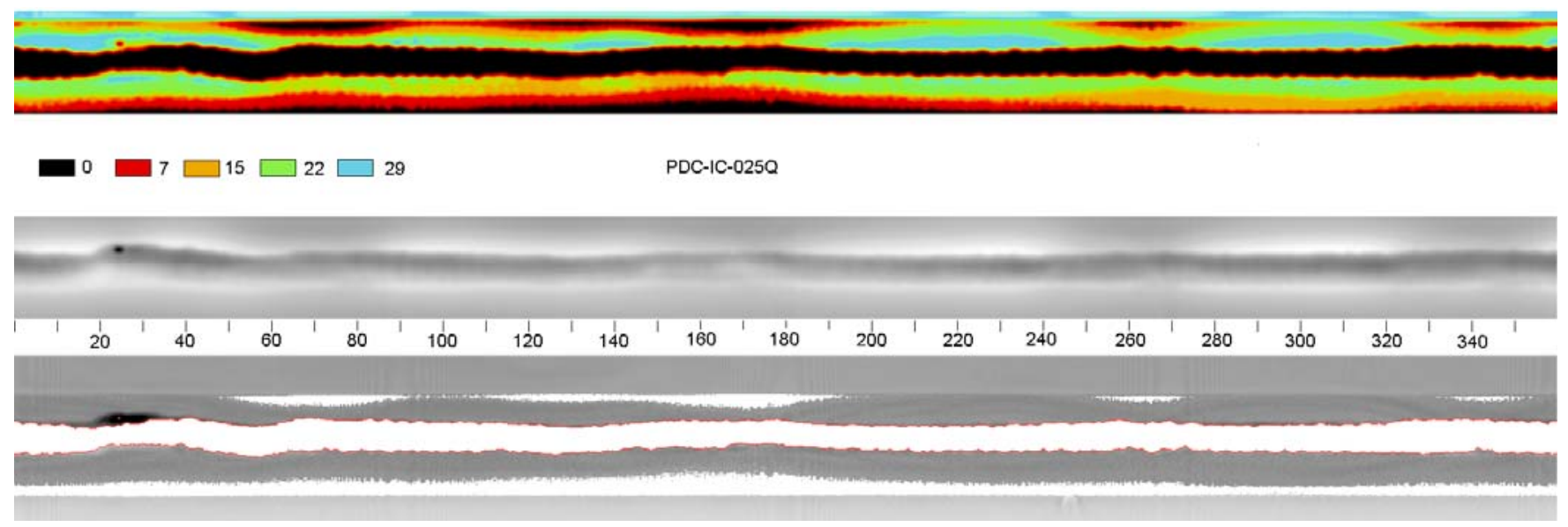

Figure 39. DR results for PDCF-IC-025Q that had a mast movement during welding shown at approximately $20^{\circ}$.

A test to evaluate the effect of just the mast movement was conducted. It was determined that mast movement had an adverse effect on the weld location, surface appearance, ligament, etc. but did not cause lack of fusion defects. For instance, the PDCF-IC-025Q was welded with the mast movement but not the helium gas release and a weld anomaly was detected, but it did not result in a weld failure, as shown in Figure 39 at about $20^{\circ}$. This finding is consistent with the fact that several cans had been had been welded without lack of fusion defects but with gross weld instability irregularities.

No detailed confirmatory tests were conducted to prove or disprove that all of the mechanical process / welding variable effects on welding had been identified. One of the challenges with interpreting the data is that the automated process was being modified simultaneously with the welding variables studies. This duality of process modification and experimentation resulted in several tests that had confounded results; further, the costs for materials and testing combined with schedule pressure precluded additional testing. Thus a decision was made to continue to the qualification phase using the "same process" as had been implemented in FBL and HS, i.e., three sequential tacks followed by the closure weld. A justification for using this approach was that 
there was no observable improvement in the weld consistency of prototypic cans when ISAA or a modified tacking sequence was tested using single test articles. A benefit for using this approach was that a weld specification procedure (WPS) already existed and would not require additional testing, evaluation, and documentation to be implemented. In summary, a weld instability remains for the PDC-IC closure welding process that causes the apparent difference between the final PDC welds and the earlier FBL and HS welds. It is suspected that it was linked with 1) venting restrictions introduced by the "hard" seating of the plug that was done for nearly all of the developmental testing but was eliminated just prior to starting the validation testing, 2) a PDC plug design with a long skirt that may introduce vent gas flow restrictions or induce stresses near the weld zone, 3) the magnetic differences between the PDC can and the FBL and HS cans that may introduce arc response differences.

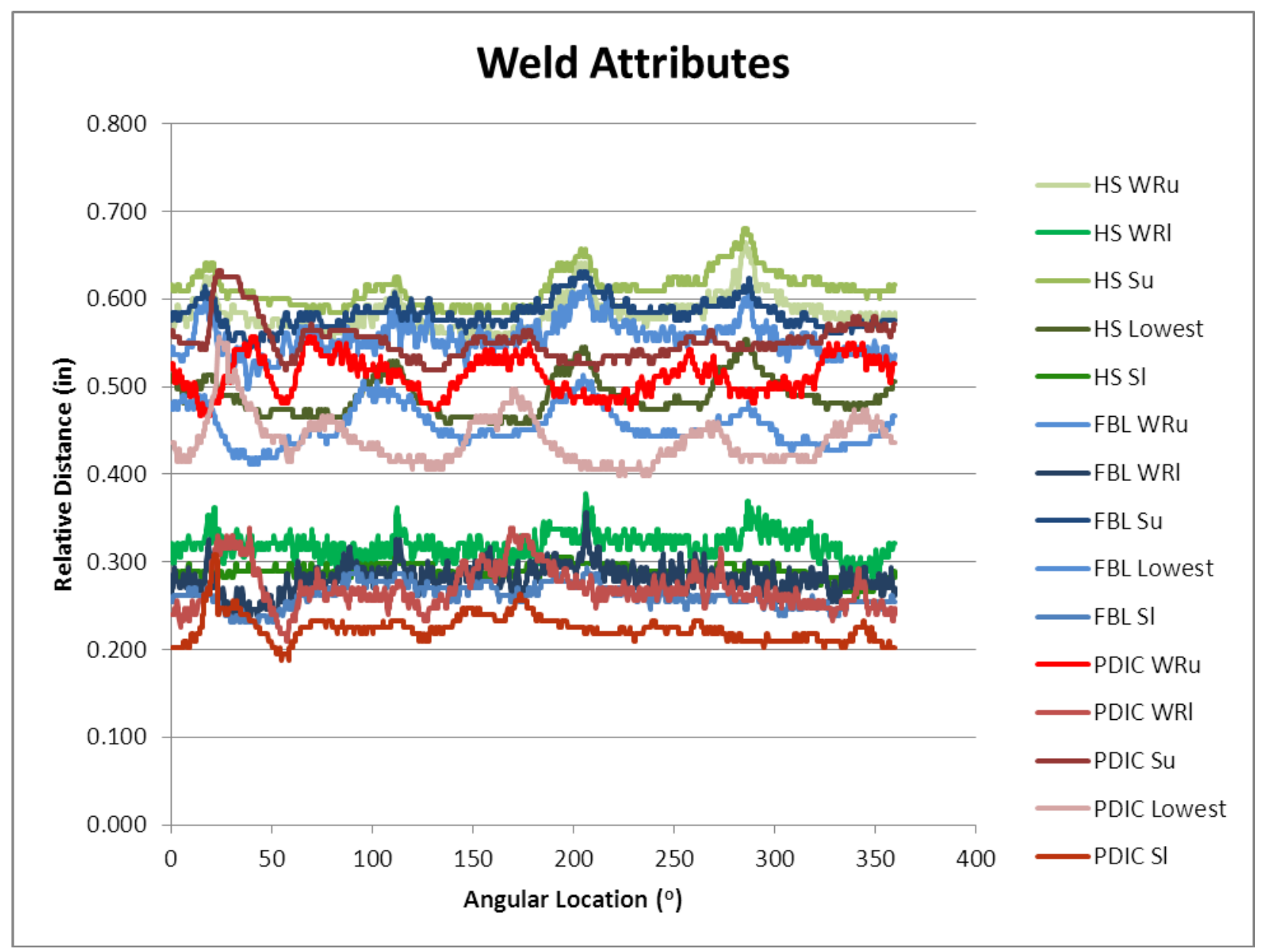

Figure 40. Weld attribute location for cans welded for PDC, FBL, and HS.

In comparison with the FBL and HS closure welds, the PDC closure weld continues to exhibit greater variation in outer weld surface consistency, with noticeable weld bead centerline variation between and across tack areas, as well as noticeable differences in variations in weld ripple widths around the circumference of the closure weld. These observations indicate that there may be technical opportunities to reduce the variability of the weld by process, material, and design changes and improvements. The standard deviations for these single can welds, HS6938, FBL9BC4384 and PDCF-IC-025Q, are listed in Table 8. It is noteworthy that the location of the weld root lower and the weld nadir (lowest point) are the two dimensions that exhibit the greatest variability for the PDC IC's. 
Table 8. Standard deviations of characteristic attributes of the welds.

\begin{tabular}{|l|l|l|l|l|l|}
\hline & WRu & WRI & Su & Lowest & SI \\
\hline HS6938 & 0.020 & 0.014 & 0.020 & 0.022 & 0.008 \\
\hline FBLBC4384 & 0.019 & 0.016 & 0.016 & 0.022 & 0.013 \\
\hline PDCF-IC-025Q & 0.021 & 0.024 & 0.022 & 0.028 & 0.015 \\
\hline
\end{tabular}

Despite the efforts and various development tests, no influence on the final weld characteristics due to the changes in magnetic characteristics, i.e., the measured \% ferrite, was identified. In addition, it was determined that a new Weld Process Specification (WPS) would not be required if the FBL and HS processes were used. The decision to use the FBL and HS process conditions was made. This process has produced weld ligaments of 0.150 to 0.250 " that with the weld mapping data can be cut to provide the required minimum remaining ligament length of $0.045^{\prime \prime}(12,13)$.

\section{Conclusions}

The mechanical properties of the PDC, FBL, and HS can materials are similar for tensile, yield, and elongation. The difference in magnetic material that was detected using the Feritscope was not apparent in the tensile or hardness properties.

There is a limit of approximately 0.030 inch at which the can to plug gap exceeds the molten metal's ability to bridge the gap. This limit is an approximate value since the plug to can gap values were measured after weld cool down and dynamic variations in the actual in-process weld gap remains unquantified. The experimentally observed lack of fusion defects are similar to those observed for the welding of actual cans.

Changing the tack welding sequence and number from three sequential to five or six in a "cross-tightening" pattern reduced the measured can to plug gap in the welded samples but may have reduced the gas path dimensions and contributed to pressurization challenges: additional testing may be warranted using the current "best practices". A beneficial effect for the actual cans using a sub-optimized process was not found.

In-Situ Arc Annealing produced significantly more consistent welds for sample welds on can remnants, however, the ISAA on actual cans did not provide any improvements in either the ligament or the can to plug gap. Increasing the number of tack welds on an ISAA prepared can did not improve the weld quality metrics with the sub-optimized process that was largely used during the developmental phase.

For moving forward with the IC qualification testing, it is recommended to use the three sequential tack weld process followed by a pulse weld at the same current and travel speed as was used for the legacy processes. In addition, the weld clamps to be used shall be consistent with those used in legacy operations, the He puff associated with plug operations shall be eliminated, the timing of the mast movement shall be changed to occur during weld head travel between the tacks, and the plug shall be raised .020" above the plug seat position.

Any future testing performed to optimize the welding process should use prototypic can and plug designs to simulate the actual can and plug. The development testing must include prototypic weld samples with comparable gas flow paths, free volumes, residual stress, and fabrication routes. 


\section{Acknowledgements}

The authors wish to acknowledge the support of J. Varble PDC DA, D. Immel DR Expert, G. Rawls, 3013 DA, L. Reid MS\&CED manager, T. Curtis, Metallographer, M. Anton, Metallographic support, L. Thacker Metallographic Lab Manager, A. Busby RDE Canning Project Lead, PDC project for financial support.

\section{References}

1. SRNL-L4410-2011-00043, Proposal for addressing PDC 3013 IC closure weld failure, P. Korinko, S. Howard, D. Maxwell, and T. Adams, Sept. 2011.

2. SRNL-L3100-2011-00105, Path Forward for evaluation of the Pit Disassembly and Conversion (PDC) Project Inncer Can Wall Failure (PDC-IC-009Q), J. B. Fiscus and A. S. Busby, October 2011.

3. J. Talonen, P. Aspengren, and H. Hanninen, Comparison of Different Methods for Measuring Strain Induced $\alpha^{\prime}$-Martensite in Austenitic Steels, materials Science and Technology, Vol. 20, pp 1506-1512, Dec. 2004.

4. SRNL-L4410-2011-00049, Rev. 1, Mechanical Properties of Pit Disassembly Project Canisters, M. J. Morgan, G. K. Chapman, P.S. Korinko, Oct. 2011.

5. ASM Metals Handbook, Desk Edition, $2^{\text {nd }}$ Edition, J.R. Davis, Ed., ASM International, 1998.

6. WSRC-TR-2000-00531, Weldability and Compositional Effects of Type 304L and 316L Stainless Steel, P.S. Korinko and S.H. Malene, March 15, 2001.

7. ASTM E8/E8M-2009, Standard Test Methods for Tension Testing of Metallic Materials, ASTM International, 100 Barr Harbor Drive, PO Box C700, West Conshohocken, PA 19428-2959, United States.

8. SRT-MTS-2001-40122, Tensile Properties of Typical Bagless Transfer Container, W.L. Daugherty, Sept. 2001.

9. H. Nordberg, "Note on the Sensitivity of Stainless Steel to Strain Rate", AvestaPllarit Research Foundation, Research Report No. 04.0-1, March 2004.

10. J.A. Lichtenfeld, M.C. Mataya, C.J. Van Tyne, "Effect of Strain Rate on Stress-Strain Behavior of Alloy 309 and 304L Austenitic Stainless Steel, Metallurgical and Materials Transactions A, Vol 37A, Jan 2006.

11. The Science and Engineering of Materials, D. R. Askeland, Prindle, Webster, and Schmidt Publishers, Duxbury Press, Boston, MA, 1984.

12. SRNL-TR-2011-00027, Pit Disassembly and Conversion Project Basis Document - Test Plan for PDC 3013 IC Qualification, PICN Welding Process Controls and Welding System Validation, and PICN Automation Functions Demonstration (U), S. R. Howard, July 2011.

13. M-TPL-A-0008, Pit Disassembly and Conversion Project Test Plan for PDC 3013 IC Qualification, PICN Welding Process Controls and Welding System Validation, and PICN Automation Functions Demonstration (U), S. R. Howard, July 2011. 
Appendix A. Weld Schedules for Standard Welds and 4, 5, and 6 Tack Welds

\begin{tabular}{|c|c|c|c|c|c|c|c|c|c|c|c|c|}
\hline \multicolumn{13}{|c|}{ PDC PICN Inner Can Weld Schedule 011 - Position Breakdown } \\
\hline & Canister OD (inches): & \multirow[b]{2}{*}{$\begin{array}{c}\text { PTI } \\
\begin{array}{c}\text { Programmed Time } \\
\text { Interval }\end{array}\end{array}$} & \multirow[b]{2}{*}{$\begin{array}{l}\text { CONTrot } \\
\text { Programmed } \\
\text { Cont. Rotation } \\
\text { Speed (rpm) }\end{array}$} & \multirow[b]{2}{*}{\begin{tabular}{|c|} 
PRIrot \\
Programmed \\
Step Rotation \\
Speed- \\
PRIMARY \\
(rpm)
\end{tabular}} & \multirow[b]{2}{*}{$\begin{array}{c}\text { BCKrot } \\
\text { Programmed } \\
\text { Step Rotation } \\
\text { Speed - } \\
\text { BACKGROUND } \\
\text { (rpm) }\end{array}$} & \multirow[b]{2}{*}{$\begin{array}{l}\text { PRIpulse } \\
\text { Programmed } \\
\text { Step Pulse- } \\
\text { PRIMARY (sec) }\end{array}$} & \multirow[b]{2}{*}{$\begin{array}{c}\text { BCKpulse } \\
\text { Programmed } \\
\text { Step Pulse- } \\
\text { BACKGROUND } \\
\text { (sec) }\end{array}$} & \multirow[b]{2}{*}{$\begin{array}{l}\text { WPULSES/level } \\
\text { Total Number of } \\
\text { Pulses during the } \\
\text { level }\end{array}$} & \multicolumn{2}{|c|}{ Start Pos on Can } & \multicolumn{2}{|c|}{ Finish Position on Can } \\
\hline Program Level & Description & & & & & & & & $\begin{array}{c}\text { Circumferential } \\
\text { (inches) }\end{array}$ & $\begin{array}{c}\text { Degrees } \\
\text { Start } \\
\star \star\end{array}$ & $\begin{array}{c}\text { Circumferential } \\
\text { (inches) }\end{array}$ & $\begin{array}{c}\text { Degrees } \\
\text { Finish } \\
* \star \star \star\end{array}$ \\
\hline & Tack\# 1 & 9 & & 0.62 & 0.00 & 0.40 & 0.20 & 15 & 0.000 & 0.000 & 0.884 & 22.320 \\
\hline & 2 Travel to Tack\# 2 & 5 & 2.00 & & & & & & 0.884 & 22.320 & 3.261 & 82.320 \\
\hline & 3 Tack\# 2 & 9 & & 0.62 & 0.00 & 0.40 & 0.20 & 15 & 3.261 & 82.320 & 4.146 & 104.640 \\
\hline & Travel to Tack\# 3 & 6 & 2.00 & & & & & & 4.146 & 104.640 & 6.998 & 176.640 \\
\hline & 5 Tack\# 3 & 9 & & 0.62 & 0.00 & 0.40 & 0.20 & 15 & 6.998 & 176.640 & 7.883 & 198.960 \\
\hline & 6 Travel to Start of Cont Weld & 6 & 2.00 & & & & & & 7.883 & 198.960 & 10.735 & 270.960 \\
\hline & 7 Cont Weld & 150 & & 0.62 & 0.00 & 0.40 & 0.20 & 250 & 10.735 & 270.960 & 25.473 & 642.960 \\
\hline N/A & Down Slope & 10.9 & & 0.62 & 0.00 & 0.40 & 0.20 & 18 & 25.473 & 642.960 & 26.544 & 669.992 \\
\hline & Total Travel Time @ 15 Amps (sec) & 17 & & & & & & & & & & \\
\hline & Total Tack Time @ 145 Amps (sec) & 27 & & & & & & & & & & \\
\hline & Total Time @ 145 Amps (sec) & 177 & & & & & & & & & & \\
\hline \multicolumn{13}{|c|}{${ }^{*}$ PULSEShevel $=($ PTI)/(PRIpulse+BCKpulse $)$} \\
\hline \multirow{2}{*}{\multicolumn{13}{|c|}{${ }^{*}$ Degrees Start $_{j}=0$ degrees at start of weld sequence $O R=$ Degrees Finish $_{i}$}} \\
\hline & & & & & & & & & & & & \\
\hline & 1 & & & & & & & & & & & \\
\hline $\begin{array}{l}{ }^{* * *} \text { Degrees Fin } \\
360\{(\# \mathrm{PULSES}) \\
360\{(\mathrm{PTI})(\mathrm{PCO}\end{array}$ & $\begin{array}{l}\text { nish }_{j} \\
\text { Shevel })(\text { PRIpulse })(1 / 60)(\text { PRIrot })+(\text { HPU } \\
\text { ONTrot })(1 / 60)\}\end{array}$ & LSES/eveli)(BCKpuls & $\left.\left.e_{j}\right)(1 / 60)(B C K r o t j)\right\}$ & OR & & & & & & Degrees $\mathrm{F}$ & $\begin{array}{l}=\text { Degrees Finis } \\
\text { Finish }_{+}+\end{array}$ & ish $_{i}+$ \\
\hline & & & & & & & & & & & & \\
\hline Notes: & & & & & & & & & & & & \\
\hline $\begin{array}{l}\text { 1. Weld overlap } \\
\text { sec interval }\end{array}$ & p during Program Level 7 occurs & $-270.96=630.96$ & rees. $\mathrm{T}$ & tinus & & es $E$ - & es. Th & & Wnslope fror & $145 \mathrm{am}$ & & \\
\hline & & & & & & & & & & & & \\
\hline & & & & & & & & & & & & \\
\hline Performed By: & & & Reviewed $B$ & & & & & & & & & \\
\hline & & & & & & & & & & & & \\
\hline & & & & & & & & & & & & \\
\hline
\end{tabular}




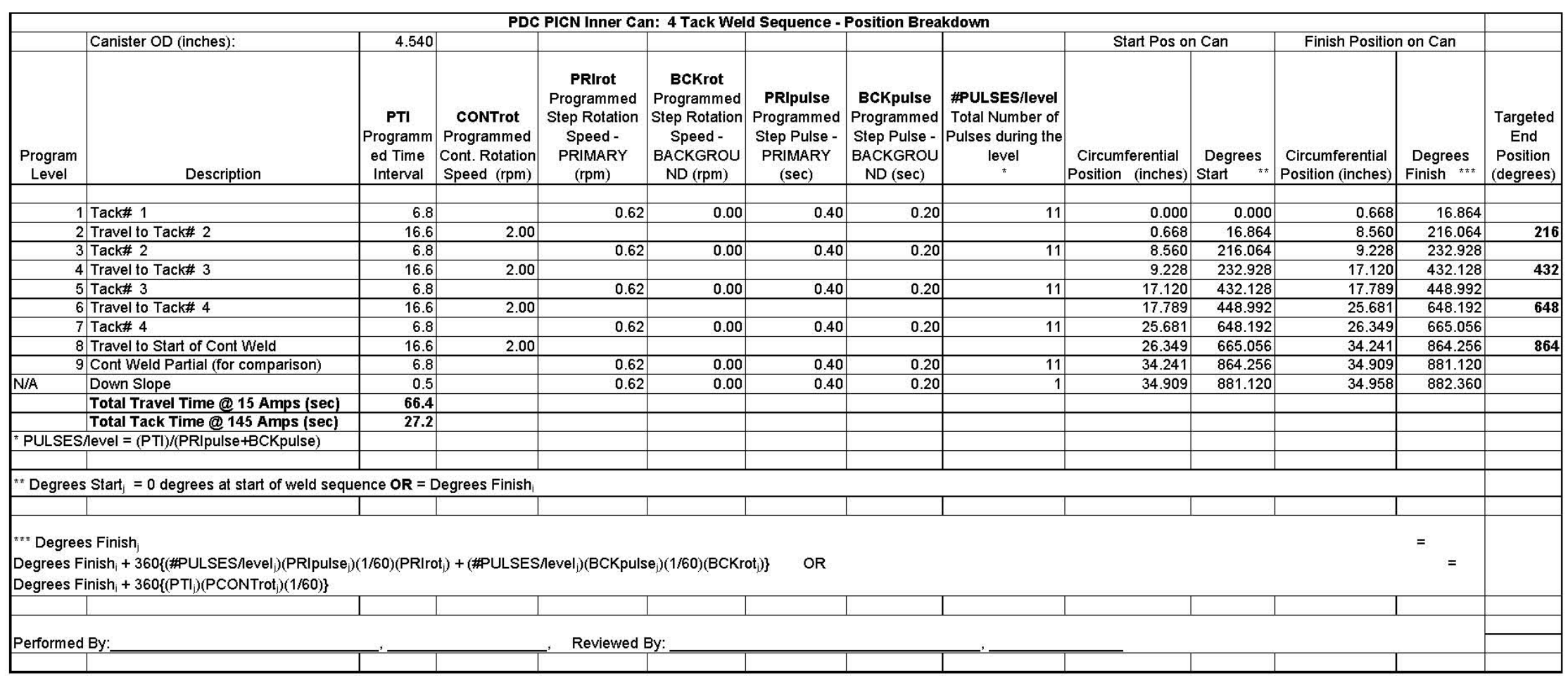




\begin{tabular}{|c|c|c|c|c|c|c|c|c|c|c|c|c|c|}
\hline \multicolumn{13}{|c|}{ PDC PICN Inner Can: 5 Tack Weld Sequence - Position Breakdown } & \multirow[b]{3}{*}{$\begin{array}{l}\text { Targeted } \\
\text { End } \\
\text { Position } \\
\text { (degrees) }\end{array}$} \\
\hline \multirow[b]{2}{*}{$\begin{array}{c}\text { Program } \\
\text { Level }\end{array}$} & \multirow[b]{2}{*}{$\begin{array}{r}\text { Canister OD (inches): } \\
\\
\text { Description }\end{array}$} & \multirow[b]{2}{*}{\begin{tabular}{|c|}
4.540 \\
\\
PTI \\
Programm \\
ed Time \\
Interval \\
\end{tabular}} & \multirow[b]{2}{*}{\begin{tabular}{|c|} 
CONTrot \\
Programmed \\
Cont. Rotation \\
Speed (rpm) \\
\end{tabular}} & \multirow[b]{2}{*}{\begin{tabular}{|c|} 
PRIrot \\
Programmed \\
Step Rotation \\
Speed- \\
PRIMARY \\
(rpm)
\end{tabular}} & \multirow[b]{2}{*}{\begin{tabular}{|c|} 
BCKrot \\
Programmed \\
Step Rotation \\
Speed- \\
BACKGROUN \\
D (rpm) \\
\end{tabular}} & \multirow[b]{2}{*}{\begin{tabular}{c|} 
PRIpulse \\
Programmed \\
Step Pulse - \\
PRIMARY (sec) \\
\end{tabular}} & \multirow[b]{2}{*}{\begin{tabular}{|c|} 
BCKpulse \\
Programmed \\
Step Pulse - \\
BACKGROU \\
ND (sec)
\end{tabular}} & \multirow[b]{2}{*}{$\begin{array}{l}\text { \#PULSES/level } \\
\text { Total Number of } \\
\text { Pulses during the } \\
\text { level }\end{array}$} & \multicolumn{2}{|c|}{ Start Pos on Can } & \multicolumn{2}{|c|}{ Finish Position on Can } & \\
\hline & & & & & & & & & $\begin{array}{c}\text { Circumferential } \\
\text { (inches) }\end{array}$ & $\begin{array}{c}\text { Degrees } \\
\text { Start } \\
\star \star\end{array}$ & \multicolumn{2}{|c|}{\begin{tabular}{c|c}
$\begin{array}{c}\text { Circumferential } \\
\text { (inches) }\end{array}$ & $\begin{array}{c}\text { Degrees } \\
\text { Finish }\end{array}$ \\
Fi*
\end{tabular}} & \\
\hline & Tack\# 1 & 5.4 & & 0.62 & 0.00 & 0.40 & 0.20 & 9 & 0.000 & 0.000 & 0.531 & 13.392 & \\
\hline & Travel to Tack\# 2 & 13.9 & 2.00 & & & & & & 0.531 & 13.392 & 7.139 & 180.192 & 180 \\
\hline & Tack\# 2 & 5.4 & & 0.62 & 0.00 & 0.40 & 0.20 & 9 & 7.139 & 180.192 & 7.670 & 193.584 & \\
\hline & Travel to Tack\# 3 & 8.9 & 2.00 & & & & & & 7.670 & 193.584 & 11.901 & 300.384 & 300 \\
\hline & Tack\# 3 & 5.4 & & 0.62 & 0.00 & 0.40 & 0.20 & 9 & 11.901 & 300.384 & 12.431 & 313.776 & \\
\hline & Travel to Tack\# 4 & 13.9 & 2.00 & & & & & & 12.431 & 313.776 & 19.040 & 480.576 & 480 \\
\hline & Tack\# 4 & 5.4 & & 0.62 & 0.00 & 0.40 & 0.20 & 9 & 19.040 & 480.576 & 19.571 & 493.968 & \\
\hline & Travel to Tack\# 5 & 8.8 & 2.00 & & & & & & 19.571 & 493.968 & 23.754 & 599.568 & 600 \\
\hline & Tack\# 5 & 5.4 & & 0.62 & 0.00 & 0.40 & 0.20 & 9 & 23.754 & 599.568 & 24.285 & 612.960 & \\
\hline & Travel to Start of Cont Weld & 13.9 & 2.00 & & & & & & 24.285 & 612.960 & 30.893 & 779.760 & 780 \\
\hline 11 & Cont Weld Partial (for comparison) & 5.4 & & 0.62 & 0.00 & 0.40 & 0.20 & 9 & 30.893 & 779.760 & 31.424 & 793.152 & \\
\hline N/A & Down Slope & 0.5 & & 0.62 & 0.00 & 0.40 & 0.20 & 1 & 31.424 & 793.152 & 31.473 & 794.392 & \\
\hline & Total Travel Time @ 15 Amps (sec) & 59.4 & & & & & & & & & & & \\
\hline & Total Tack Time @ 145 Amps (sec) & 27.0 & & & & & & & & & & & \\
\hline${ }^{*}$ PULSES & hevel $=($ PTI)/(PRIpulse+BCKpulse $)$ & & & & & & & & & & & & \\
\hline & & & & & & & & & & & & & \\
\hline${ }^{* *}$ Degrees & $S_{\text {Start }}=0$ degrees at start of weld seq & ence $\mathbf{O R}=\mathrm{D}$ & egrees Finish ${ }_{i}$ & & & & & & & & & & \\
\hline & 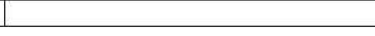 & & & & & & & & & & & 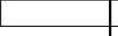 & \\
\hline $\begin{array}{l}* * \text { Degree } \\
\text { Finish }_{4}+3 \\
\text { Finish }_{+}+3\end{array}$ & $\begin{array}{l}\text { s } \text { Finish }_{j} \\
60\{(\# \text { ULSES/evel })(\text { PRIpulse })(1 / 60)(\mathrm{P} \\
60\left\{(\mathrm{PTI})\left(\mathrm{PCONTrot}_{\mathrm{j}}\right)(1 / 60)\right\}\end{array}$ & $o t)+(\# P U$ & JLSES/evel $)(B C$ & CKpulse $)(1 / 60)(B$ & $B C K$ roti $\left.\left._{j}\right)\right\}$ & & & & & & & $\begin{array}{l}=\text { Degrees } \\
\text { grees }\end{array}$ & \\
\hline & & 1 & & & & & & & & & & & \\
\hline Performed & & & & Reviewed B & & & & & & & & & \\
\hline
\end{tabular}




\begin{tabular}{|c|c|c|c|c|c|c|c|c|c|c|c|c|c|}
\hline \multicolumn{13}{|c|}{ PDC PICN Inner Can: 6 Tack Weld Sequence - Position Breakdown } & \multirow[b]{3}{*}{\begin{tabular}{|l} 
Targeted \\
Finish \\
Position \\
(degrees)
\end{tabular}} \\
\hline \multirow[b]{2}{*}{$\begin{array}{c}\text { Program } \\
\text { Level }\end{array}$} & \multirow[b]{2}{*}{$\begin{array}{r}\text { Canister OD (inches): } \\
\\
\text { Description }\end{array}$} & \multicolumn{2}{|l|}{4.540} & \multirow[b]{2}{*}{\begin{tabular}{c|} 
PRIrot \\
Programmed \\
Step Rotation \\
Speed- \\
PRIMARY \\
(rpm) \\
\end{tabular}} & \multirow[b]{2}{*}{\begin{tabular}{|c|} 
BCKrot \\
Programmed \\
Step \\
Rotation \\
Speed- \\
BACKGROU \\
ND (rpm) \\
\end{tabular}} & \multirow[b]{2}{*}{$\begin{array}{c}\text { PRIpulse } \\
\text { Programmed } \\
\text { Step Pulse - } \\
\text { PRIMARY } \\
(\mathrm{sec})\end{array}$} & \multirow[b]{2}{*}{\begin{tabular}{|c|} 
BCKpulse \\
Programmed \\
Step Pulse - \\
BACKGROUN \\
D (sec) \\
\end{tabular}} & \multirow[b]{2}{*}{$\begin{array}{l}\text { \#PULSES/level } \\
\text { Total Number of } \\
\text { Pulses during the } \\
\text { level }\end{array}$} & \multicolumn{2}{|c|}{ Start Pos on Can } & \multicolumn{2}{|c|}{ Finish Position on Can } & \\
\hline & & \begin{tabular}{c|} 
PTI \\
Programmed \\
Time Interval \\
\end{tabular} & \begin{tabular}{c|} 
CONTrot \\
Programmed \\
Cont. Rotation \\
Speed (rpm) \\
\end{tabular} & & & & & & $\begin{array}{c}\text { Circumferential } \\
\text { (inches) }\end{array}$ & $\begin{array}{c}\text { Degrees } \\
\text { Start } \\
\pi \star \\
\end{array}$ & \multicolumn{2}{|c|}{\begin{tabular}{|c|c}
$\begin{array}{c}\text { Circumferential } \\
\text { (inches) }\end{array}$ & $\begin{array}{c}\text { Degrees } \\
\text { Finish }\end{array}$ \\
\end{tabular}} & \\
\hline & Tack\# 1 & 4.5 & & 0.62 & 0.00 & 0.40 & 0.20 & 8 & 0.000 & 0.000 & 0.442 & 11.160 & \\
\hline & Travel to Tack\# 2 & 11.9 & 2.00 & & & & & & 0.442 & 11.160 & 6.100 & 153.960 & 154.3 \\
\hline & Tack\# 2 & 4.5 & & 0.62 & 0.00 & 0.40 & 0.20 & 8 & 6.100 & 153.960 & 6.542 & 165.120 & \\
\hline & Travel to Tack\# 3 & 11.9 & 2.00 & & & & & & 6.542 & 165.120 & 12.199 & 307.920 & 308.6 \\
\hline & Tack\# 3 & 4.5 & & 0.62 & 0.00 & 0.40 & 0.20 & 8 & 12.199 & 307.920 & 12.642 & 319.080 & \\
\hline & Travel to Tack\# 4 & 12.0 & 2.00 & & & & & & 12.642 & 319.080 & 18.347 & 463.080 & 462.9 \\
\hline & Tack\# 4 & 4.5 & & 0.62 & 0.00 & 0.40 & 0.20 & 8 & 18.347 & 463.080 & 18.789 & 474.240 & \\
\hline & Travel to Tack\# 5 & 11.9 & 2.00 & & & & & & 18.789 & 474.240 & 24.446 & 617.040 & 617.1 \\
\hline & Tack\# 5 & 4.5 & & 0.62 & 0.00 & 0.40 & 0.20 & 8 & 24.446 & 617.040 & 24.889 & 628.200 & \\
\hline 10 & Travel to Tack\# 5 & 11.9 & 2.00 & & & & & & 24.889 & 628.200 & 30.546 & 771.000 & 771.4 \\
\hline 11 & Tack\# 5 & 4.5 & & 0.62 & 0.00 & 0.40 & 0.20 & 8 & 30.546 & 771.000 & 30.988 & 782.160 & \\
\hline & Travel to Start of Cont Weld & 11.9 & 2.00 & & & & & & 30.988 & 782.160 & 36.646 & 924.960 & 925.7 \\
\hline & Cont Weld Partial (for comparison) & 4.5 & & 0.62 & 0.00 & 0.40 & 0.20 & 8 & 36.646 & 924.960 & 37.088 & 936.120 & \\
\hline N/A & Down Slope & 0.5 & & 0.62 & 0.00 & 0.40 & 0.20 & 1 & 37.088 & 936.120 & 37.137 & 937.360 & \\
\hline & Total Travel Time @ 15 Amps (sec) & 71.5 & & & & & & & & & & & \\
\hline & Total Tack Time @ 145 Amps (sec) & 27.0 & & & & & & & & & & & \\
\hline${ }^{\text {P PULSES }}$ & level $=($ PTI) $/($ PRIpulse+BCKpulse $)$ & & & & & & & & & & & & \\
\hline & & & & & & & & & & & & & \\
\hline "* Degrees & Start $f_{j}=0$ degrees at start of weld seq & nce $\mathrm{OR}=$ Degre & es Finish & & & & & & & & & & \\
\hline & & & & & & & & & & & & & \\
\hline $\begin{array}{l}* * * \text { Degree } \\
\text { Finish }_{1}+3 \\
360\left\{\left(\mathrm{PTI}_{\mathrm{l}}\right)\right.\end{array}$ & $\begin{array}{l}\text { s Finish } \\
60\{(\# P U L S E S / \text { evel })(\text { PRIpulse })(1 / 60)(\mathrm{F} \\
\text { PCONTrot })(1 / 60)\}\end{array}$ & rot $)+($ \#PULSES & Shevel)(BCKpulse & )$(1 / 60)(B C K r o t)\}$ & OR & & & & & & $\begin{aligned}=D e \\
=D e g r e e\end{aligned}$ & $\begin{array}{l}\text { egrees } \\
\text { es Finish }\end{array}$ & \\
\hline & & & & & & & & & & & & & \\
\hline & & & & & & & & & & & & & \\
\hline Performed & & & & viewed By: & & & & & & & & & \\
\hline
\end{tabular}

